\title{
Directed Synthesis of $\mathrm{CS}_{2}$ - and $\mathrm{CS}_{3}$-Bridged Decaborane-14 Analogues
}

Chandan Nandi, ${ }^{a}$ Ketaki Kar, ${ }^{a}$ Sourav Gayen, ${ }^{a}$ Thierry Roisnel,,${ }^{b}$ and Sundargopal Ghosh ${ }^{* a}$

${ }^{a}$ Department of Chemistry, Indian Institute of Technology Madras, Chennai 600036, India. Tel: +94 $44-$ 22574230; Fax: +91 44-22574202; E-mail: sghosh@iitm.ac.in

${ }^{b}$ Univ Rennes, CNRS, ISCR (Institut des Sciences Chimiques de Rennes)-UMR 6226, F-35000 Rennes, France. 


\section{Table of contents}

I Spectroscopic details

Figure S1 ESI-MS spectrum of nido-3 in $\mathrm{CH}_{2} \mathrm{Cl}_{2}$

Figure S2 $\quad{ }^{1} \mathrm{H}$ NMR spectrum of nido-3 in $\mathrm{CDCl}_{3}$

Figure S3 Stacked ${ }^{1} \mathrm{H}$ (bottom) and ${ }^{1} \mathrm{H}\left\{{ }^{11} \mathrm{~B}\right\} \mathrm{NMR}$ (top) spectrum of nido-3 in $\mathrm{CDCl}_{3}$

Figure $\mathrm{S} 4 \quad{ }^{11} \mathrm{~B}\left\{{ }^{1} \mathrm{H}\right\}$ NMR spectrum of nido-3 in $\mathrm{CDCl}_{3}$

Figure S5 $\quad{ }^{13} \mathrm{C}\left\{{ }^{1} \mathrm{H}\right\}$ NMR spectrum of nido-3 in $\mathrm{CDCl}_{3}$

Figure $\mathrm{S} 6 \quad$ IR spectrum of nido-3 in $\mathrm{CH}_{2} \mathrm{Cl}_{2}$

Figure $\mathrm{S7} \quad \mathrm{ESI}-\mathrm{MS}$ spectrum of nido-4 in $\mathrm{CH}_{2} \mathrm{Cl}_{2}$

Figure $\mathrm{S} 8 \quad{ }^{1} \mathrm{H}$ NMR spectrum of nido-4 in $\mathrm{CDCl}_{3}$

Figure S9 Stacked ${ }^{1} \mathrm{H}$ (bottom) and ${ }^{1} \mathrm{H}\left\{{ }^{11} \mathrm{~B}\right\} \mathrm{NMR}$ (top) spectrum of nido-4 in $\mathrm{CDCl}_{3}$

Figure $\mathrm{S} 10 \quad{ }^{11} \mathrm{~B}\left\{{ }^{1} \mathrm{H}\right\}$ NMR spectrum of nido- 4 in $\mathrm{CDCl}_{3}$

Figure S11 $\quad{ }^{13} \mathrm{C}\left\{{ }^{1} \mathrm{H}\right\}$ NMR spectrum of nido-4 in $\mathrm{CDCl}_{3}$

Figure $\mathrm{S} 12 \quad \mathrm{IR}$ spectrum of nido-4 in $\mathrm{CH}_{2} \mathrm{Cl}_{2}$

Figure $\mathrm{S} 13 \quad \mathrm{ESI}-\mathrm{MS}$ spectrum of nido-5 in $\mathrm{CH}_{2} \mathrm{Cl}_{2}$

Figure $\mathrm{S} 14 \quad{ }^{1} \mathrm{H}$ NMR spectrum of nido-5 in $\mathrm{CDCl}_{3}$

Figure S15 Stacked ${ }^{1} \mathrm{H}$ (bottom) and ${ }^{1} \mathrm{H}\left\{{ }^{11} \mathrm{~B}\right\}$ NMR (top) spectrum of nido-5 in $\mathrm{CDCl}_{3}$

Figure $\mathrm{S} 16 \quad{ }^{11} \mathrm{~B}\left\{{ }^{1} \mathrm{H}\right\}$ NMR spectrum of nido-5 in $\mathrm{CDCl}_{3}$

Figure $\mathrm{S} 17 \quad{ }^{13} \mathrm{C}\left\{{ }^{1} \mathrm{H}\right\}$ NMR spectrum of nido-5 in $\mathrm{CDCl}_{3}$

Figure $\mathrm{S} 18 \quad$ IR spectrum of nido-5 in $\mathrm{CH}_{2} \mathrm{Cl}_{2}$

Figure S19 ESI-MS spectrum of nido-10 in $\mathrm{CH}_{2} \mathrm{Cl}_{2}$

Figure $\mathrm{S} 20 \quad{ }^{1} \mathrm{H}$ NMR spectrum of nido-10 in $\mathrm{CDCl}_{3}$

Figure S21 Stacked ${ }^{1} \mathrm{H}$ (bottom) and ${ }^{1} \mathrm{H}\left\{{ }^{11} \mathrm{~B}\right\} \mathrm{NMR}$ (top) spectrum of nido-10 in $\mathrm{CDCl}_{3}$

Figure $\mathrm{S} 22 \quad{ }^{11} \mathrm{~B}\left\{{ }^{1} \mathrm{H}\right\}$ NMR spectrum of nido-10 in $\mathrm{CDCl}_{3}$

Figure $\mathrm{S} 23 \quad{ }^{13} \mathrm{C}\left\{{ }^{1} \mathrm{H}\right\}$ NMR spectrum of nido-10 in $\mathrm{CDCl}_{3}$

Figure $\mathrm{S} 24 \quad$ IR spectrum of nido-10 in $\mathrm{CH}_{2} \mathrm{Cl}_{2}$

Figure $\mathrm{S} 25 \quad$ ESI-MS spectrum of nido-11 in $\mathrm{CH}_{2} \mathrm{Cl}_{2}$

Figure $\mathrm{S} 26 \quad{ }^{1} \mathrm{H}$ NMR spectrum of nido-11 in $\mathrm{CDCl}_{3}$

Figure S27 Stacked ${ }^{1} \mathrm{H}$ (bottom) and ${ }^{1} \mathrm{H}\left\{{ }^{11} \mathrm{~B}\right\}$ NMR (top) spectrum of nido-11 in $\mathrm{CDCl}_{3}$

Figure $\mathrm{S} 28 \quad{ }^{11} \mathrm{~B}\left\{{ }^{1} \mathrm{H}\right\}$ NMR spectrum of nido-11 in $\mathrm{CDCl}_{3}$

Figure S29 ${ }^{13} \mathrm{C}\left\{{ }^{1} \mathrm{H}\right\}$ NMR spectrum of nido-11 in $\mathrm{CDCl}_{3}$ 
Figure $\mathrm{S} 30 \quad$ IR spectrum of nido-11 in $\mathrm{CH}_{2} \mathrm{Cl}_{2}$

Figure S31 ESI-MS spectrum of nido-12 in $\mathrm{CH}_{2} \mathrm{Cl}_{2}$

Figure $\mathrm{S} 32 \quad{ }^{1} \mathrm{H}$ NMR spectrum of nido-12 in $\mathrm{CDCl}_{3}$

Figure S33 Stacked ${ }^{1} \mathrm{H}$ (bottom) and ${ }^{1} \mathrm{H}\left\{{ }^{11} \mathrm{~B}\right\}$ NMR (top) spectrum of nido-12 in $\mathrm{CDCl}_{3}$

Figure S34 ${ }^{11} \mathrm{~B}\left\{{ }^{1} \mathrm{H}\right\}$ NMR spectrum of nido-12 in $\mathrm{CDCl}_{3}$

Figure S35 ${ }^{13} \mathrm{C}\left\{{ }^{1} \mathrm{H}\right\}$ NMR spectrum of nido-12 in $\mathrm{CDCl}_{3}$

Figure $\mathrm{S} 36 \quad$ IR spectrum of nido-12 in $\mathrm{CH}_{2} \mathrm{Cl}_{2}$

Figure S37 ESI-MS spectrum of nido-13 in $\mathrm{CH}_{2} \mathrm{Cl}_{2}$

Figure $\mathrm{S} 38 \quad{ }^{1} \mathrm{H}$ NMR spectrum of nido-13 in $\mathrm{CD}_{3} \mathrm{Cl}_{3}$

Figure S39 Stacked ${ }^{1} \mathrm{H}$ (bottom) and ${ }^{1} \mathrm{H}\left\{{ }^{11} \mathrm{~B}\right\}$ NMR (top) spectrum of nido-13

Figure $\mathrm{S} 40 \quad{ }^{11} \mathrm{~B}\left\{{ }^{1} \mathrm{H}\right\}$ NMR spectrum of nido-13 in $\mathrm{CDCl}_{3}$

Figure S41 ${ }^{13} \mathrm{C}\left\{{ }^{1} \mathrm{H}\right\}$ NMR spectrum of nido-13 in $\mathrm{CDCl}_{3}$

Figure $\mathrm{S} 42 \quad \mathrm{IR}$ spectrum of nido-13 in $\mathrm{CH}_{2} \mathrm{Cl}_{2}$

Figure S43 ESI-MS spectrum of nido-14 in $\mathrm{CH}_{2} \mathrm{Cl}_{2}$

Figure $\mathrm{S} 44 \quad{ }^{1} \mathrm{H}$ NMR spectrum of nido-14 in $\mathrm{CDCl}_{3}$

Figure S45 Stacked ${ }^{1} \mathrm{H}$ (bottom) and ${ }^{1} \mathrm{H}\left\{{ }^{11} \mathrm{~B}\right\} \mathrm{NMR}$ (top) spectrum of nido-14 in $\mathrm{CDCl}_{3}$

Figure S46 ${ }^{11} \mathrm{~B}\left\{{ }^{1} \mathrm{H}\right\}$ NMR spectrum of nido-14 in $\mathrm{CDCl}_{3}$

Figure $547 \quad{ }^{13} \mathrm{C}\left\{{ }^{1} \mathrm{H}\right\}$ NMR spectrum of nido-14 in $\mathrm{CDCl}_{3}$

Figure S48 IR spectrum of nido-14 in $\mathrm{CH}_{2} \mathrm{Cl}_{2}$

Figure $\mathrm{S} 49 \quad \mathrm{ESI}-\mathrm{MS}$ spectrum of nido-15 in $\mathrm{CH}_{2} \mathrm{Cl}_{2}$

Figure $\mathrm{S} 50 \quad{ }^{1} \mathrm{H}$ NMR spectrum of nido-15 in $\mathrm{CDCl}_{3}$

Figure S51 Stacked ${ }^{1} \mathrm{H}$ (bottom) and ${ }^{1} \mathrm{H}\left\{{ }^{11} \mathrm{~B}\right\}$ NMR (top) spectrum of nido-15 in $\mathrm{CDCl}_{3}$

Figure $\mathrm{S} 52 \quad{ }^{11} \mathrm{~B}\left\{{ }^{1} \mathrm{H}\right\}$ NMR spectrum of nido-15 in $\mathrm{CDCl}_{3}$

Figure $\mathrm{S} 53 \quad{ }^{13} \mathrm{C}\left\{{ }^{1} \mathrm{H}\right\}$ NMR spectrum of nido-15 in $\mathrm{CDCl}_{3}$

Figure $\mathrm{S} 54 \quad$ IR spectrum of nido-15 in $\mathrm{CH}_{2} \mathrm{Cl}_{2}$

Table S1 Selected Structural parameters and ${ }^{11} \mathrm{~B}$ NMR values for various ten vertex nido clusters.

\section{Computational Details}

Table S2 Topological parameters at selected bond critical points (BCPs) of nido-3'-5' and nido-10-

13.

Table S3 Selected geometrical parameters and wiberg indices (WBI) of nido-3'-5' and nido-10-13. 
Table S4 Calculated (DFT) energies of the HOMO and LUMO (eV) and HOMO-LUMO gaps ( $\Delta \mathrm{E}$ $=\mathrm{E}_{\text {номо }}-\mathrm{E}_{\text {LUMо }}, \mathrm{eV}$ ) of nido-3'-5' and nido-10-13.

Figure S55 Frontier molecular orbital diagram of nido-3', 4' and $\mathbf{5}^{\prime}$. Isosurfaces are plotted at an isovalue of $\pm 0.04\left(\mathrm{e} / \mathrm{bohr}^{3}\right)^{1 / 2}$.

Figure S56 Selected frontier molecular orbitals (a) and (d) for nido-3'; (b) and (e) for nido-4'; and (c) for $5^{\prime}$. Isosurfaces are plotted at an isovalue of $\pm 0.04\left(\mathrm{e} / \mathrm{bohr}^{3}\right)^{1 / 2}$.

Figure S57 Selected M-E bonding interaction obtained from molecular orbital analysis of nido-3', 4' and 5': (a) and (b) are HOMO-17 and HOMO-14 of nido-3' respectively; (c), (d) and (e) are HOMO-13, HOMO-12 and HOMO-27 of nido-4' respectively; (f), (g) and (h) are HOMO-7, HOMO-13 and HOMO-17 of nido-5' respectively.

Figure S58 Selected frontier molecular orbitals for nido-12. Isosurfaces are plotted at an isovalue of $\pm 0.04\left(\mathrm{e} / \mathrm{bohr}^{3}\right)^{1 / 2}$.

Figure S59 Selected frontier molecular orbitals for nido-13. Isosurfaces are plotted at an isovalue of $\pm 0.04\left(\mathrm{e} / \mathrm{bohr}^{3}\right)^{1 / 2}$.

Figure S60 Selected frontier molecular orbitals of nido-15. Isosurfaces are plotted at an isovalue of $\pm 0.04\left(\mathrm{e} / \mathrm{bohr}^{3}\right)^{1 / 2}$.

Figure S61 Contour-line diagram of the Laplacian of electron density in the Co-E bond of nido-3' (a), nido-4' (b) and nido-5' (c). The solid brown lines are bond paths, while orange spheres indicate the bond critical points. Area of charge concentration $\left[\nabla^{2} \rho(r)<0\right]$ are indicated by solid lines and area of charge depletion $\left[\nabla^{2} \rho(r)>0\right]$ are shown by dashed lines.

Figure S62 Contour-line diagram of the Laplacian of electron density in the B-S bonds of nido-10 (a) and nido-11 (b). The solid brown lines are bond paths, while green and orange spheres indicate the ring and bond critical points respectively. Area of charge concentration $\left[\nabla^{2} \rho(r)\right.$ $<0]$ are indicated by solid lines and area of charge depletion $\left[\nabla^{2} \rho(r)>0\right]$ are showed by dashed lines.

Figure S63 Contour-line diagram of the Laplacian of electron density in the nido-12 (a) and nido-13 (b). The solid brown lines are bond paths, while green and orange spheres indicate the bond and ring critical points respectively. Area of charge concentration $\left[\nabla^{2} \rho(r)<0\right]$ are 
indicated by solid lines and area of charge depletion $\left[\nabla^{2} \rho(r)>0\right]$ are showed by dashed lines.

Figure S64 Optimized geometry of nido-3'.

Figure S65 Optimized geometry of nido-4'.

Figure S66 Optimized geometry of nido-5'.

Figure S67 Optimized geometry of nido-10.

Figure S68 Optimized geometry of nido-11.

Figure S69 Optimized geometry of nido-12.

Figure S70 Optimized geometry of nido-13.

Figure S71 Optimized geometry of nido-15 


\section{Spectroscopic details}

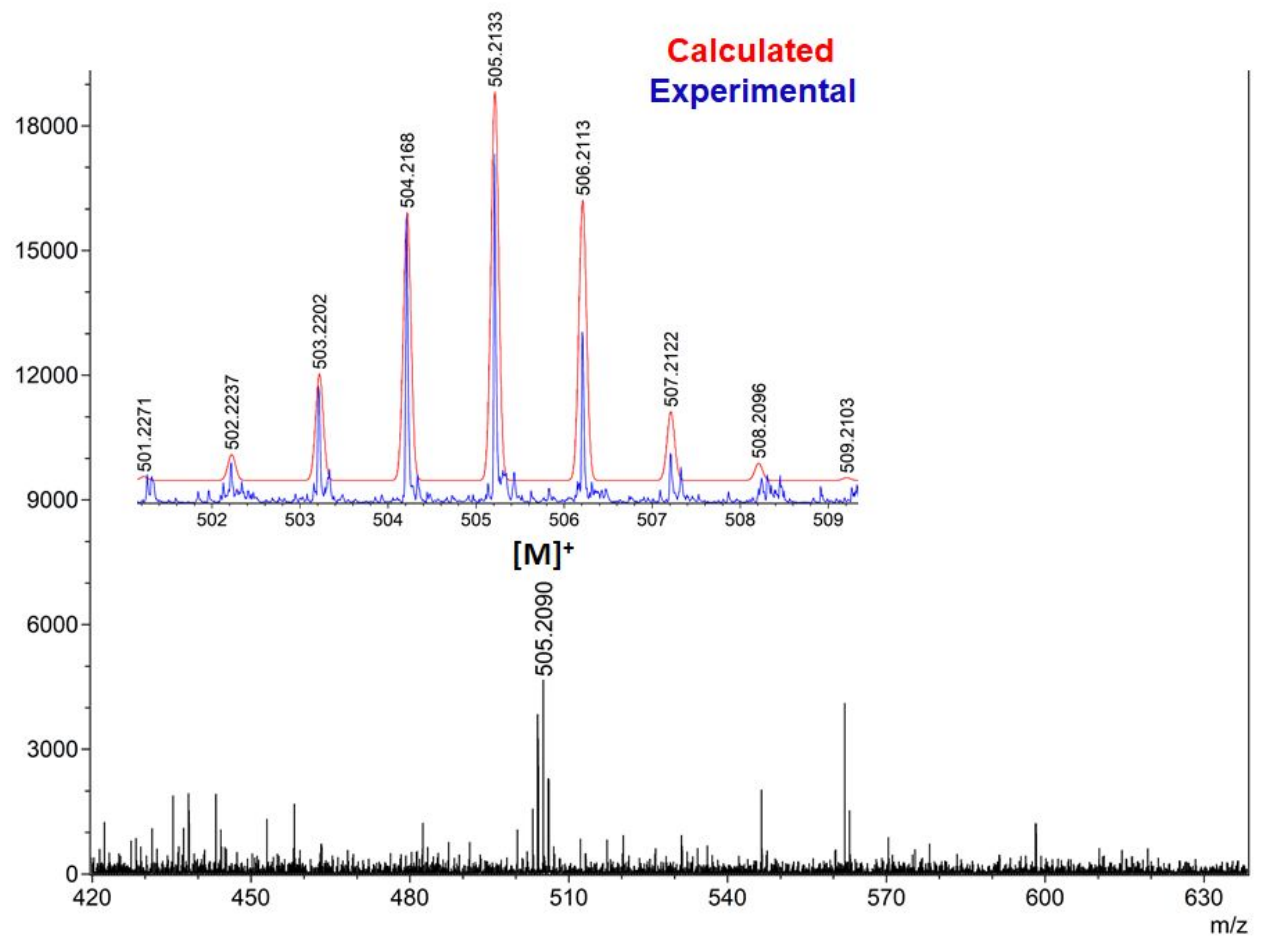

Figure S1. ESI-MS spectrum of nido-3 in $\mathrm{CH}_{2} \mathrm{Cl}_{2}$

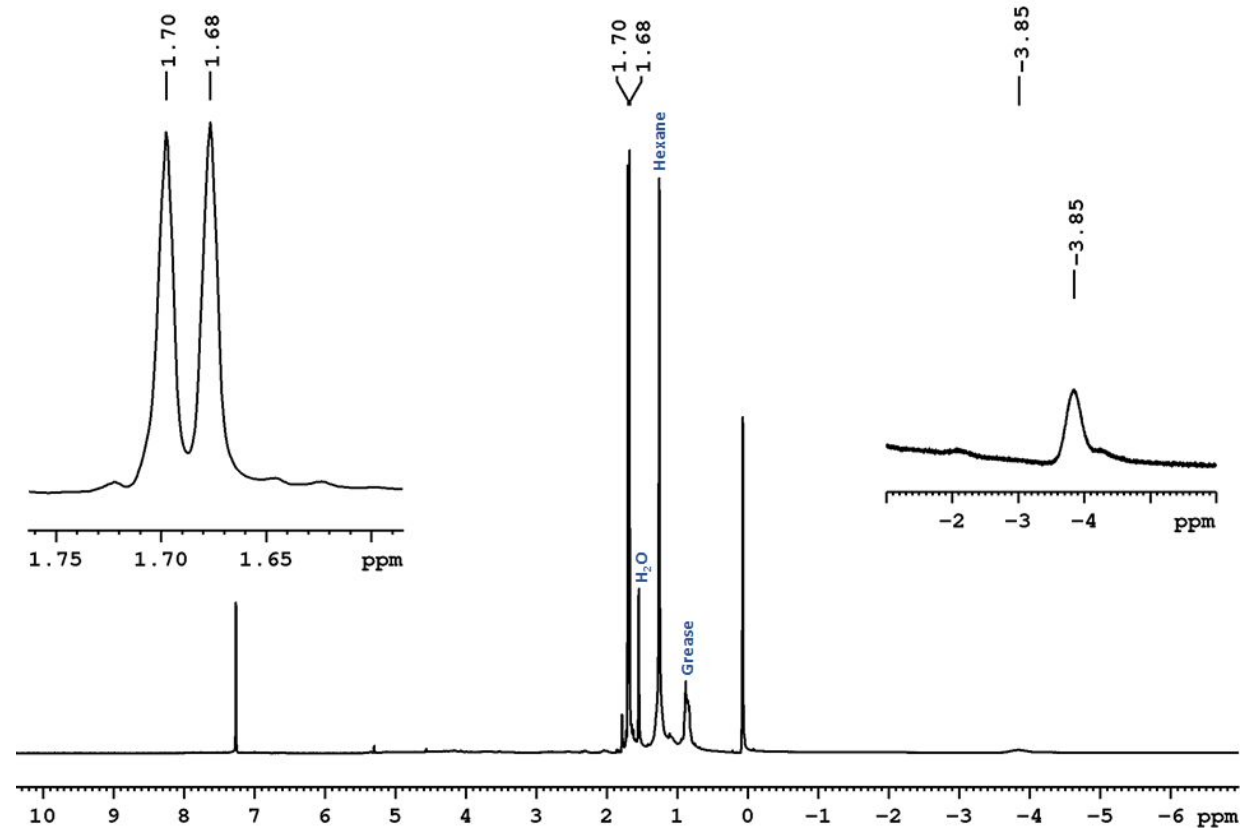

Figure S2. ${ }^{1} \mathrm{H}$ NMR spectrum of nido-3 in $\mathrm{CDCl}_{3}$ 


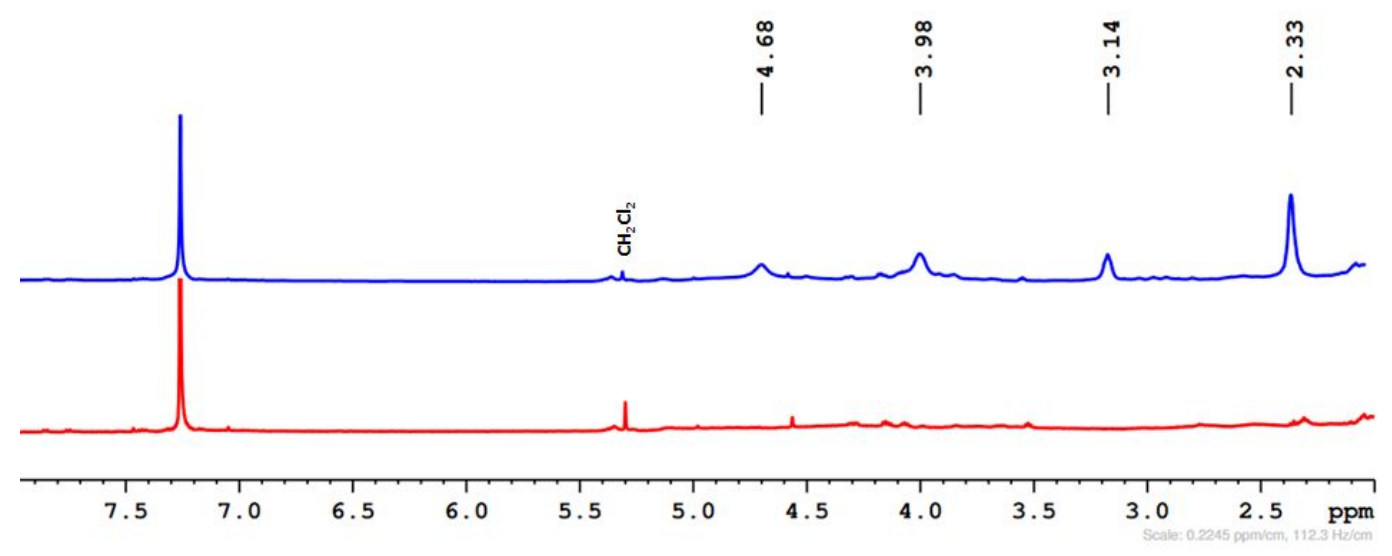

Figure S3. Stacked ${ }^{1} \mathrm{H}$ (bottom) and ${ }^{1} \mathrm{H}\left\{{ }^{11} \mathrm{~B}\right\}$ NMR (top) spectrum of nido-3 in $\mathrm{CDCl}_{3}$

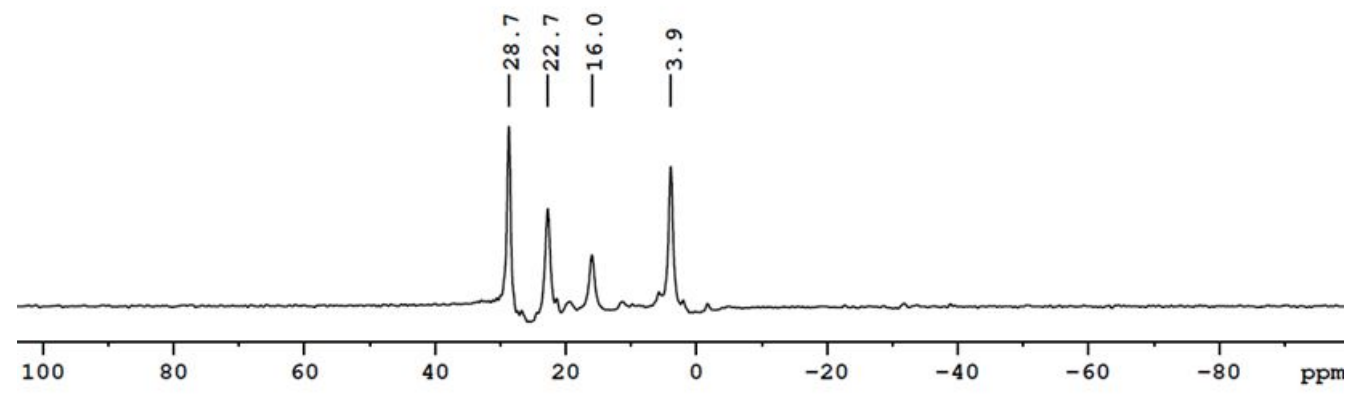

Figure S4. ${ }^{11} \mathrm{~B}\left\{{ }^{1} \mathrm{H}\right\} \mathrm{NMR}$ spectrum of nido-3 in $\mathrm{CDCl}_{3}{ }^{1}$ 


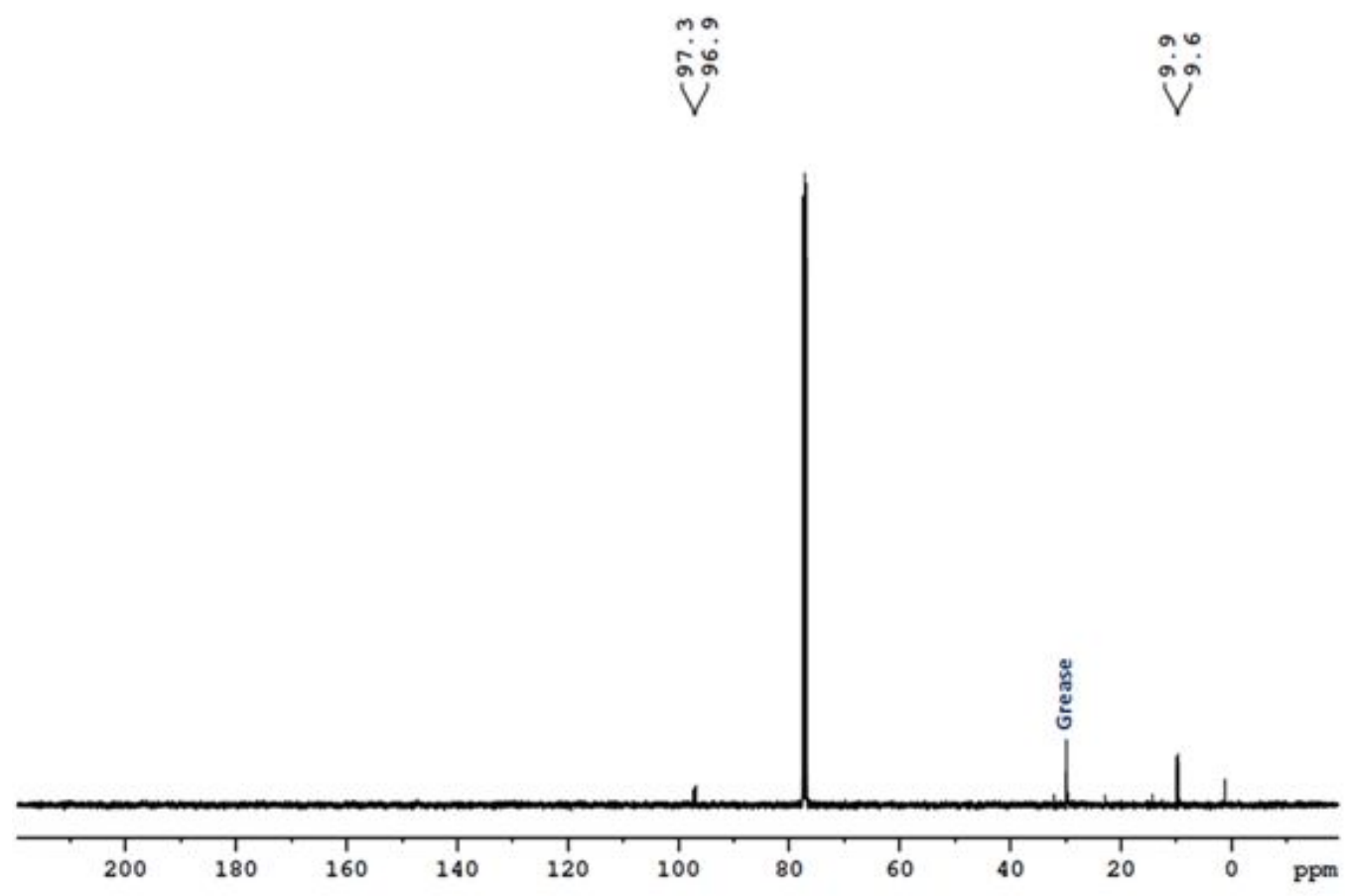

Figure S5. ${ }^{13} \mathrm{C}\left\{{ }^{1} \mathrm{H}\right\}$ NMR spectrum of nido-3 in $\mathrm{CDCl}_{3}$

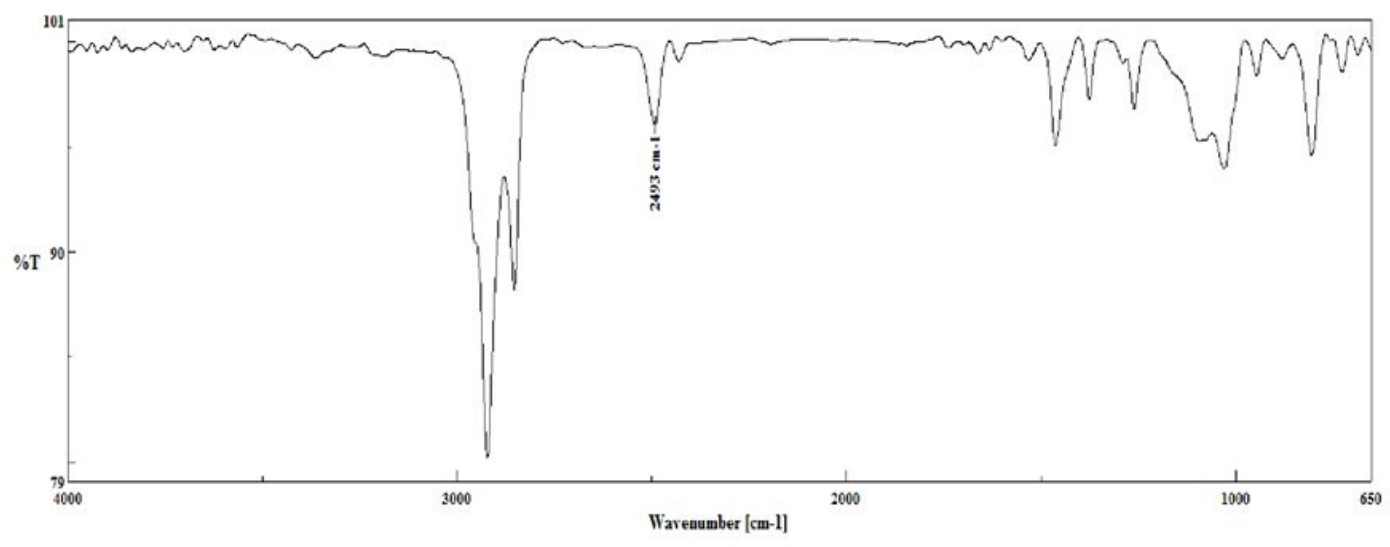

Figure S6. IR spectrum of nido-3 in $\mathrm{CH}_{2} \mathrm{Cl}_{2}$ 


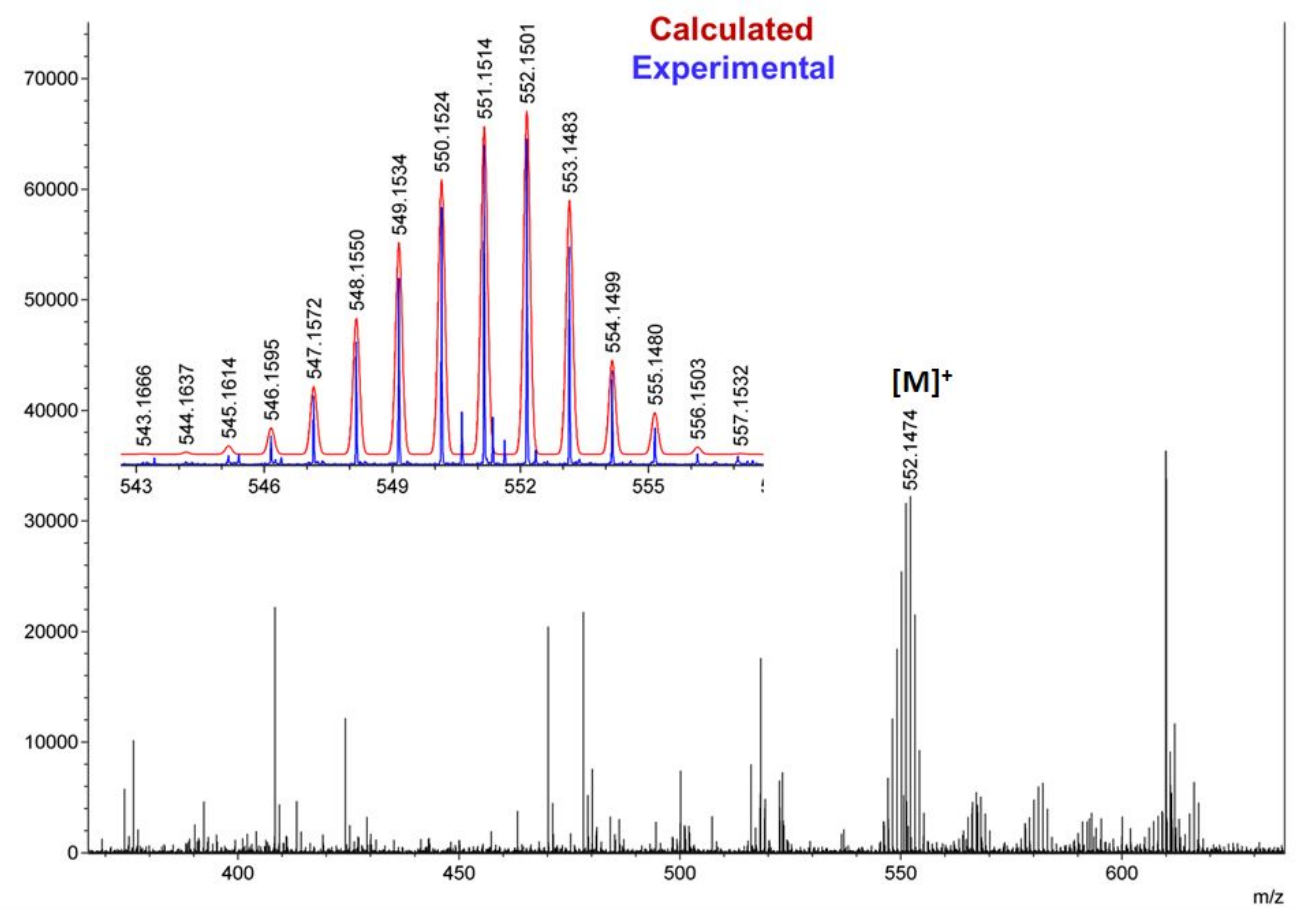

Figure S7. ESI-MS spectrum of nido-4 in $\mathrm{CH}_{2} \mathrm{Cl}_{2}$

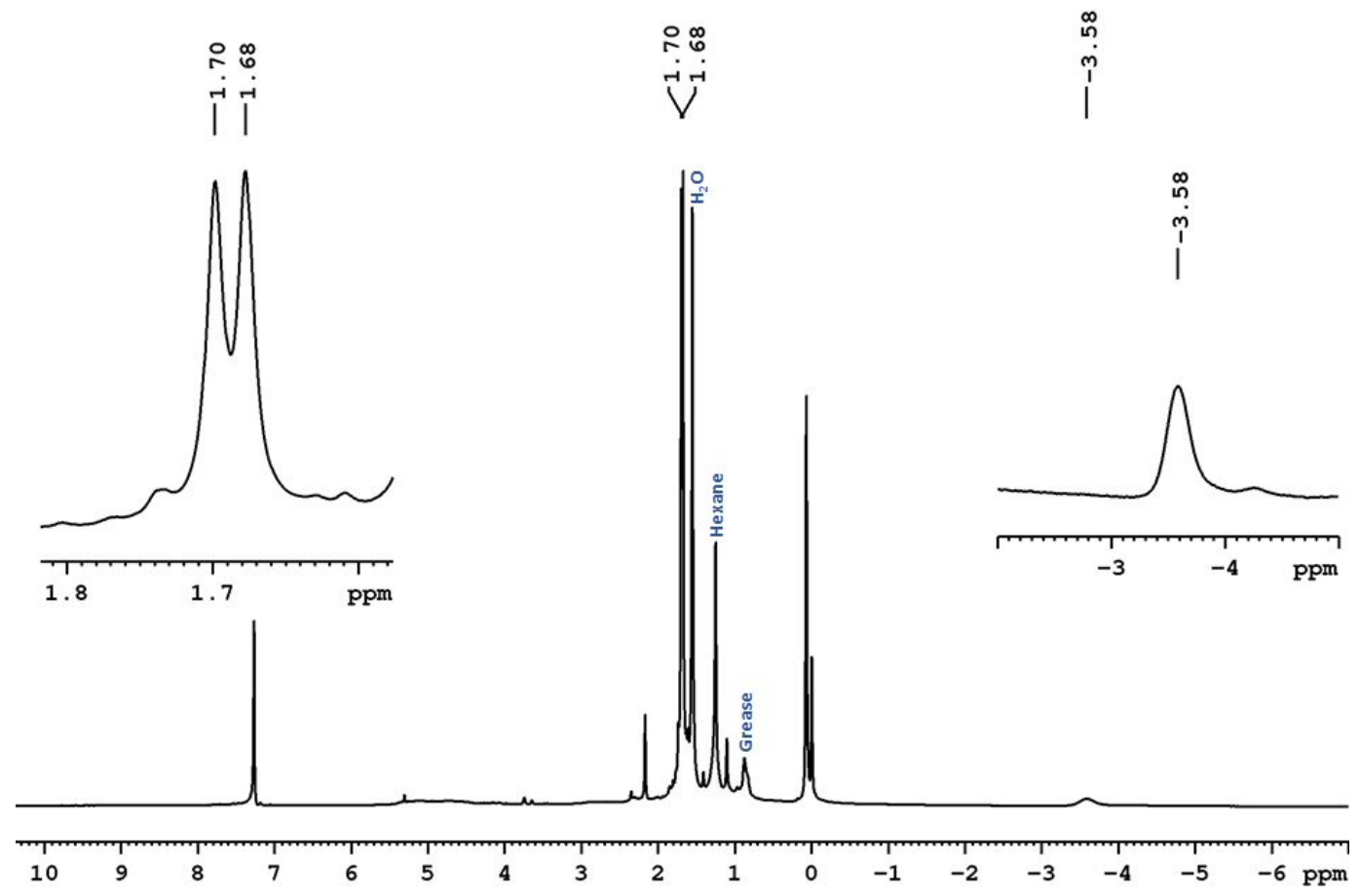

Figure S8. ${ }^{1} \mathrm{H}$ NMR spectrum of nido-4 in $\mathrm{CDCl}_{3}$ 


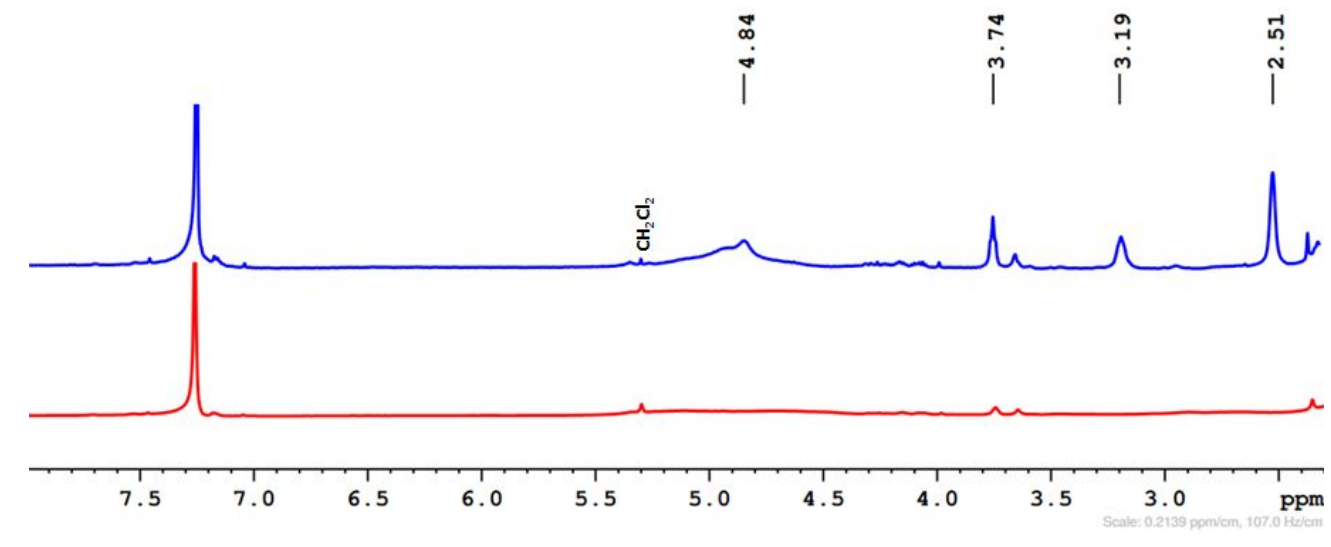

Figure S9. Stacked ${ }^{1} \mathrm{H}$ (bottom) and ${ }^{1} \mathrm{H}\left\{{ }^{11} \mathrm{~B}\right\}$ NMR (top) spectrum of nido-4 in $\mathrm{CDCl}_{3}$

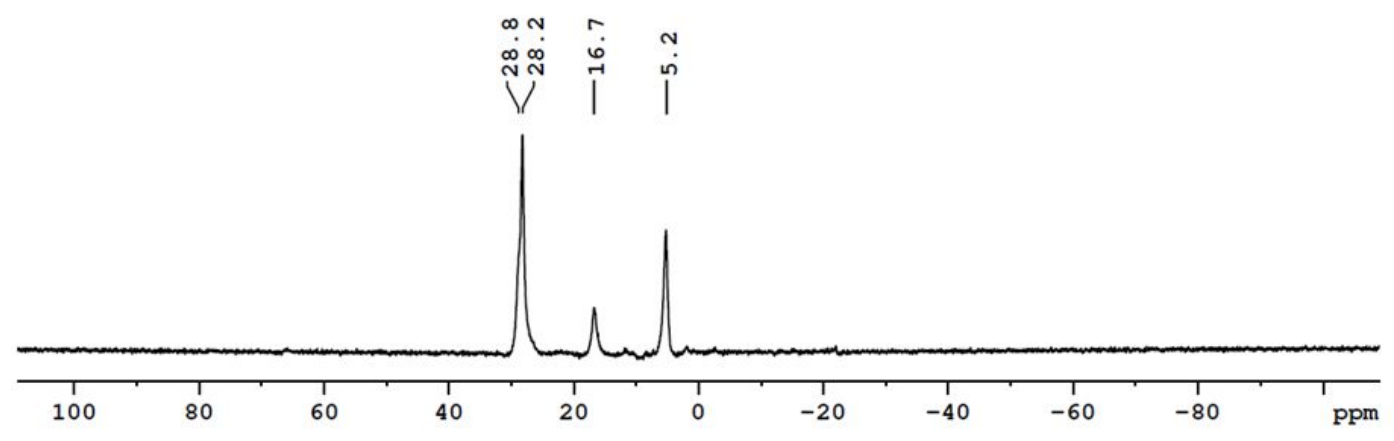

Figure S10. ${ }^{11} \mathrm{~B}\left\{{ }^{1} \mathrm{H}\right\}$ NMR spectrum of nido-4 in $\mathrm{CDCl}_{3}{ }^{1}$ 


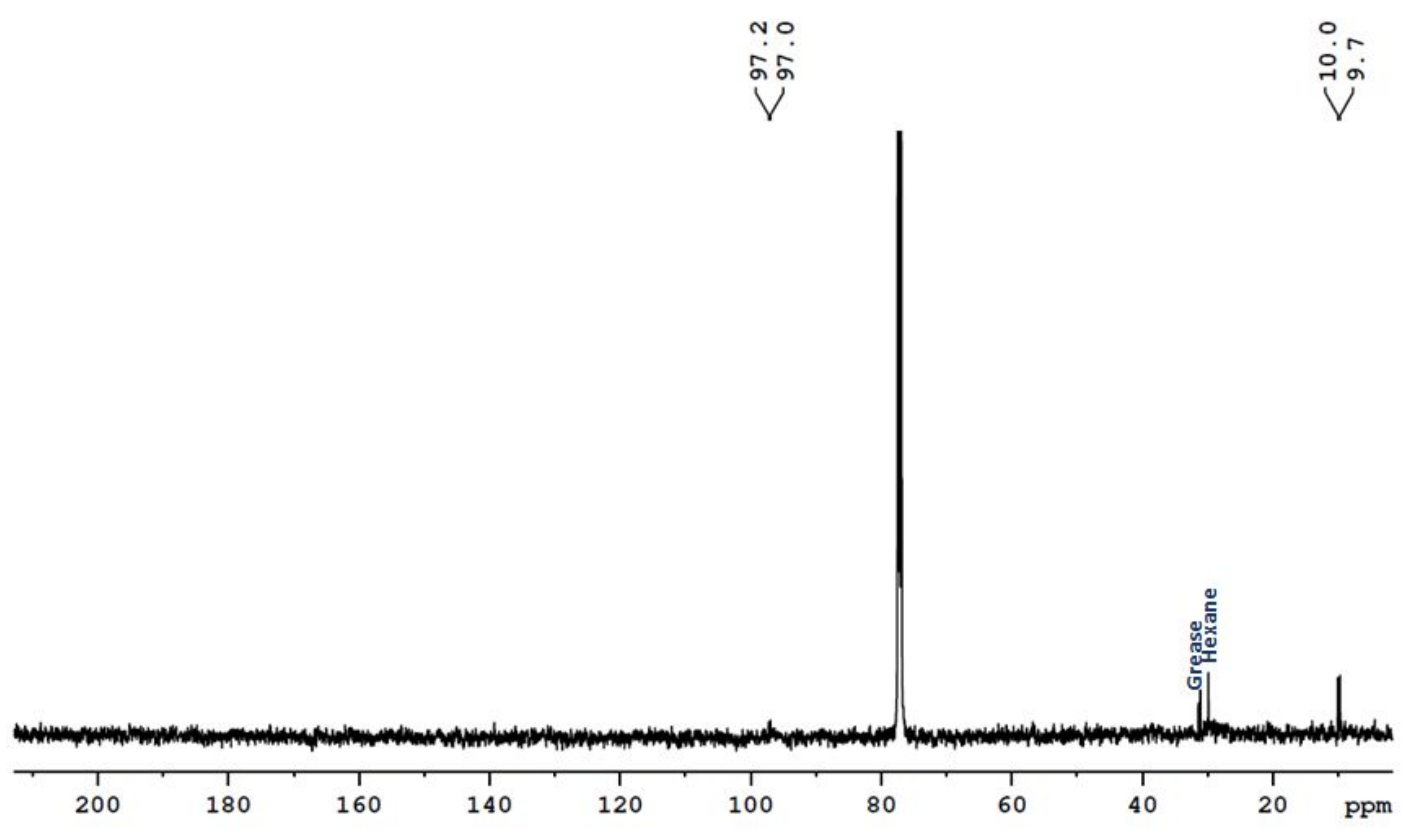

Figure S11. ${ }^{13} \mathrm{C}\left\{{ }^{1} \mathrm{H}\right\}$ NMR spectrum of nido-4 in $\mathrm{CDCl}_{3}$

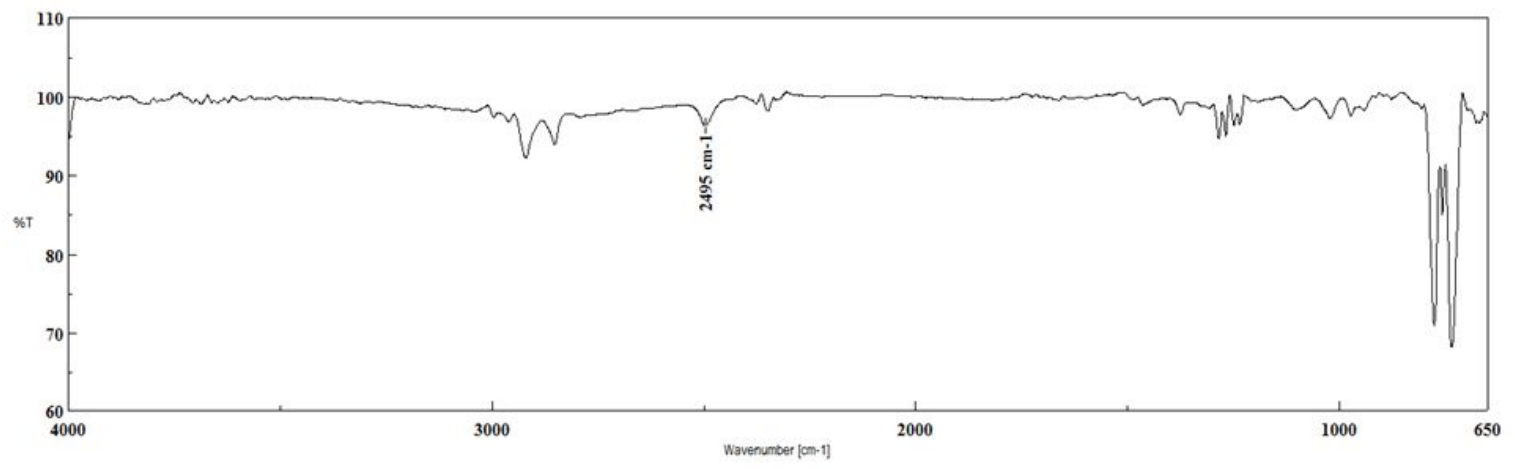

Figure S12. IR spectrum of nido-4 in $\mathrm{CH}_{2} \mathrm{Cl}_{2}$ 


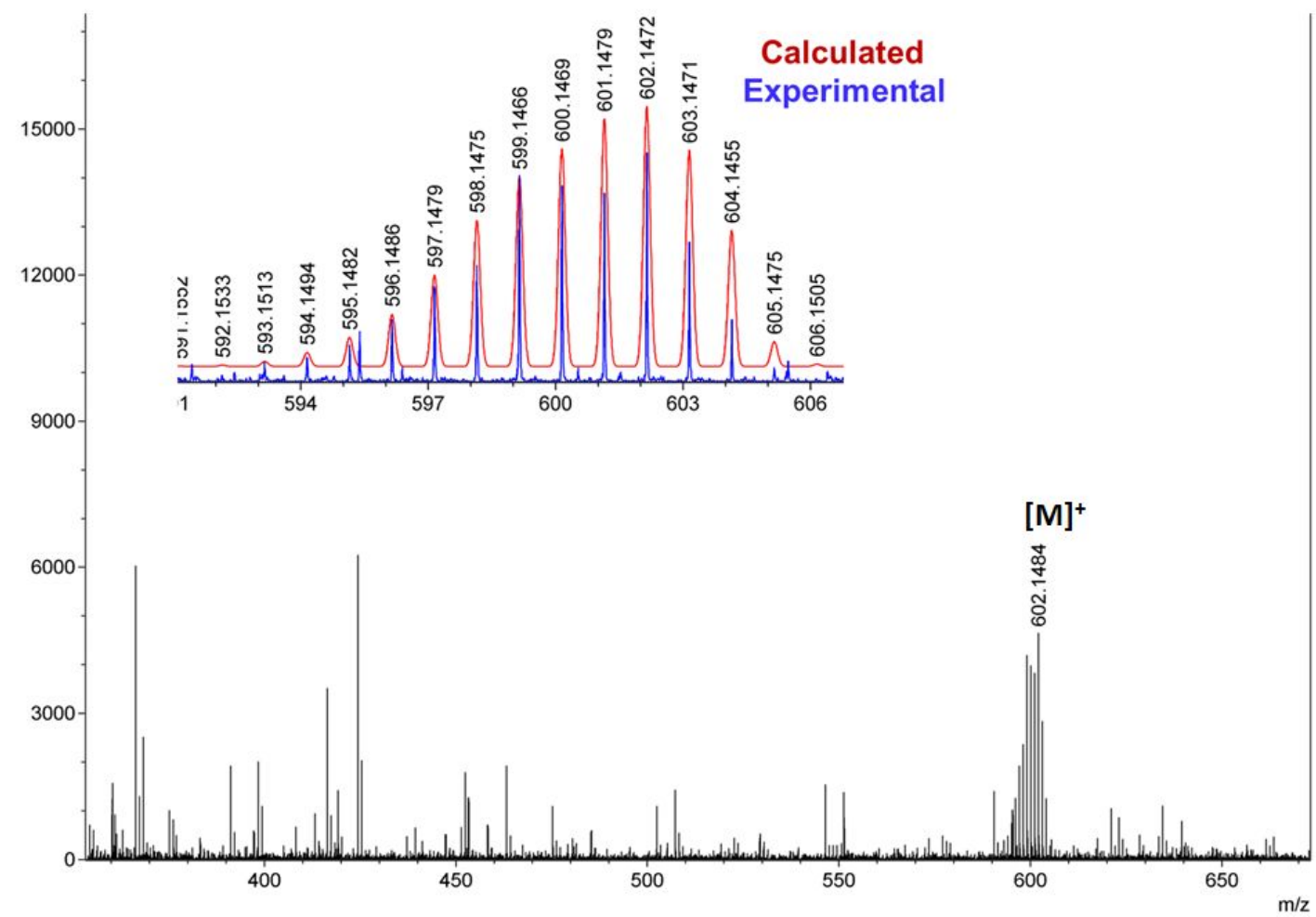

Figure S13. ESI-MS spectrum of nido-5 in $\mathrm{CH}_{2} \mathrm{Cl}_{2}$

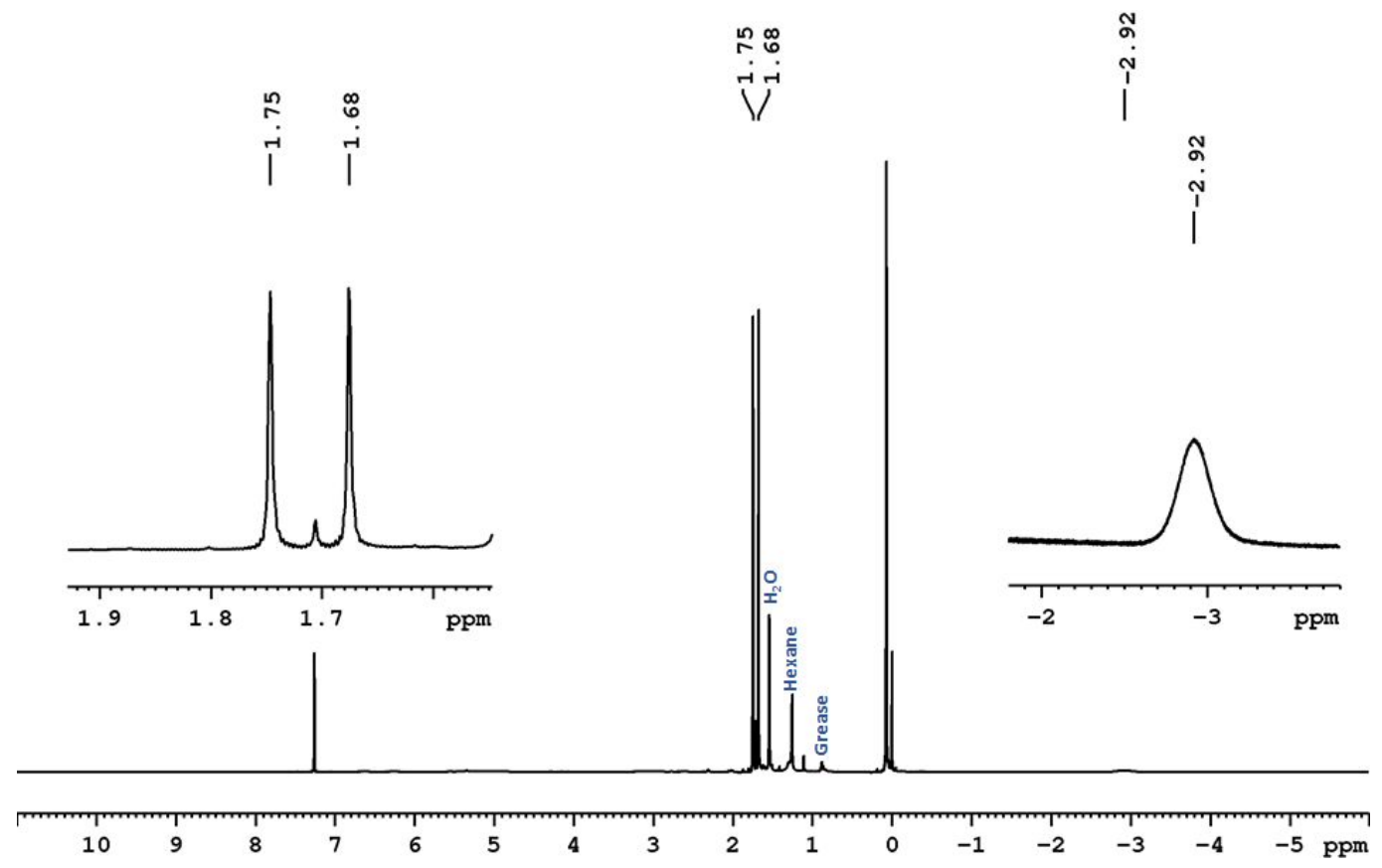

Figure S14. ${ }^{1} \mathrm{H}$ NMR spectrum of nido-5 in $\mathrm{CDCl}_{3}$ 


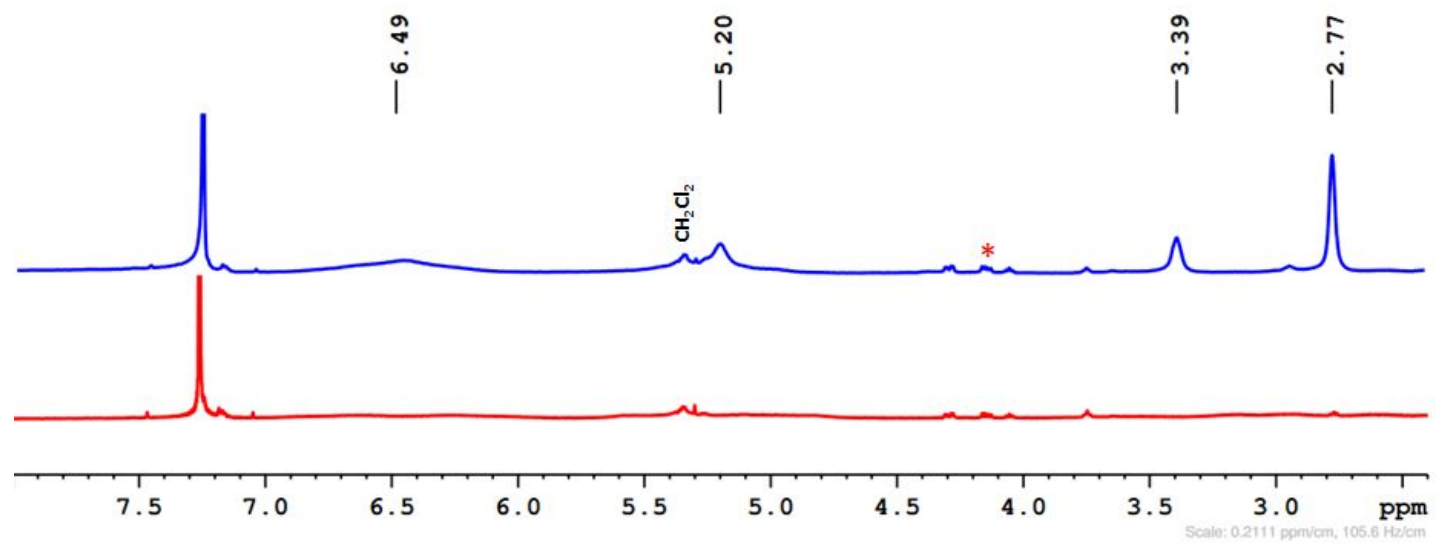

Figure S15. Stacked ${ }^{1} \mathrm{H}$ (bottom) and ${ }^{1} \mathrm{H}\left\{{ }^{11} \mathrm{~B}\right\} \mathrm{NMR}$ (top) spectrum of nido-5 in $\mathrm{CDCl}_{3}$. ( ${ }^{*}$ Unavoidable impurities)

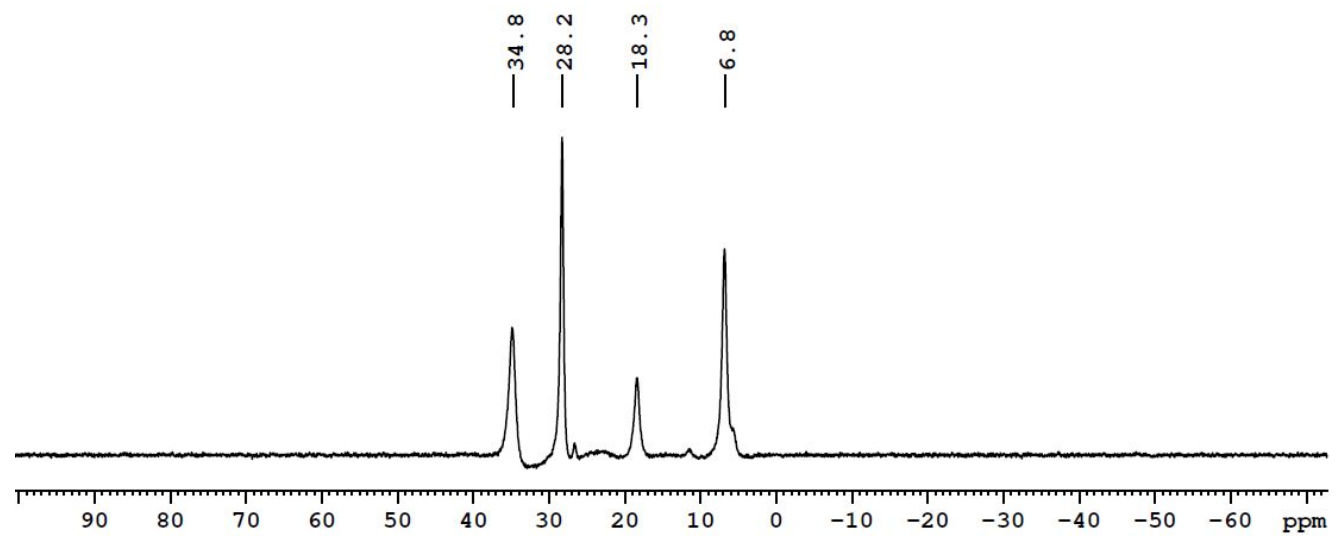

Figure S16. ${ }^{11} \mathrm{~B}\left\{{ }^{1} \mathrm{H}\right\}$ NMR spectrum of nido-5 in $\mathrm{CDCl}_{3}{ }^{1}$ 


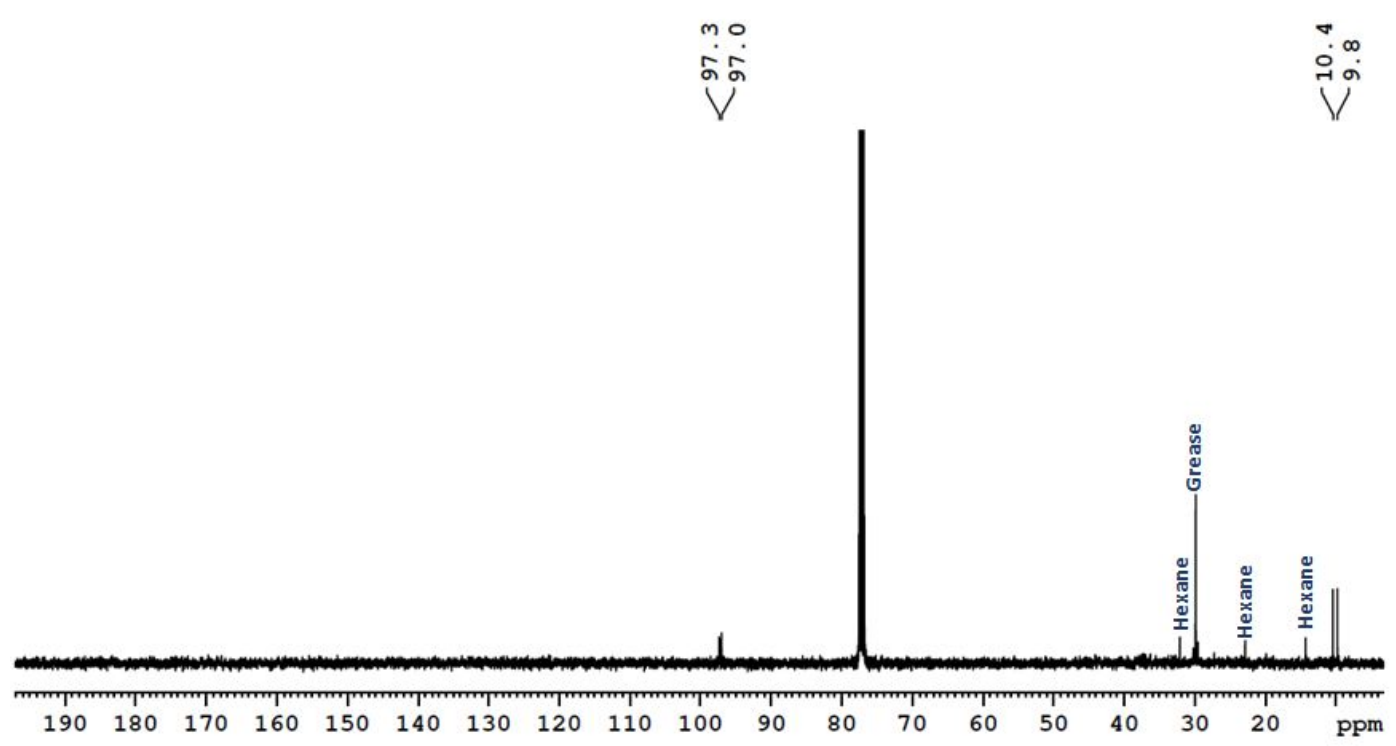

Figure S17. ${ }^{13} \mathrm{C}\left\{{ }^{1} \mathrm{H}\right\}$ NMR spectrum of nido-5 in $\mathrm{CDCl}_{3}$

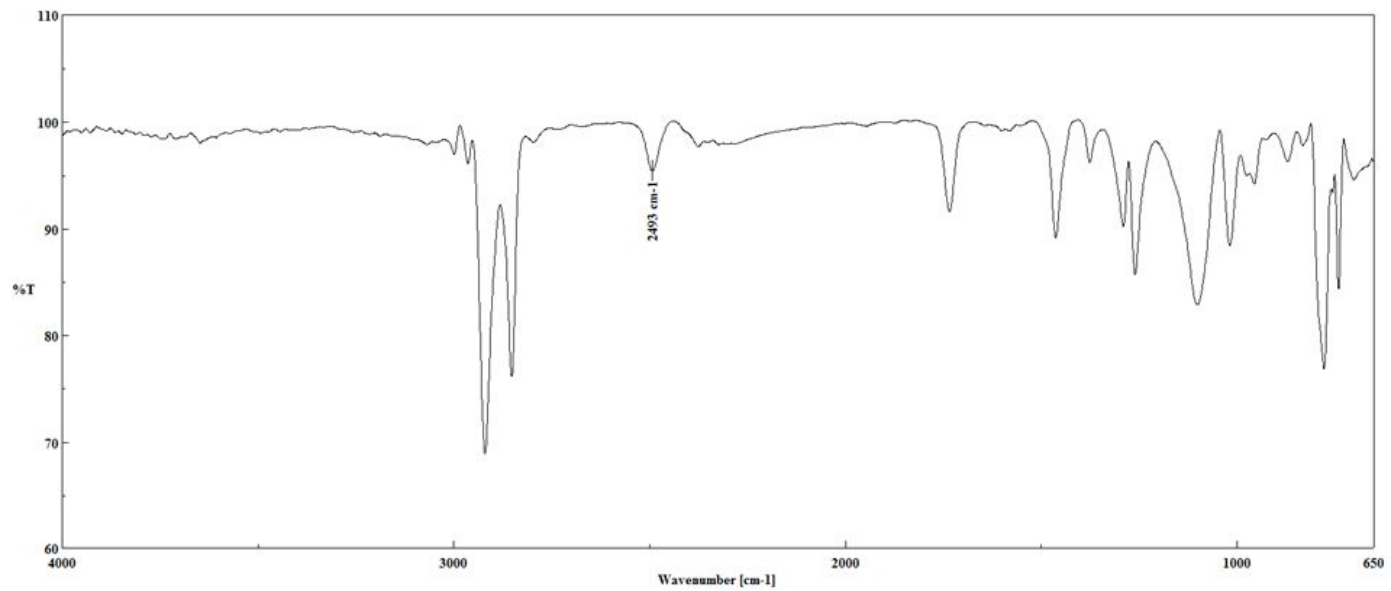

Figure S18. IR spectrum of nido-5 in $\mathrm{CH}_{2} \mathrm{Cl}_{2}$ 


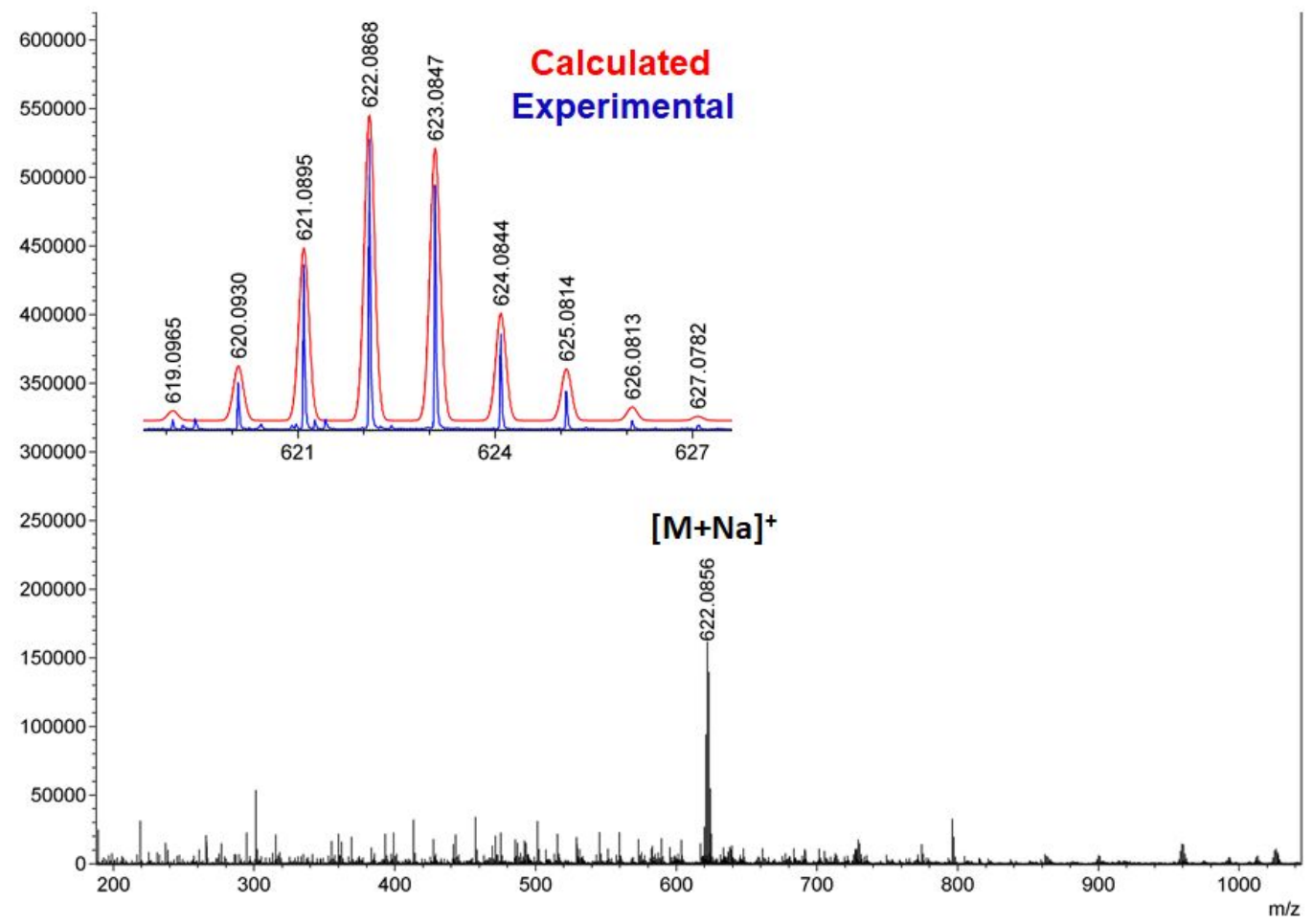

Figure S19. ESI-MS spectrum of nido-10 in $\mathrm{CH}_{2} \mathrm{Cl}_{2}$

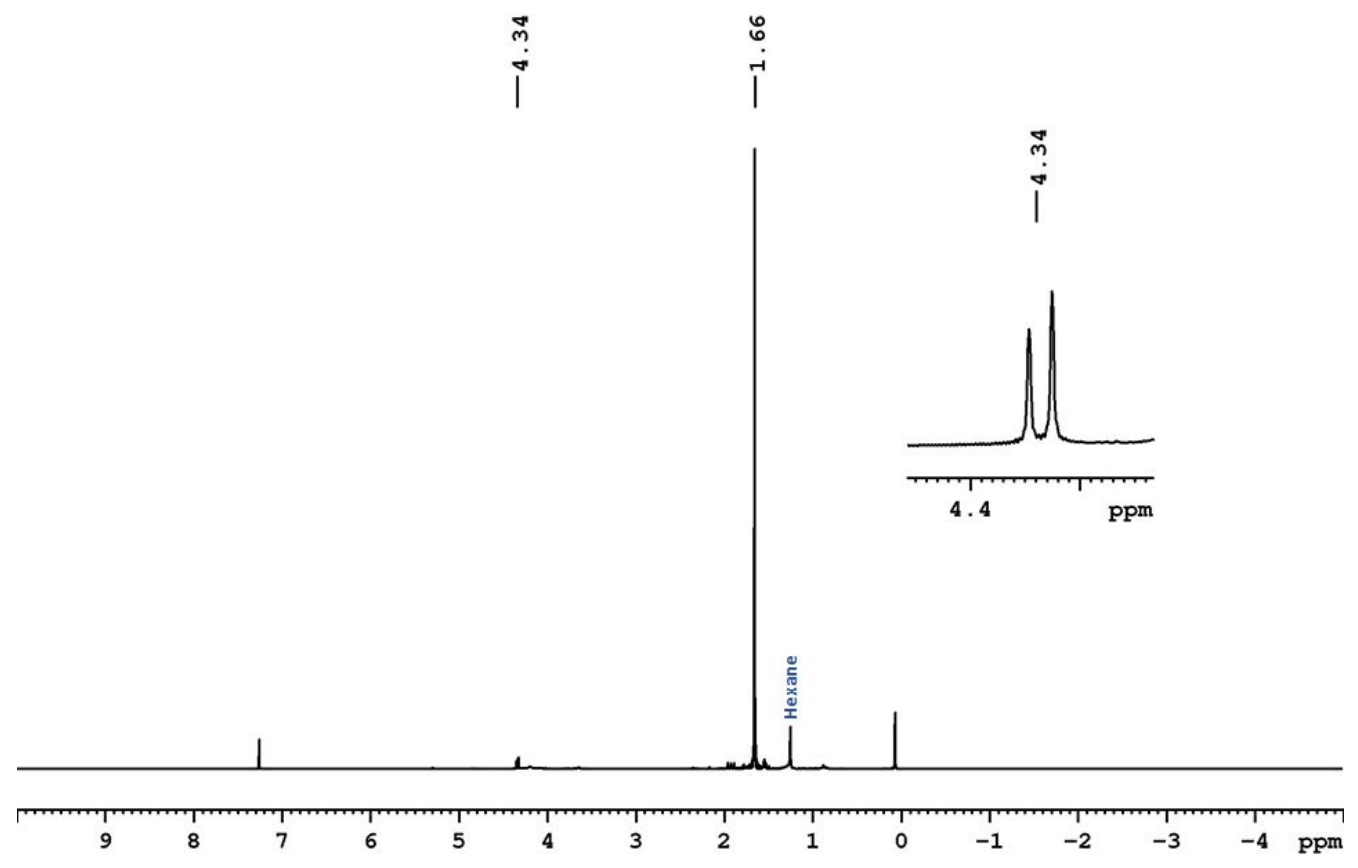

Figure S20. ${ }^{1} \mathrm{H}$ NMR spectrum of nido-10 in $\mathrm{CDCl}_{3}$ 


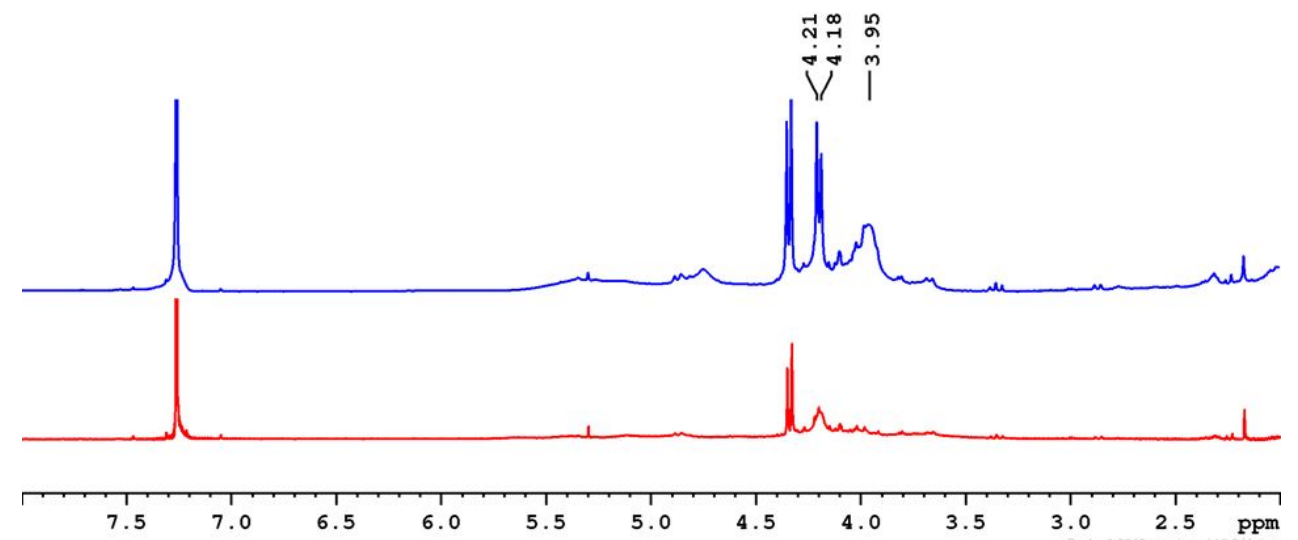

Figure S21. Stacked ${ }^{1} \mathrm{H}$ (bottom) and ${ }^{1} \mathrm{H}\left\{{ }^{11} \mathrm{~B}\right\} \mathrm{NMR}$ (top) spectrum of nido-10 in $\mathrm{CDCl}_{3}$

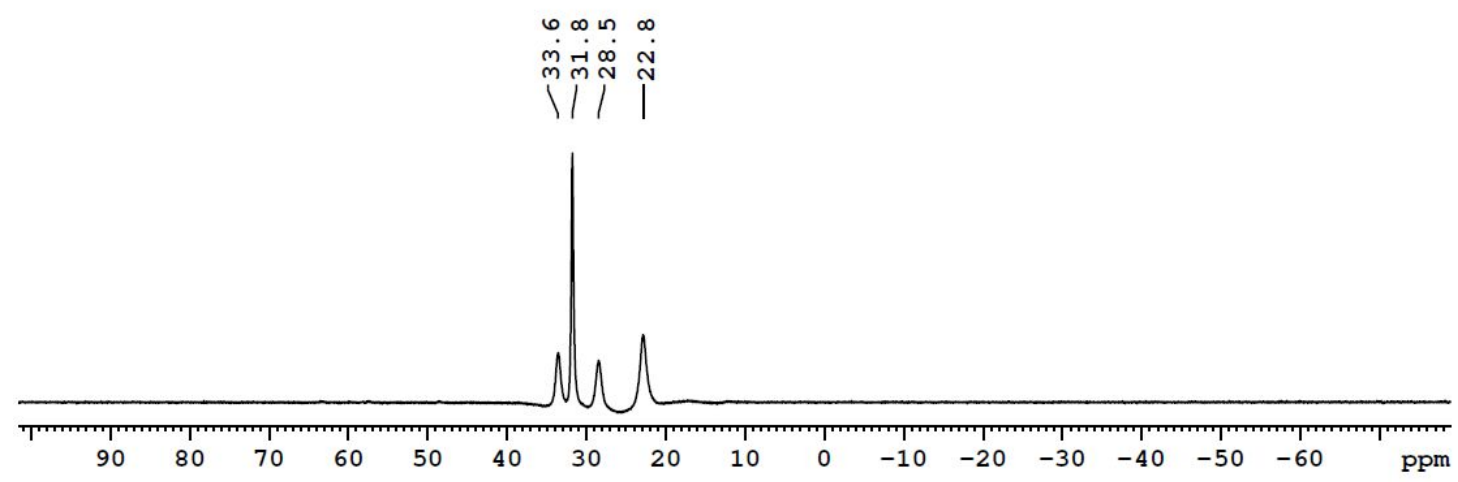

Figure S22. ${ }^{11} \mathrm{~B}\left\{{ }^{1} \mathrm{H}\right\} \mathrm{NMR}$ spectrum of nido-10 in $\mathrm{CDCl}_{3}{ }^{1}$ 


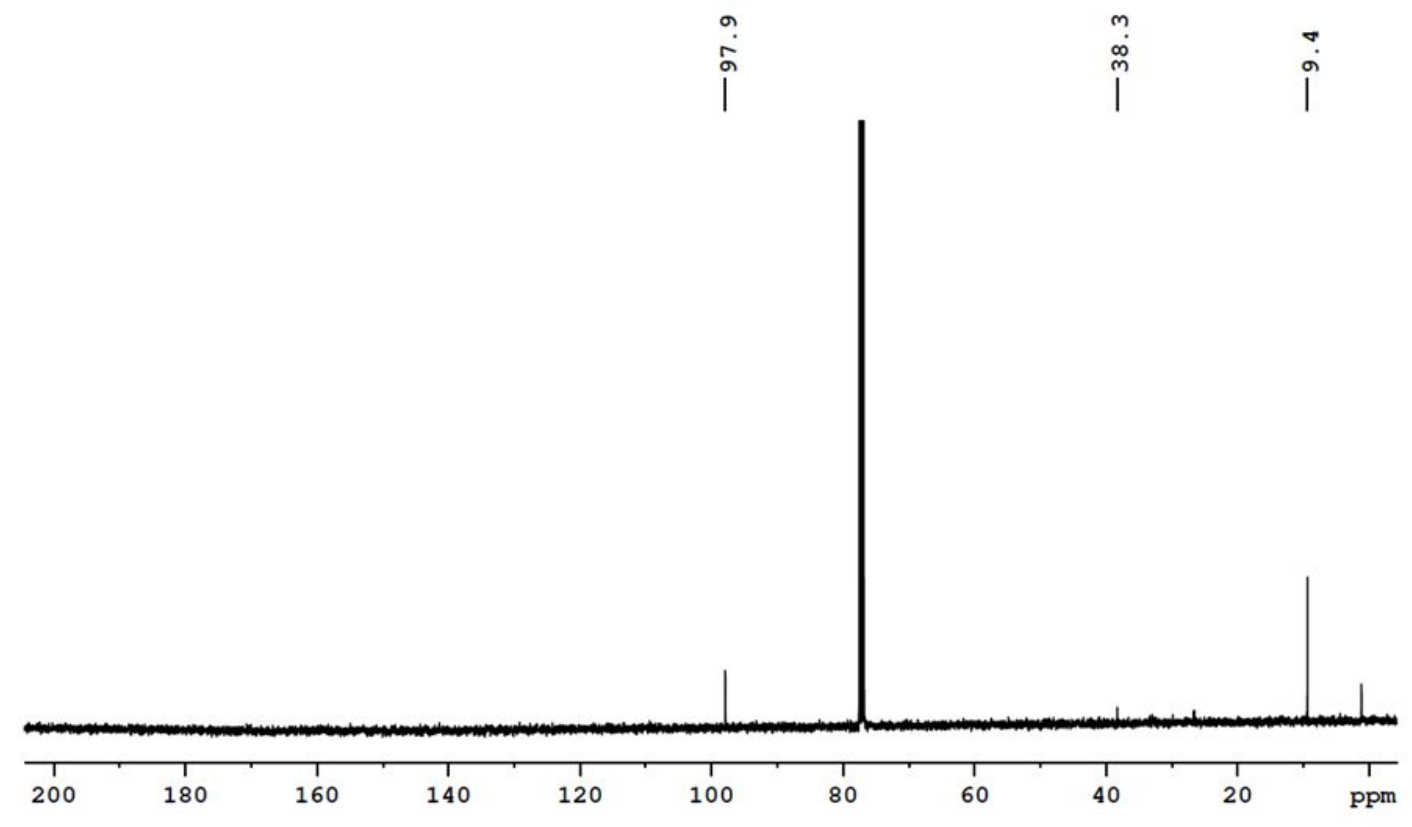

Figure S23. ${ }^{13} \mathrm{C}\left\{{ }^{1} \mathrm{H}\right\}$ NMR spectrum of nido-10 in $\mathrm{CDCl}_{3}$

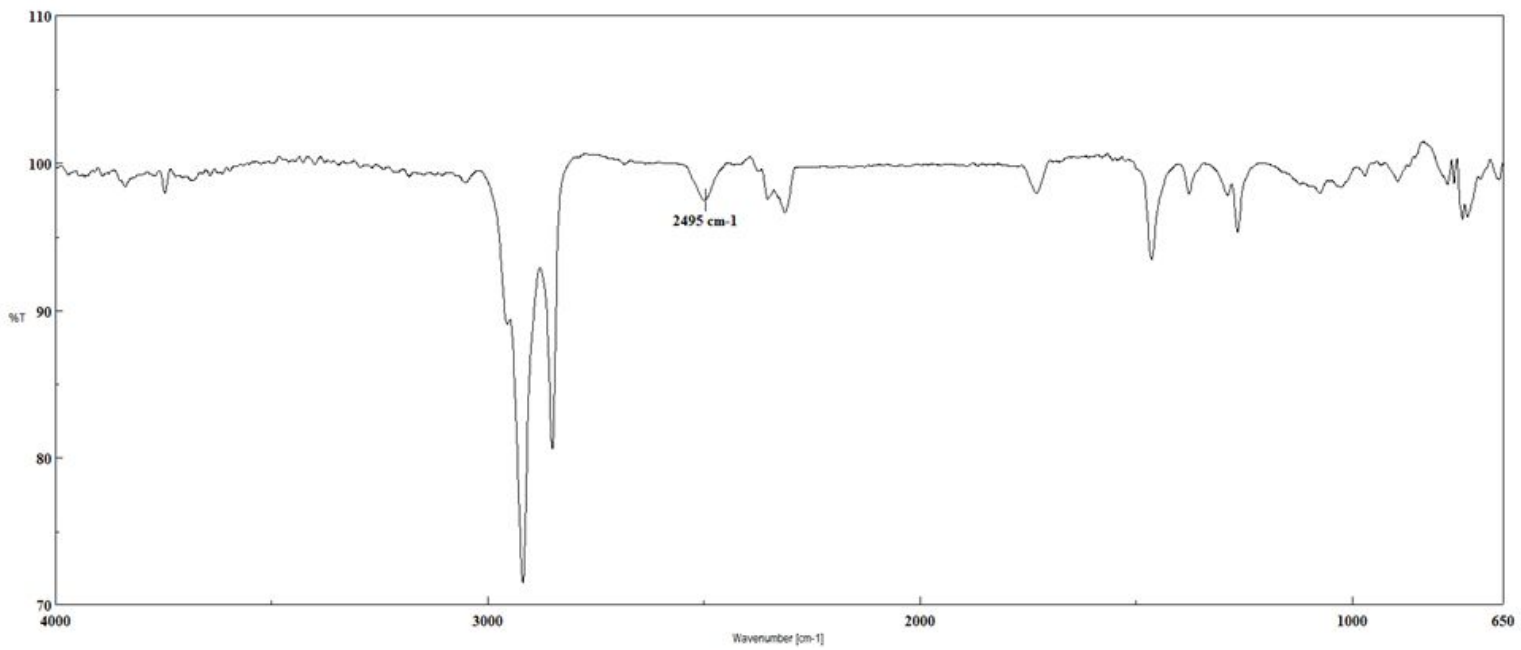

Figure S24. IR spectrum of nido-10 in $\mathrm{CH}_{2} \mathrm{Cl}_{2}$ 


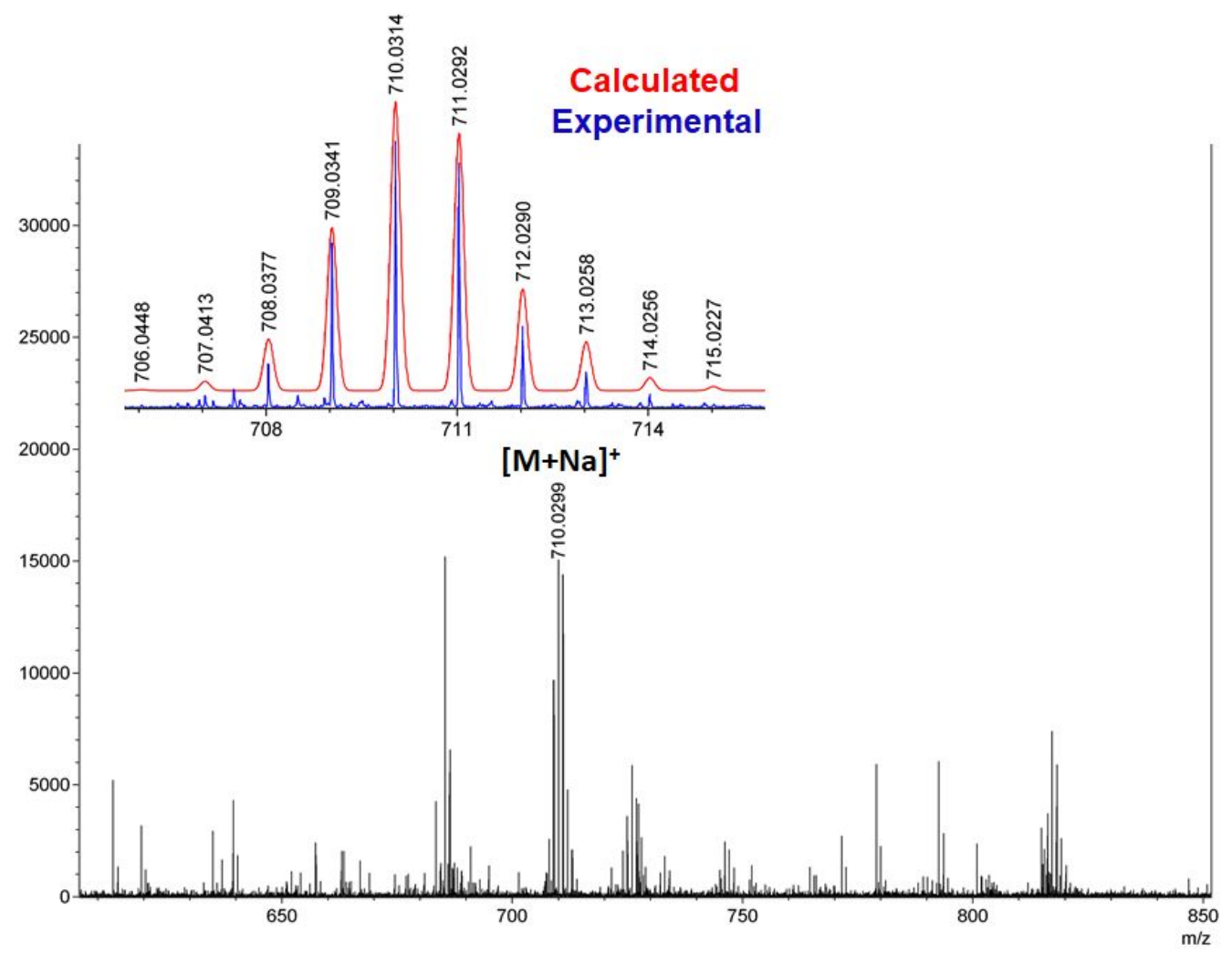

Figure S25. ESI-MS spectrum of nido-11 in $\mathrm{CH}_{2} \mathrm{Cl}_{2}$

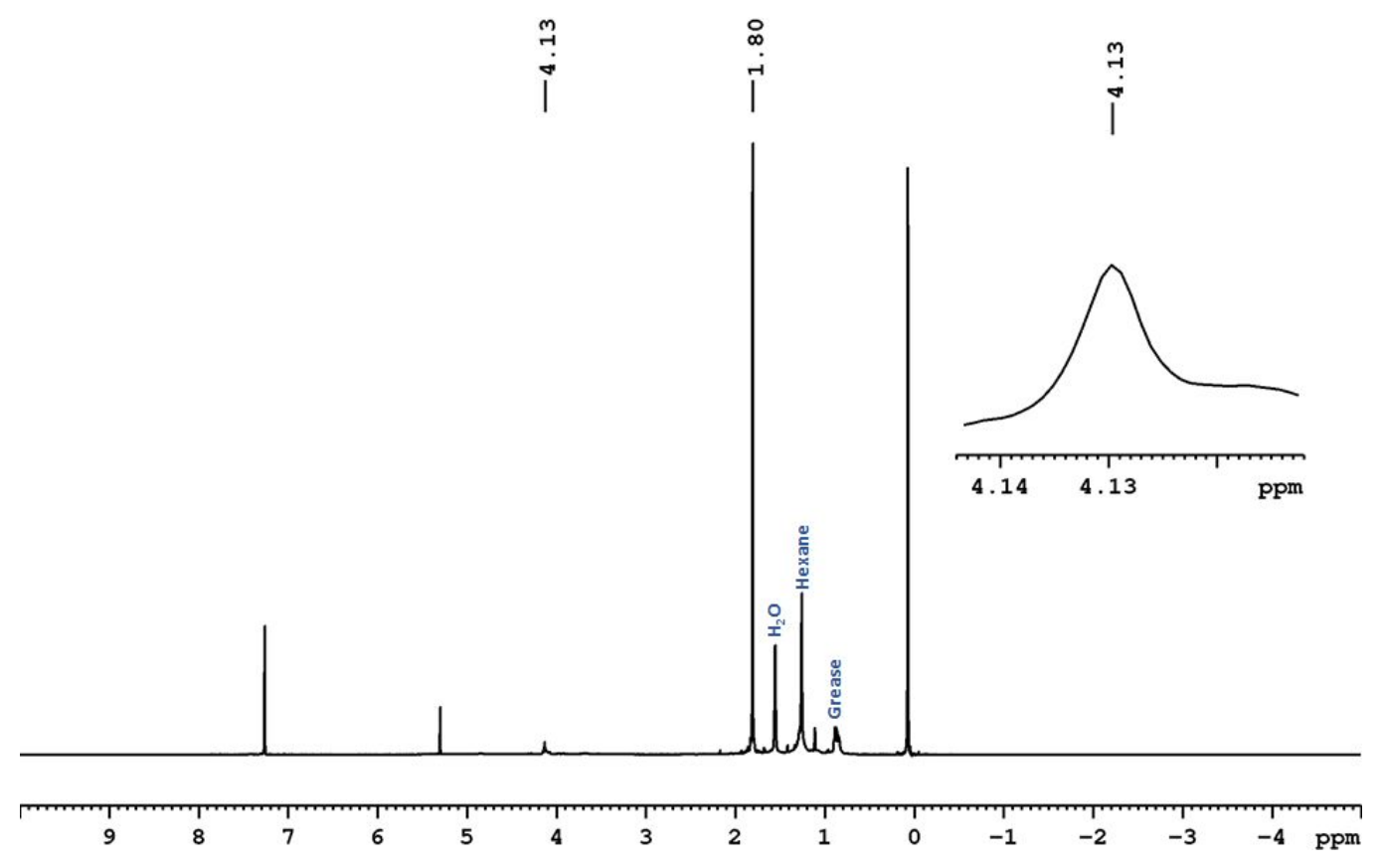

Figure S26. ${ }^{1} \mathrm{H}$ NMR spectrum of nido-11 in $\mathrm{CDCl}_{3}$ 


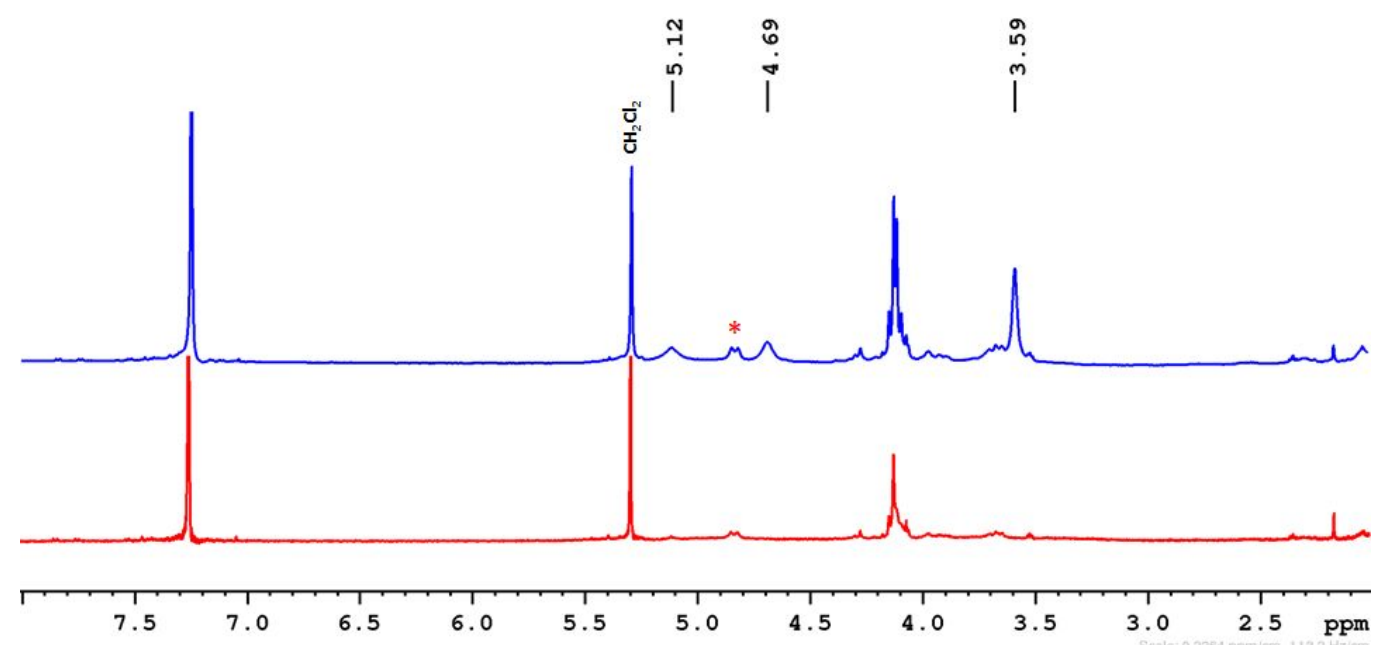

Figure S27. Stacked ${ }^{1} \mathrm{H}$ (bottom) and ${ }^{1} \mathrm{H}\left\{{ }^{11} \mathrm{~B}\right\} \mathrm{NMR}$ (top) spectrum of nido-11 in $\mathrm{CDCl}_{3}$. (* Unavoidable impurities)

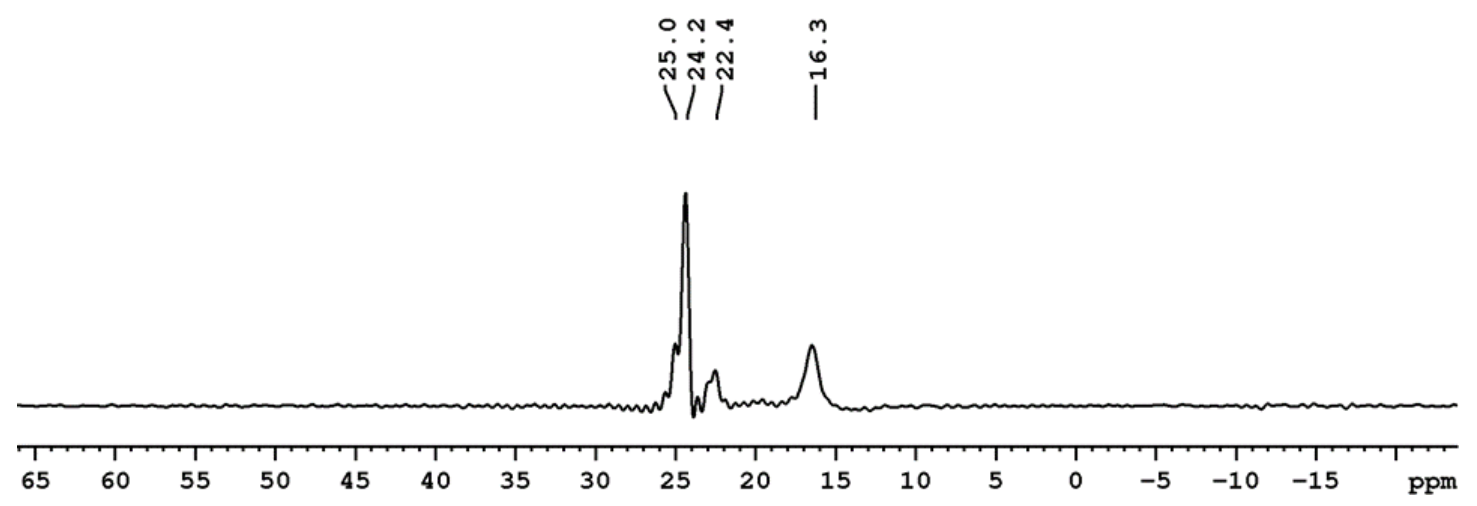

Figure S28. ${ }^{11} \mathrm{~B}\left\{{ }^{1} \mathrm{H}\right\}$ NMR spectrum of nido-11 in $\mathrm{CDCl}_{3}{ }^{1}$ 


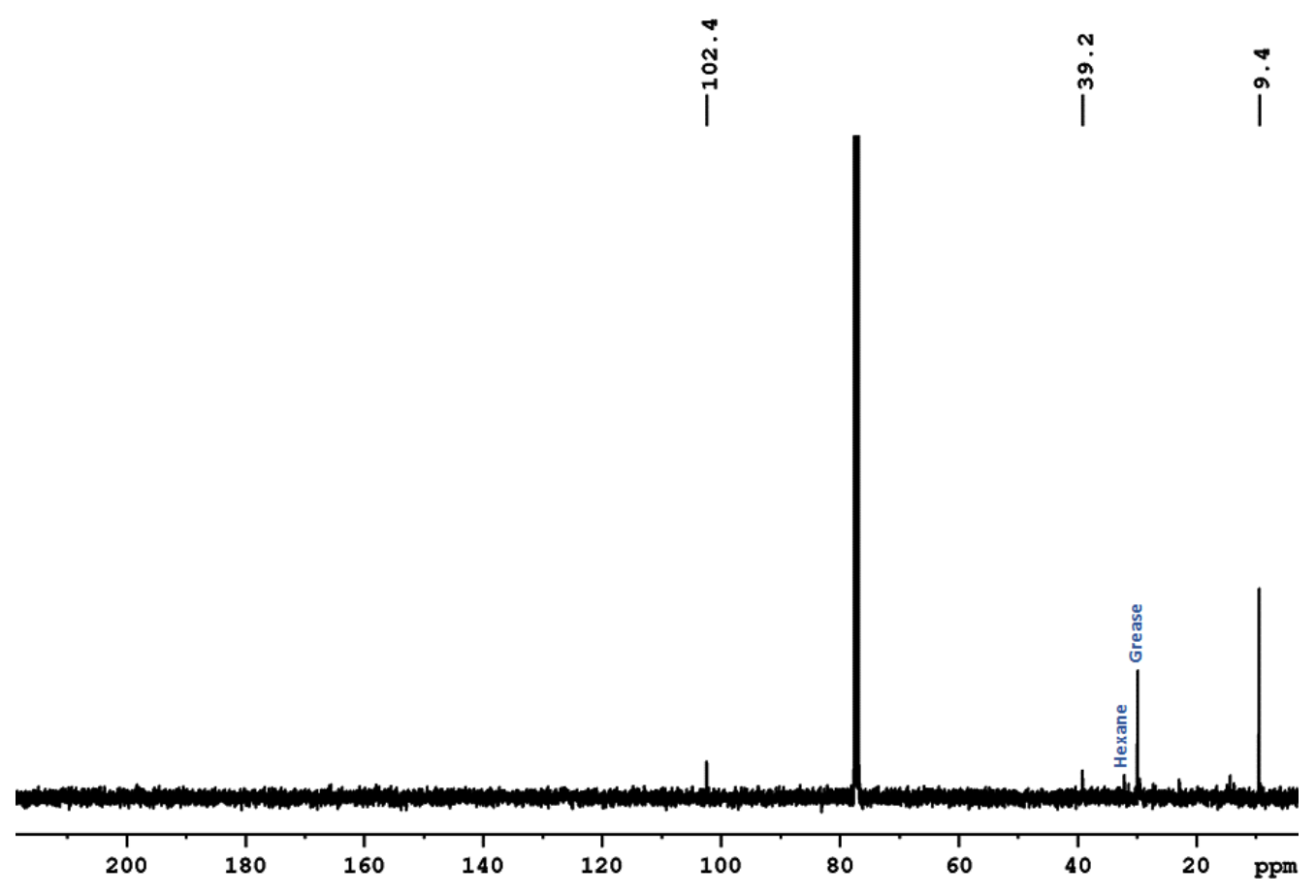

Figure S29. ${ }^{13} \mathrm{C}\left\{{ }^{1} \mathrm{H}\right\}$ NMR spectrum of nido-11 in $\mathrm{CDCl}_{3}$

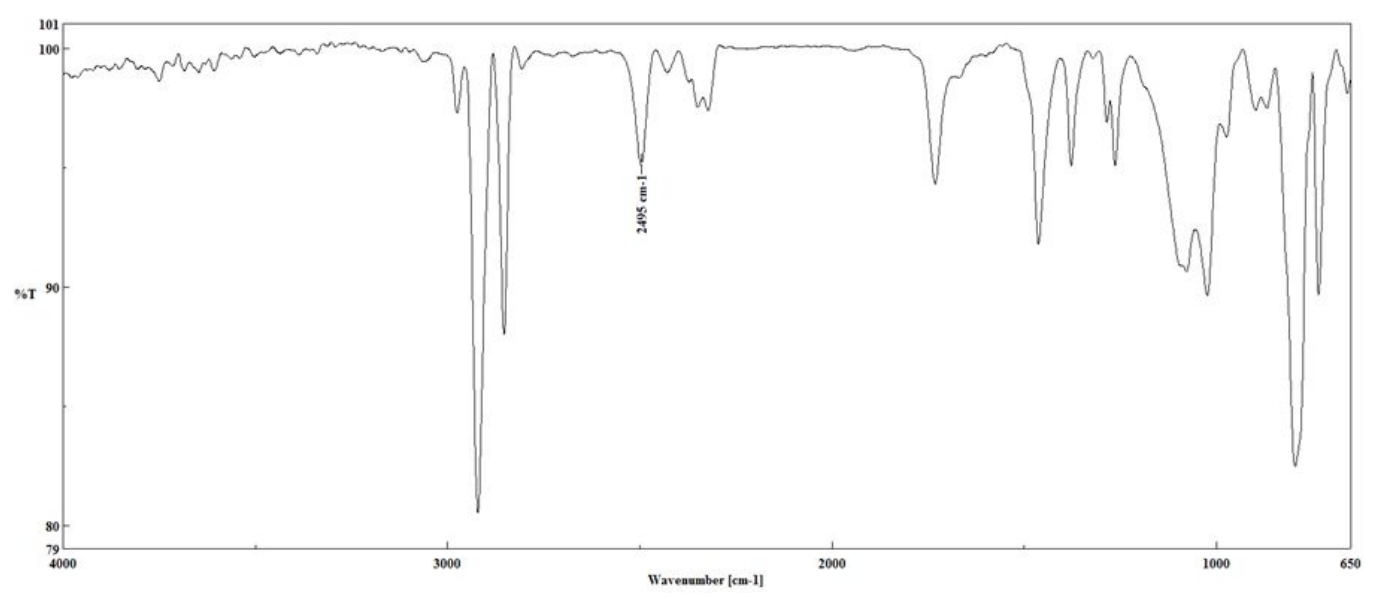

Figure S30. IR spectrum of nido-11 in $\mathrm{CH}_{2} \mathrm{Cl}_{2}$ 


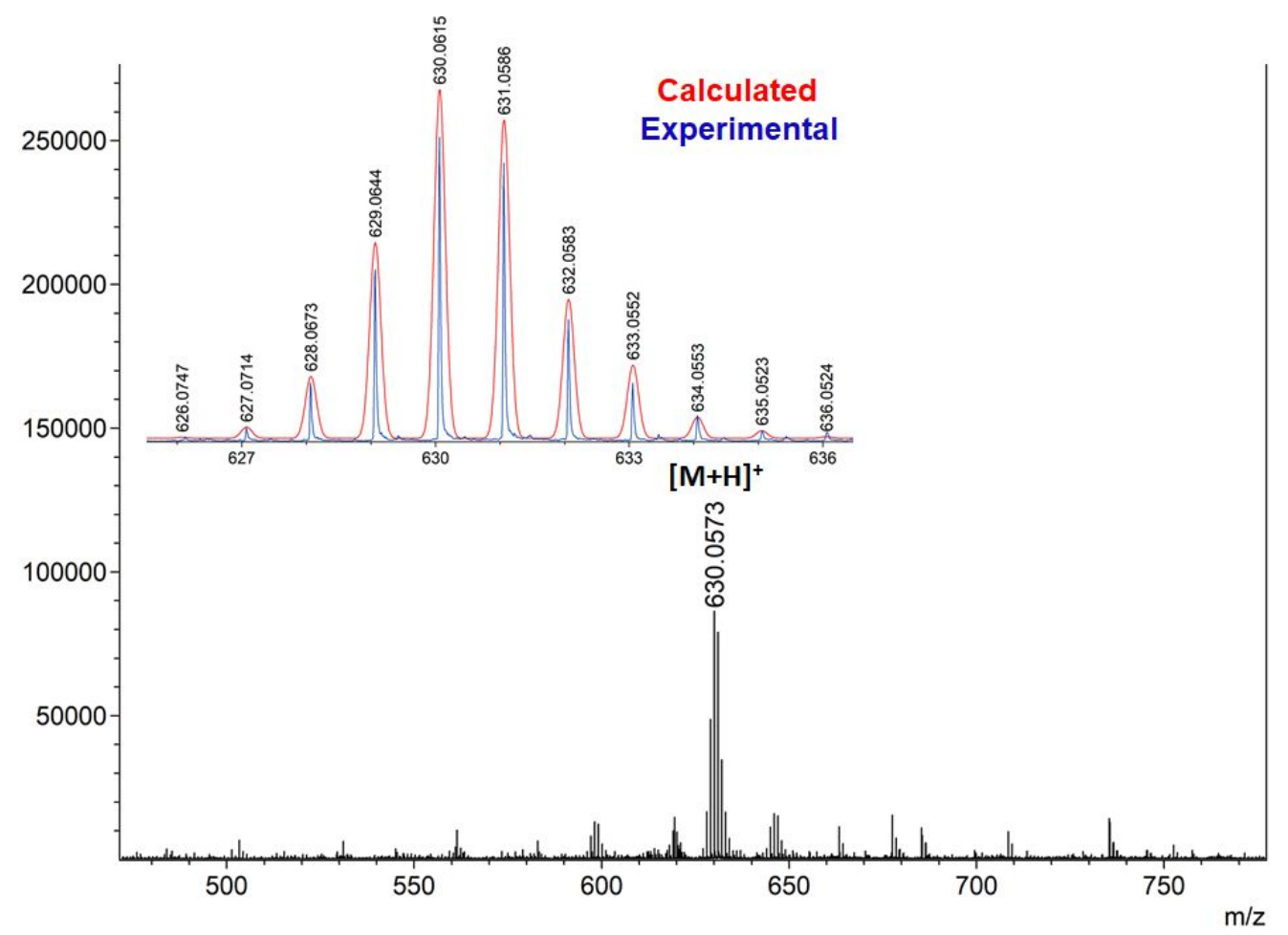

Figure S31. ESI-MS spectrum of nido-12 in $\mathrm{CH}_{2} \mathrm{Cl}_{2}$

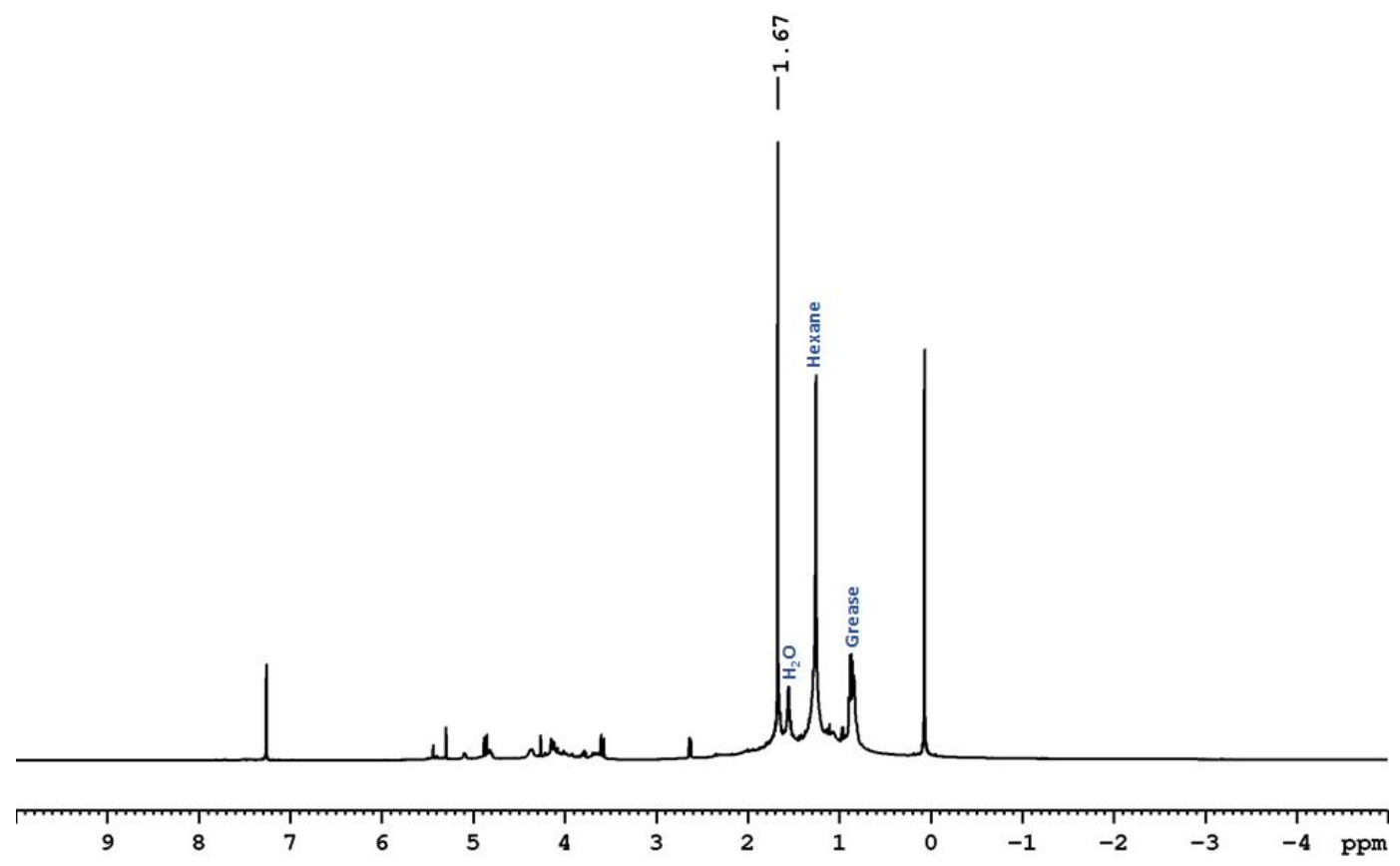

Figure. S32. ${ }^{1} \mathrm{H}$ NMR spectrum of nido-12 in $\mathrm{CDCl}_{3}$ 


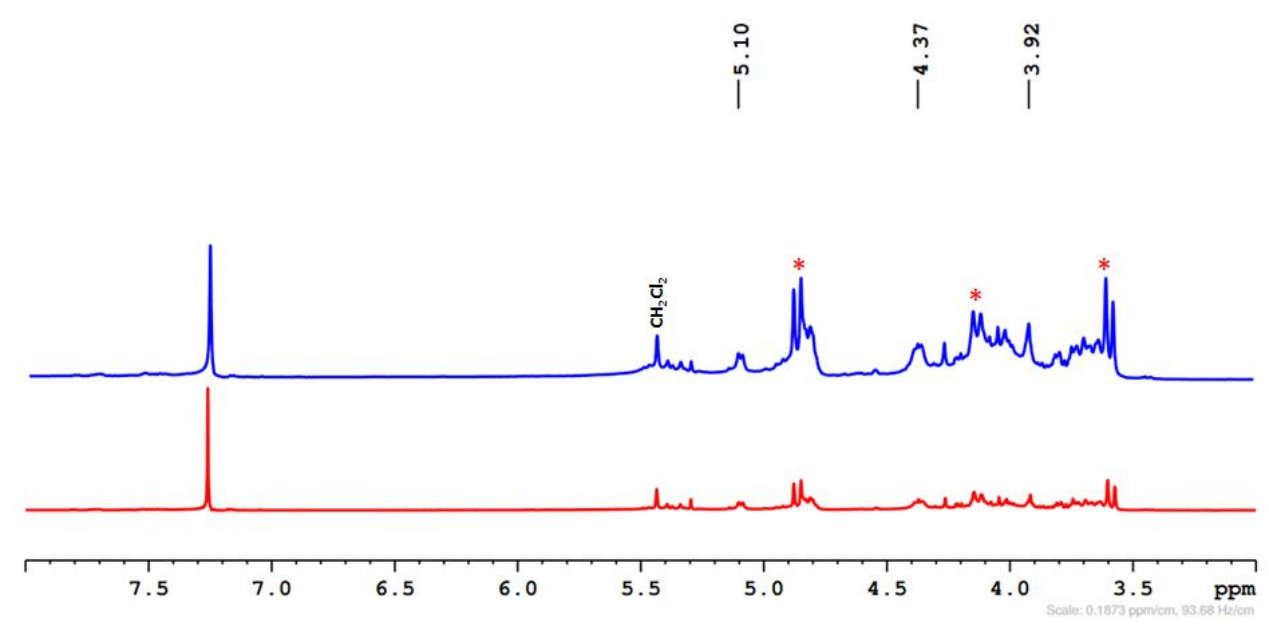

Figure S33. Stacked ${ }^{1} \mathrm{H}$ (bottom) and ${ }^{1} \mathrm{H}\left\{{ }^{11} \mathrm{~B}\right\} \mathrm{NMR}$ (top) spectrum of nido-12 in $\mathrm{CDCl}_{3}$. (* Unavoidable impurities)

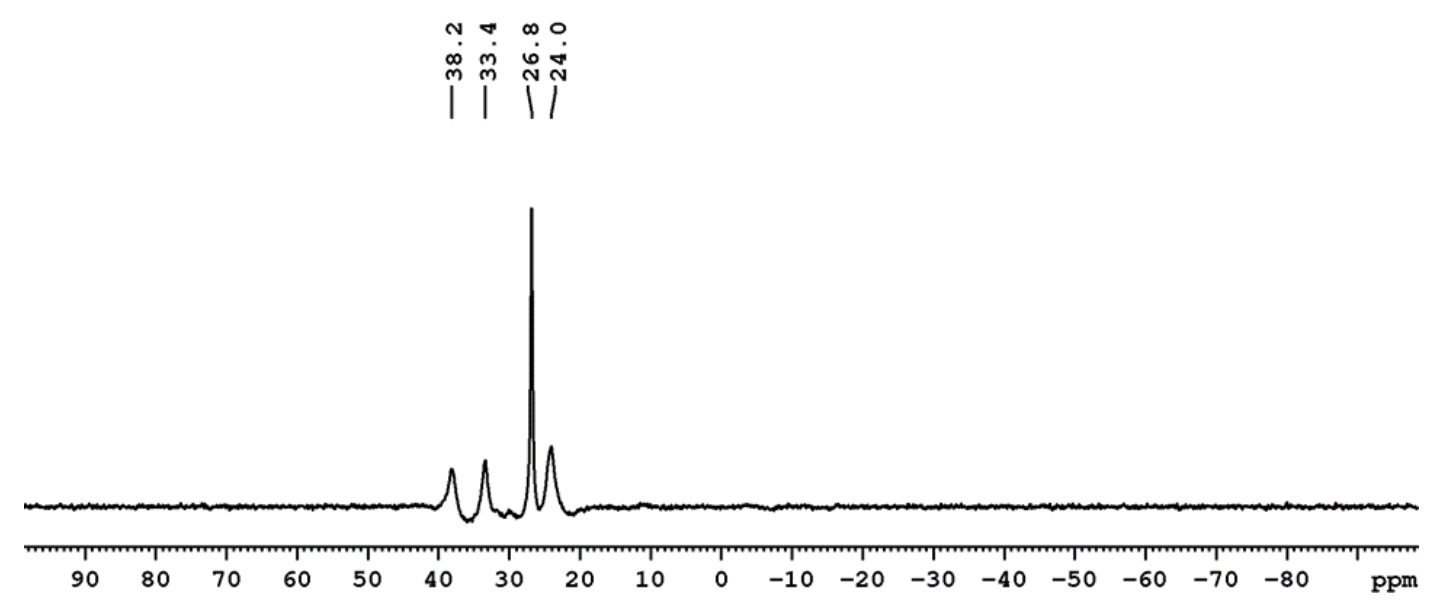

Figure S34. ${ }^{11} \mathrm{~B}\left\{{ }^{1} \mathrm{H}\right\} \mathrm{NMR}$ spectrum of nido-12 in $\mathrm{CDCl}_{3}{ }^{1}$ 


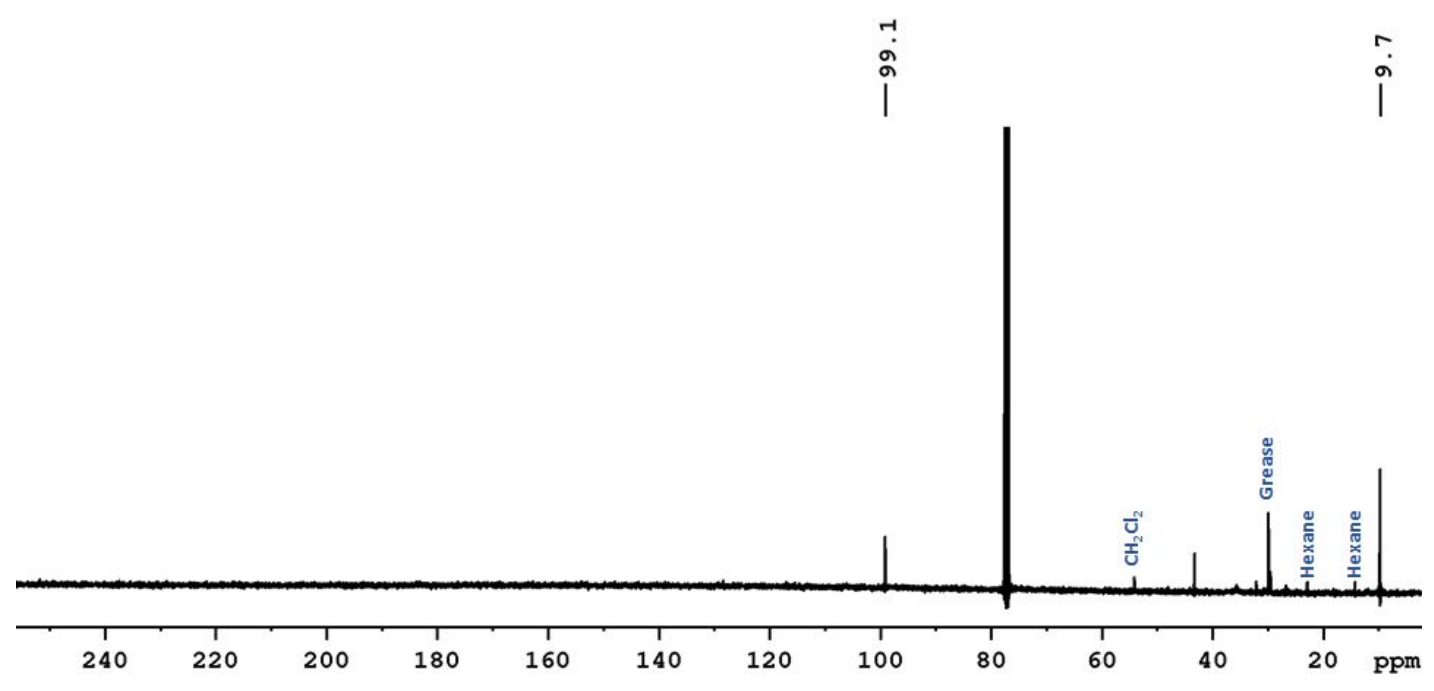

Figure S35. ${ }^{13} \mathrm{C}\left\{{ }^{1} \mathrm{H}\right\}$ NMR spectrum of nido-12 in $\mathrm{CDCl}_{3}$

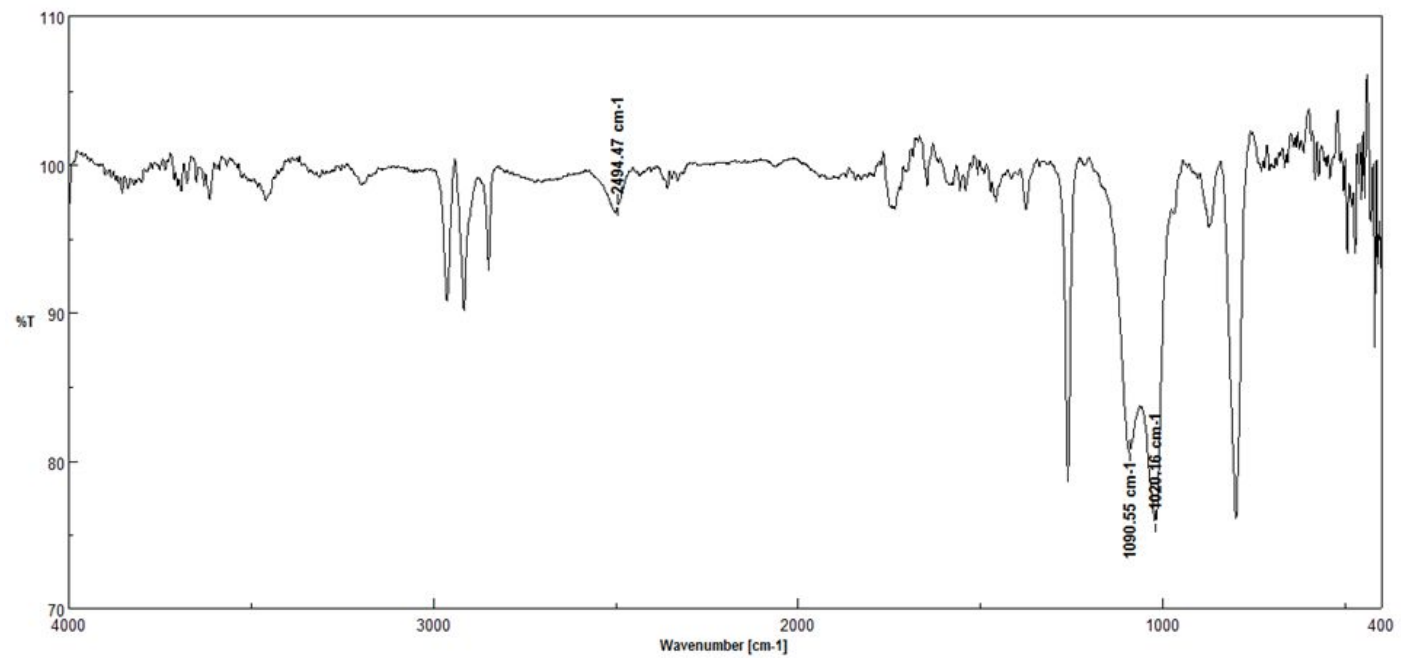

Figure S36. IR spectrum of nido-12 in $\mathrm{CH}_{2} \mathrm{Cl}_{2}$ 


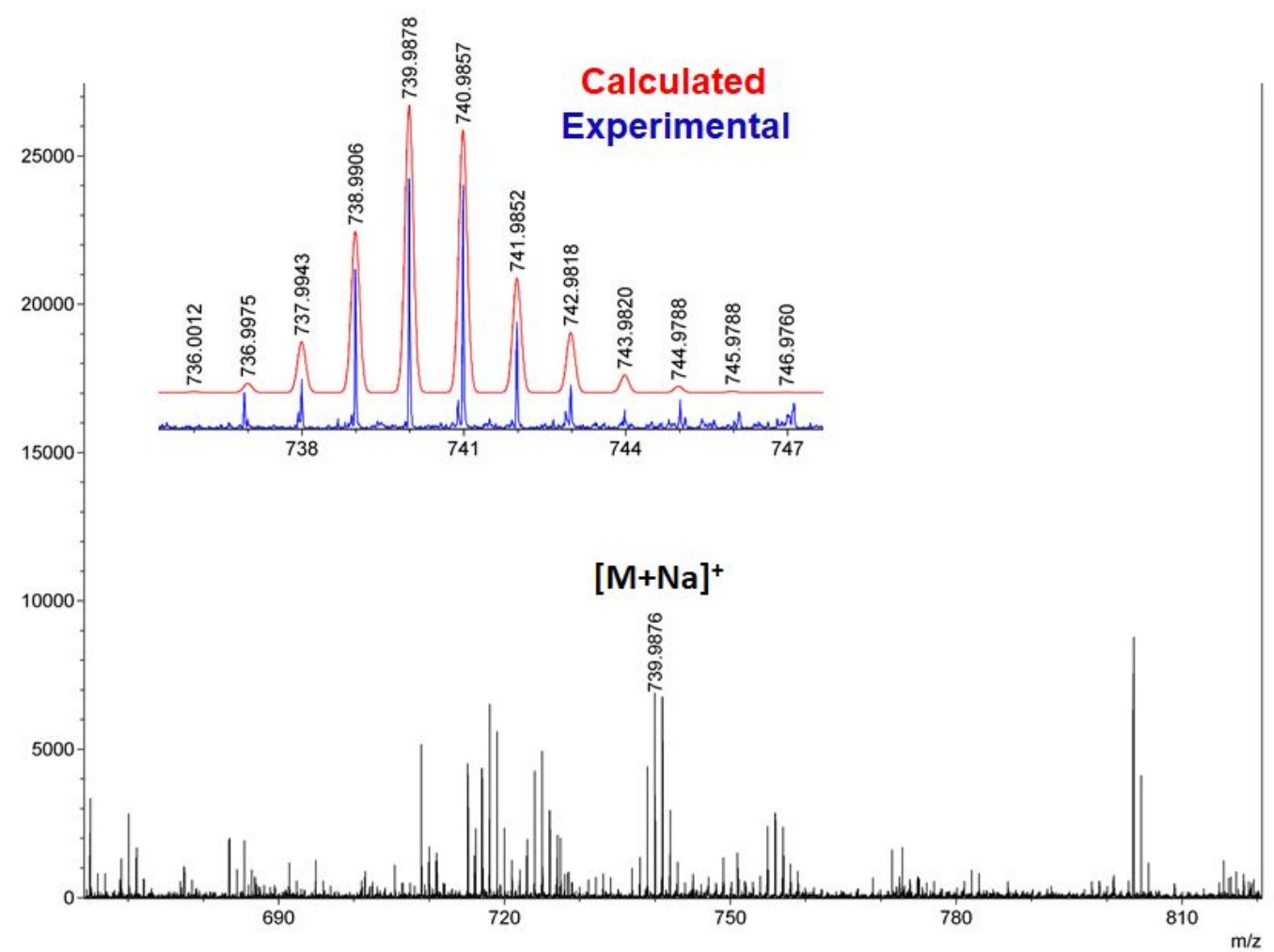

Figure S37. ESI-MS spectrum of nido-13 in $\mathrm{CH}_{2} \mathrm{Cl}_{2}$

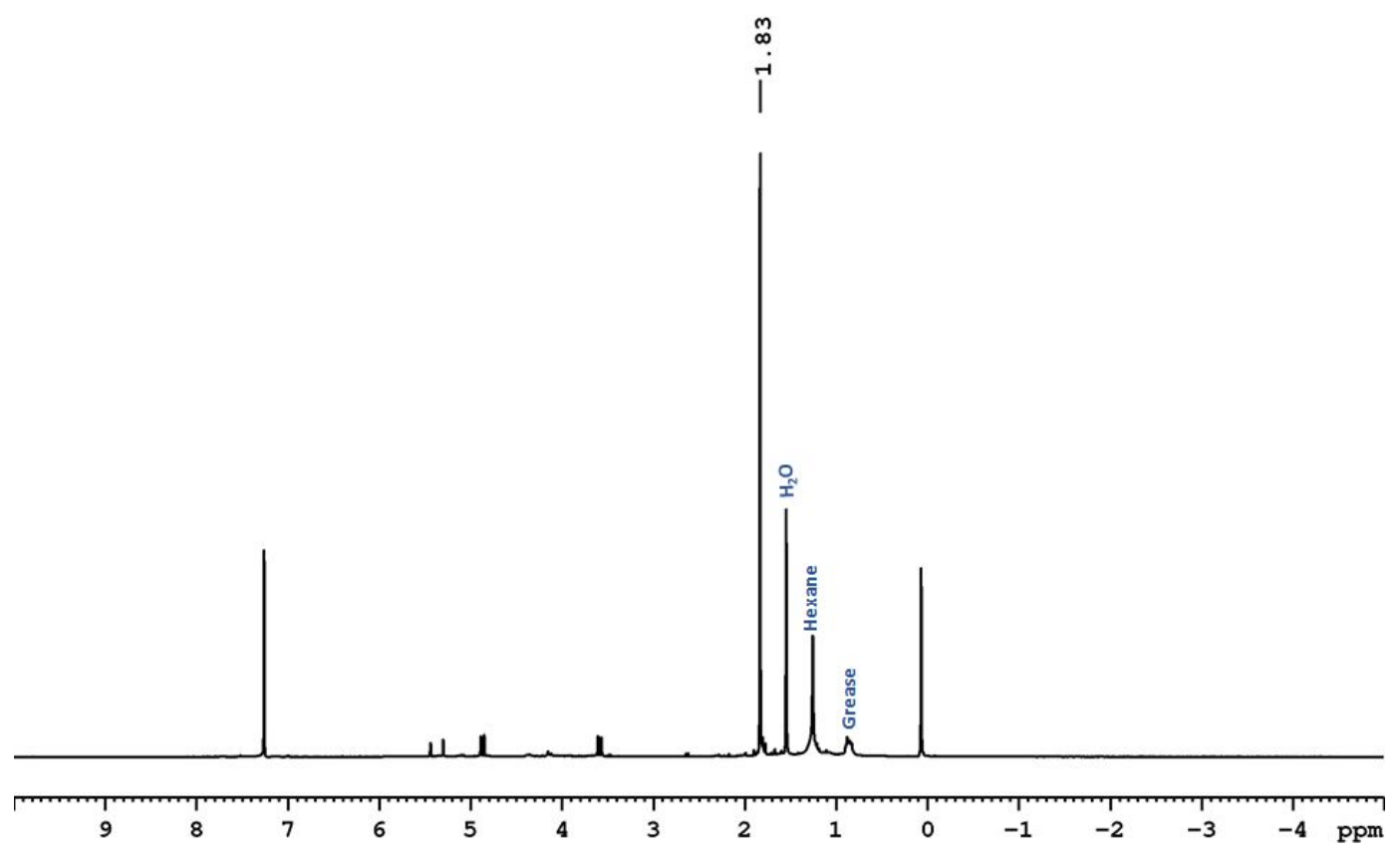

Figure S38. ${ }^{1} \mathrm{H}$ NMR spectrum of nido-13 in $\mathrm{CDCl}_{3}$ 


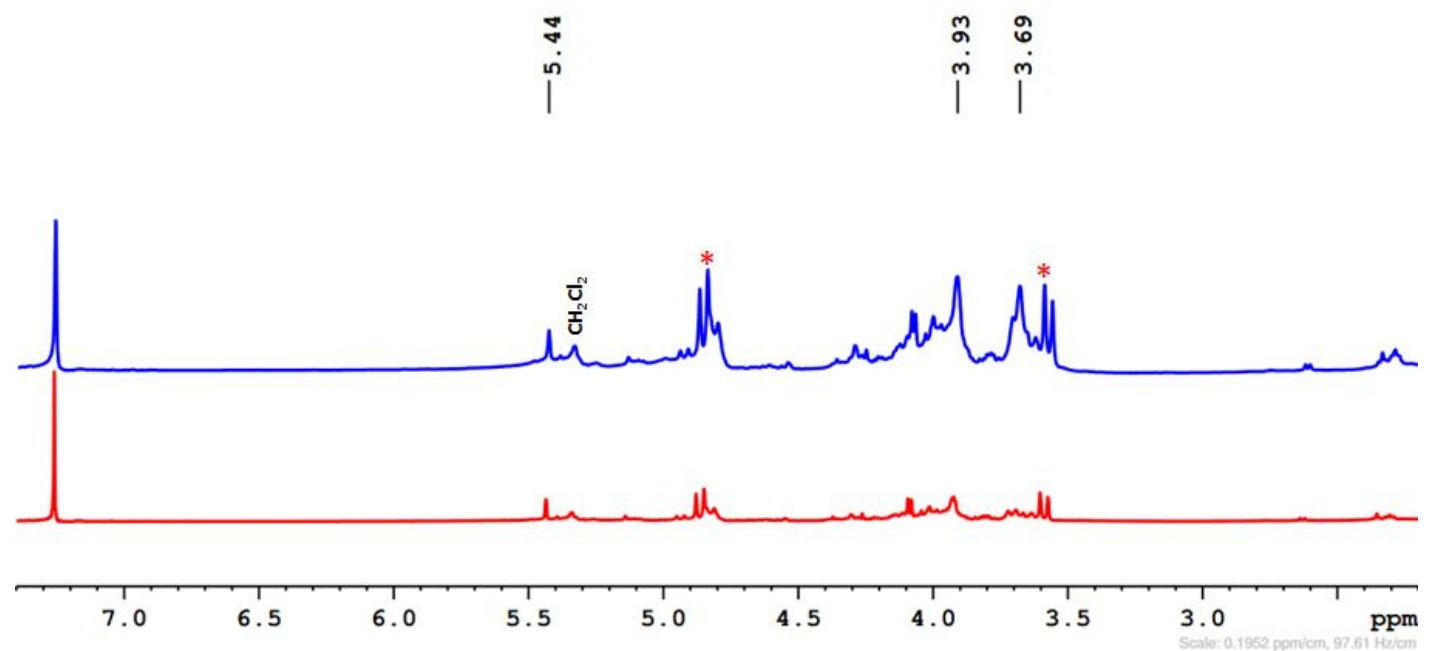

Figure S39. Stacked ${ }^{1} \mathrm{H}$ (bottom) and ${ }^{1} \mathrm{H}\left\{{ }^{11} \mathrm{~B}\right\} \mathrm{NMR}$ (top) spectrum of nido-13 in $\mathrm{CDCl}_{3}$. (* Unavoidable impurities)

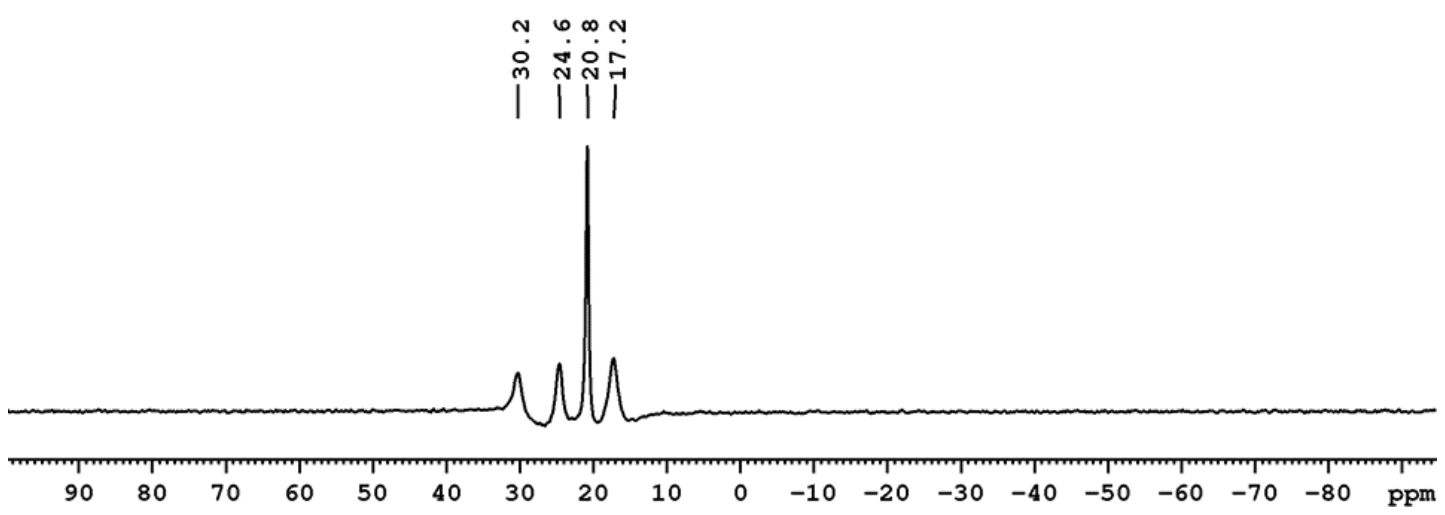

Figure S40. ${ }^{11} \mathrm{~B}\left\{{ }^{1} \mathrm{H}\right\} \mathrm{NMR}$ spectrum of nido-13 in $\mathrm{CDCl}_{3}{ }^{1}$ 


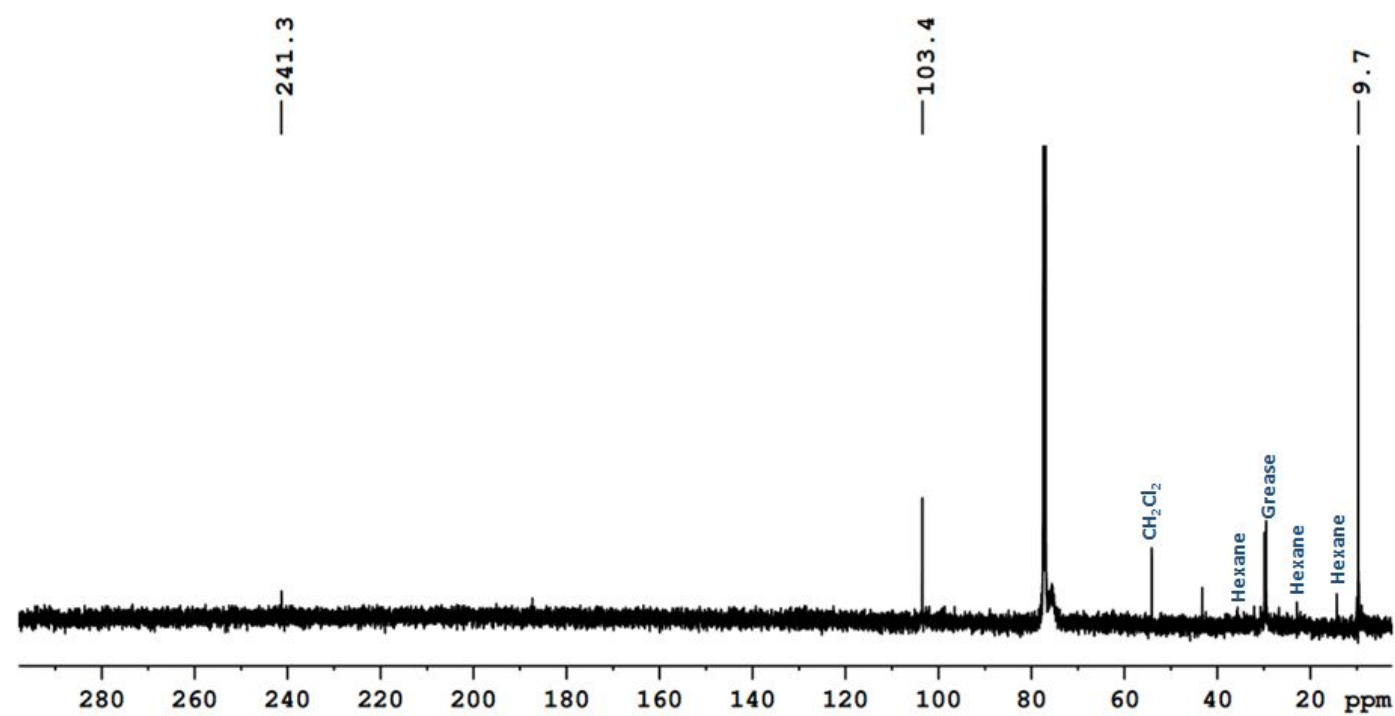

Figure $541 .{ }^{13} \mathrm{C}\left\{{ }^{1} \mathrm{H}\right\}$ NMR spectrum of nido-13 in $\mathrm{CDCl}_{3}$

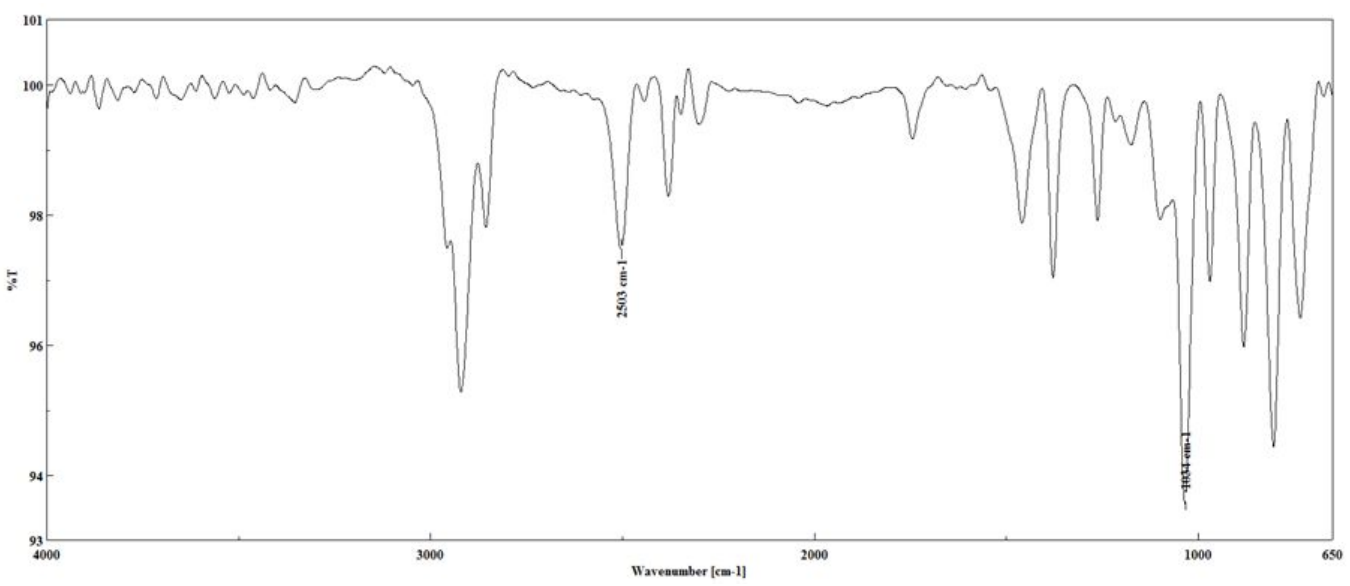

Figure S42. IR spectrum of nido-13 in $\mathrm{CH}_{2} \mathrm{Cl}_{2}$ 


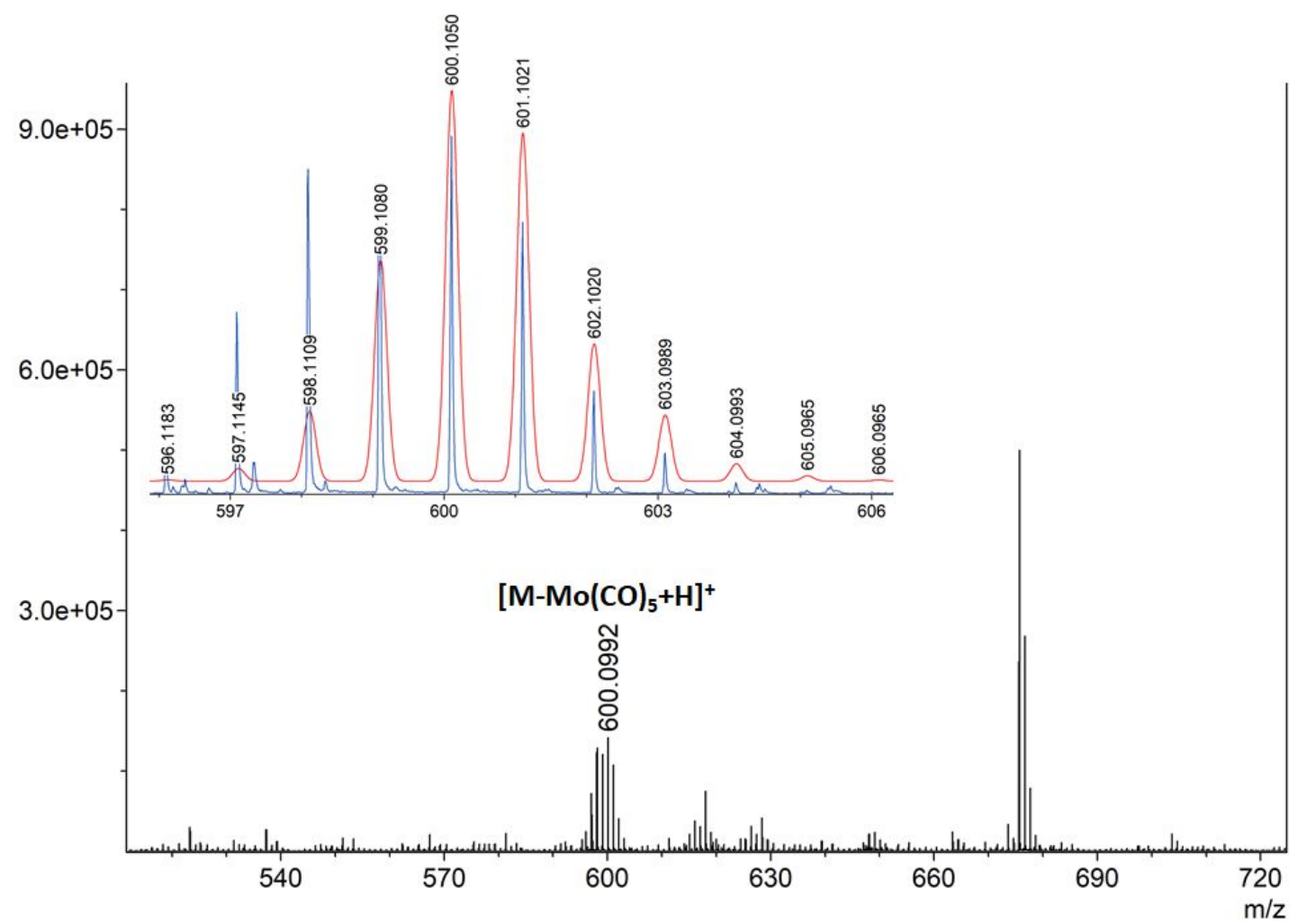

Figure S43. ESI-MS spectrum of nido-14 in $\mathrm{CH}_{2} \mathrm{Cl}_{2}$

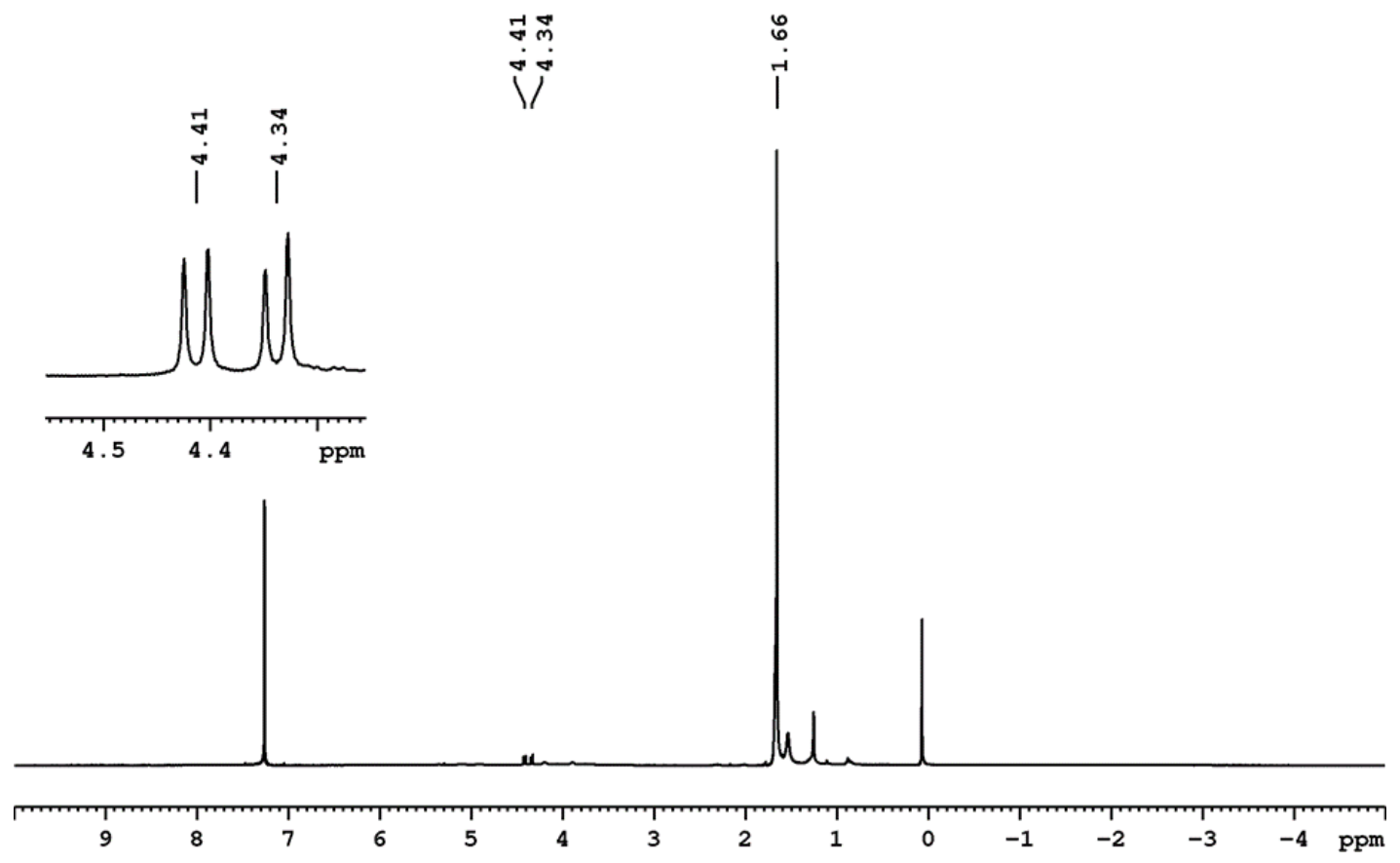

Figure S44. ${ }^{1} \mathrm{H}$ NMR spectrum of nido-14 in $\mathrm{CDCl}_{3}$ 


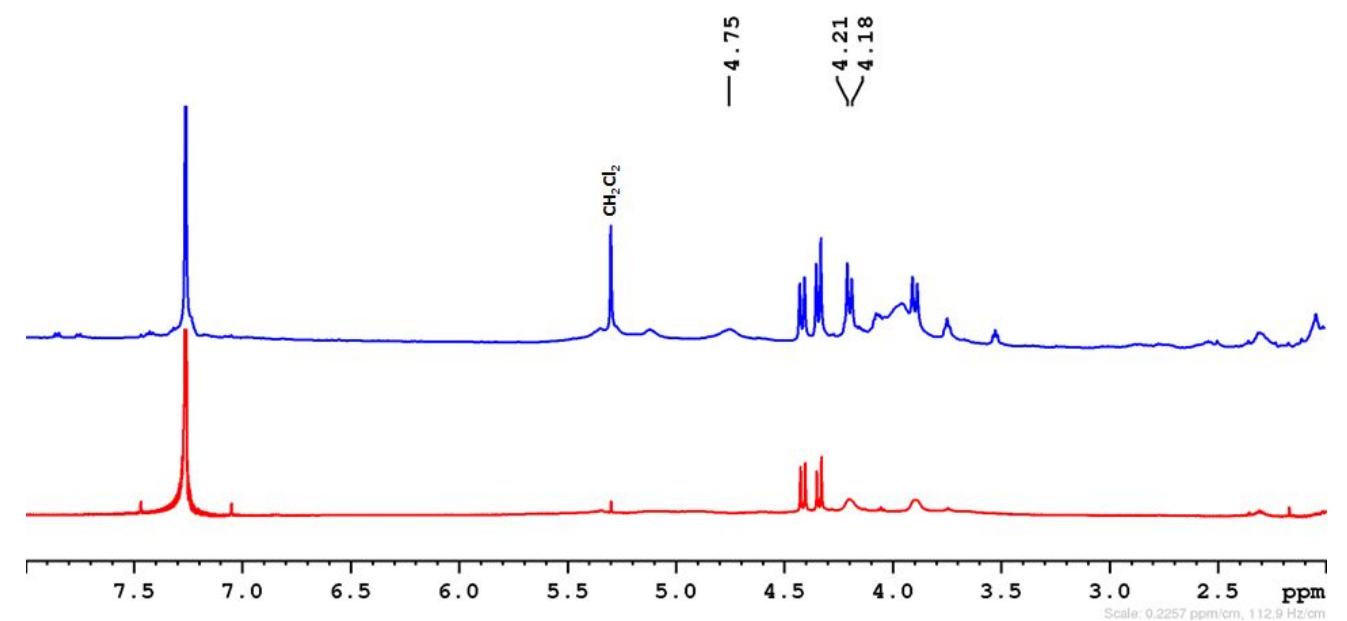

Figure S45. Stacked ${ }^{1} \mathrm{H}$ (bottom) and ${ }^{1} \mathrm{H}\left\{{ }^{11} \mathrm{~B}\right\}$ NMR (top) spectrum of nido-14 in $\mathrm{CDCl}_{3}$

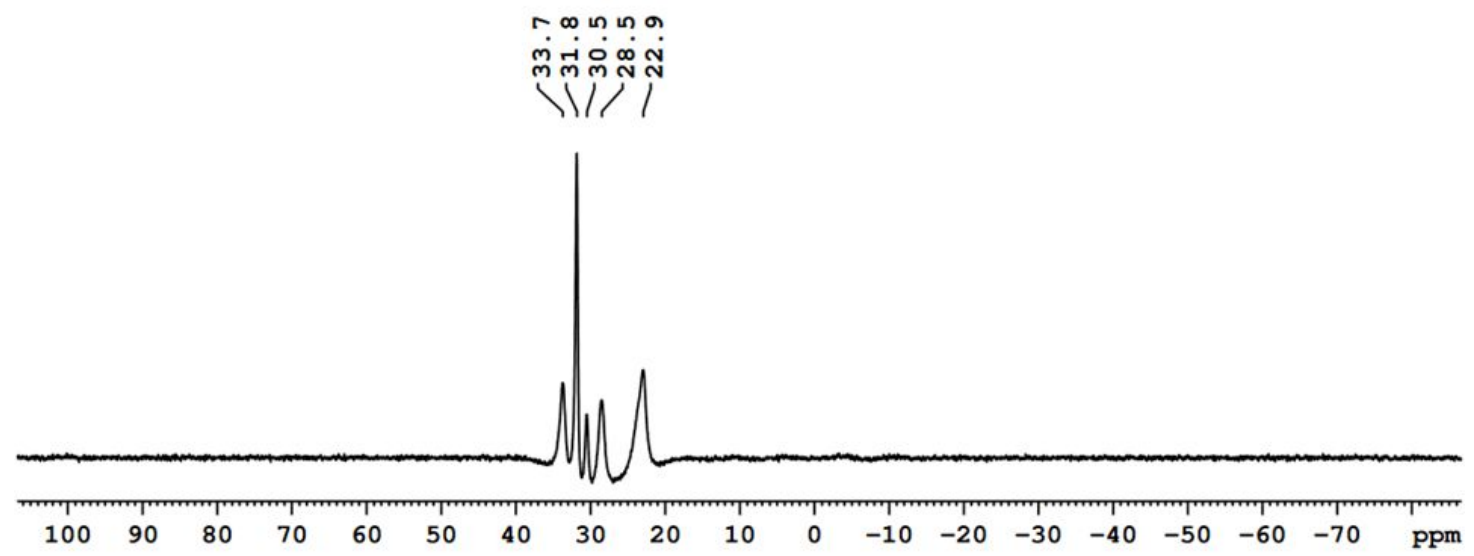

Figure S46. ${ }^{11} \mathrm{~B}\left\{{ }^{1} \mathrm{H}\right\} \mathrm{NMR}$ spectrum of nido-14 in $\mathrm{CDCl}_{3}{ }^{1}$ 


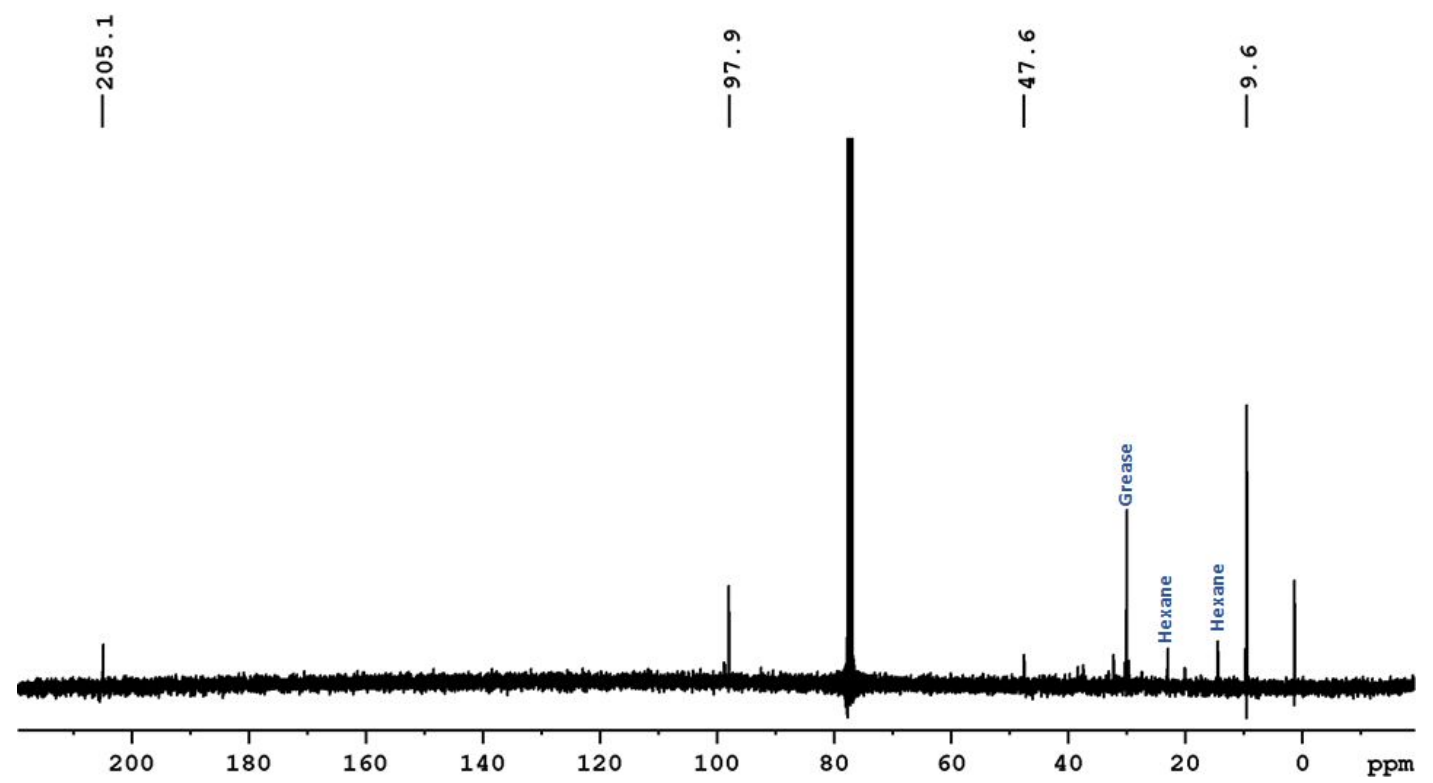

Figure S47. ${ }^{13} \mathrm{C}\left\{{ }^{1} \mathrm{H}\right\}$ NMR spectrum of nido-14 in $\mathrm{CDCl}_{3}$

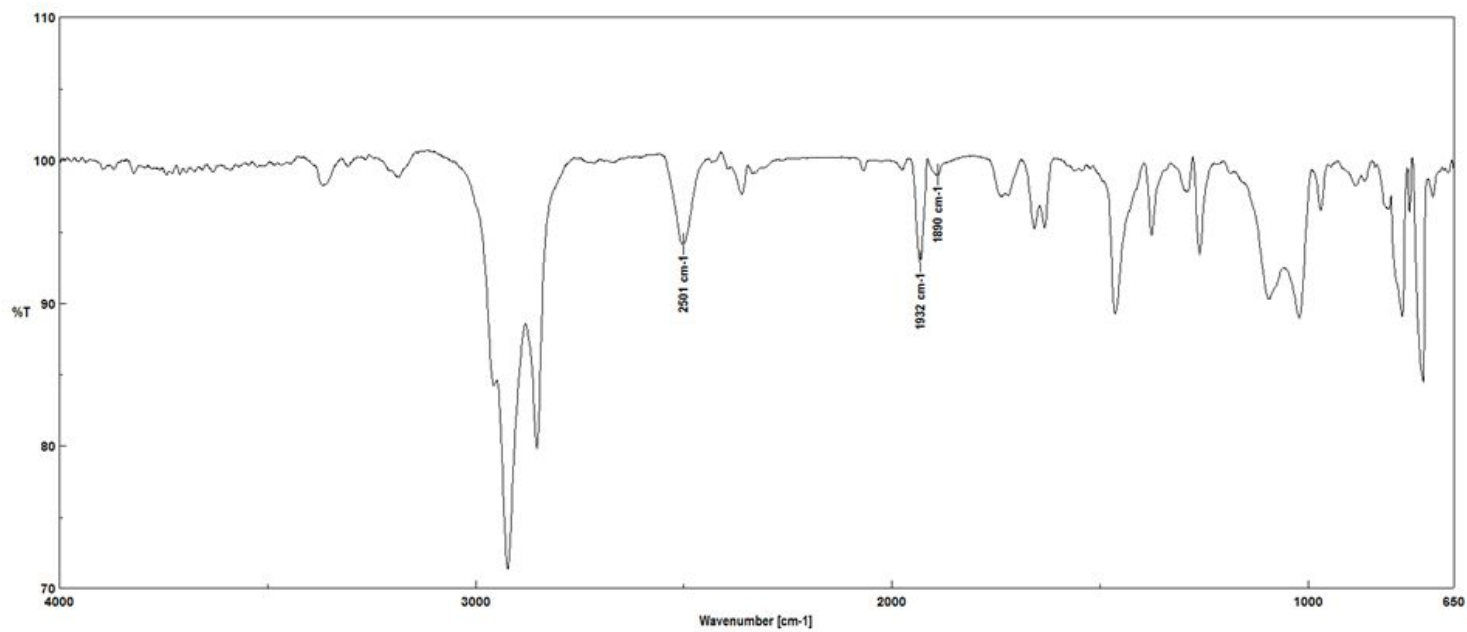

Figure S48. IR spectrum of nido-14 in $\mathrm{CH}_{2} \mathrm{Cl}_{2}$ 


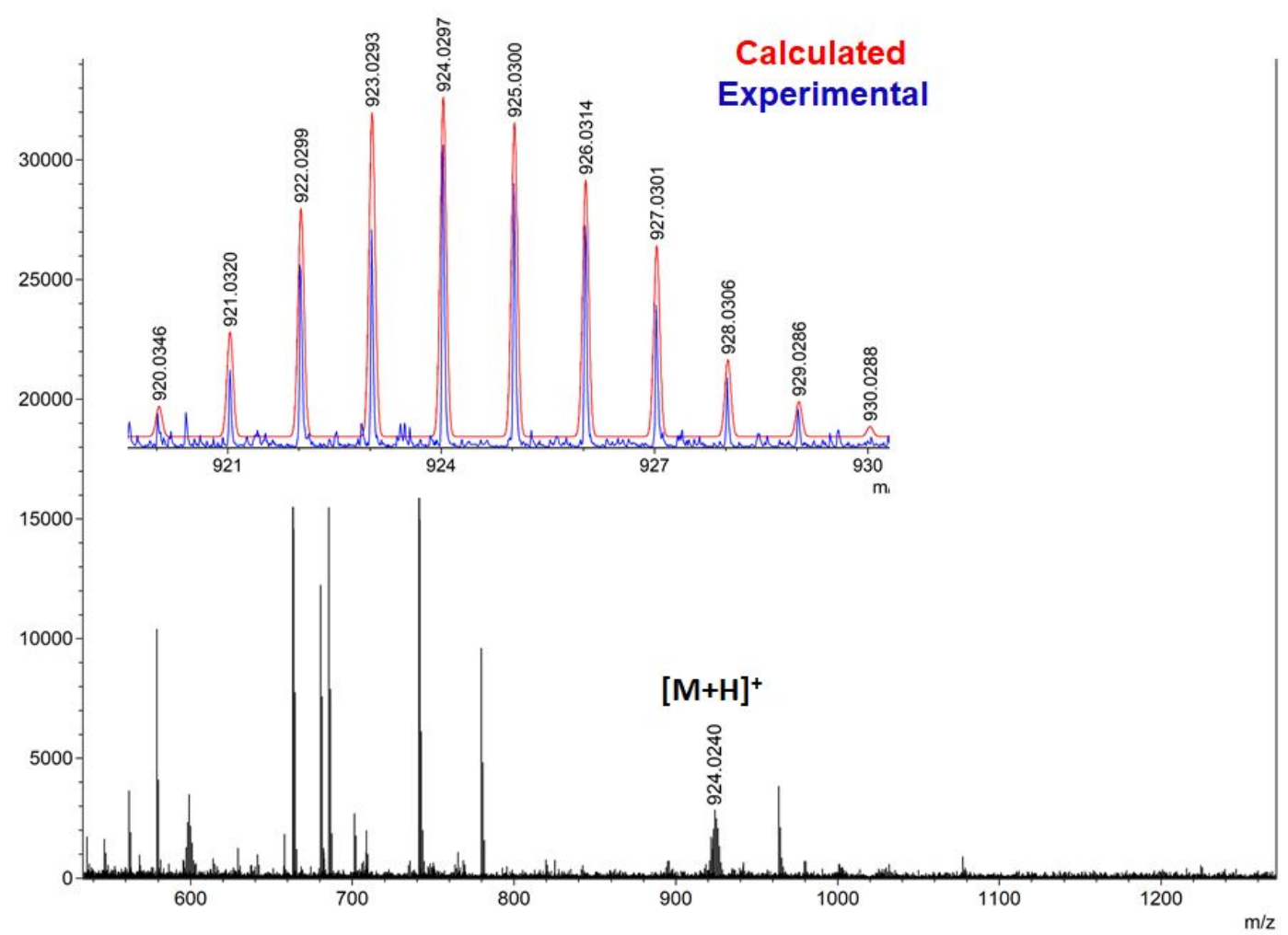

Figure S49. ESI-MS spectrum of nido-15 in $\mathrm{CH}_{2} \mathrm{Cl}_{2}$

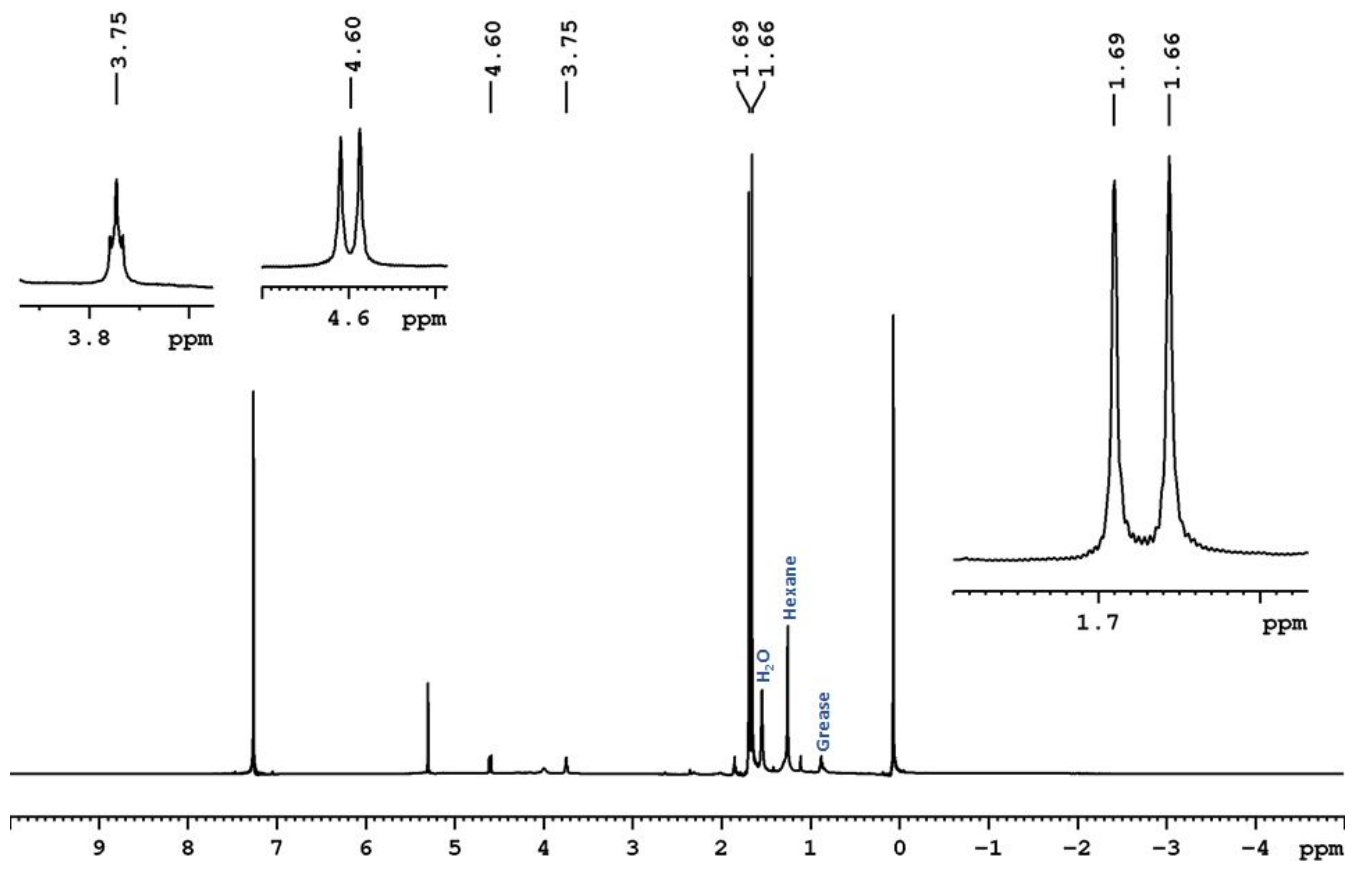

Figure S50. ${ }^{1} \mathrm{H}$ NMR spectrum of nido-15 in $\mathrm{CDCl}_{3}$ 


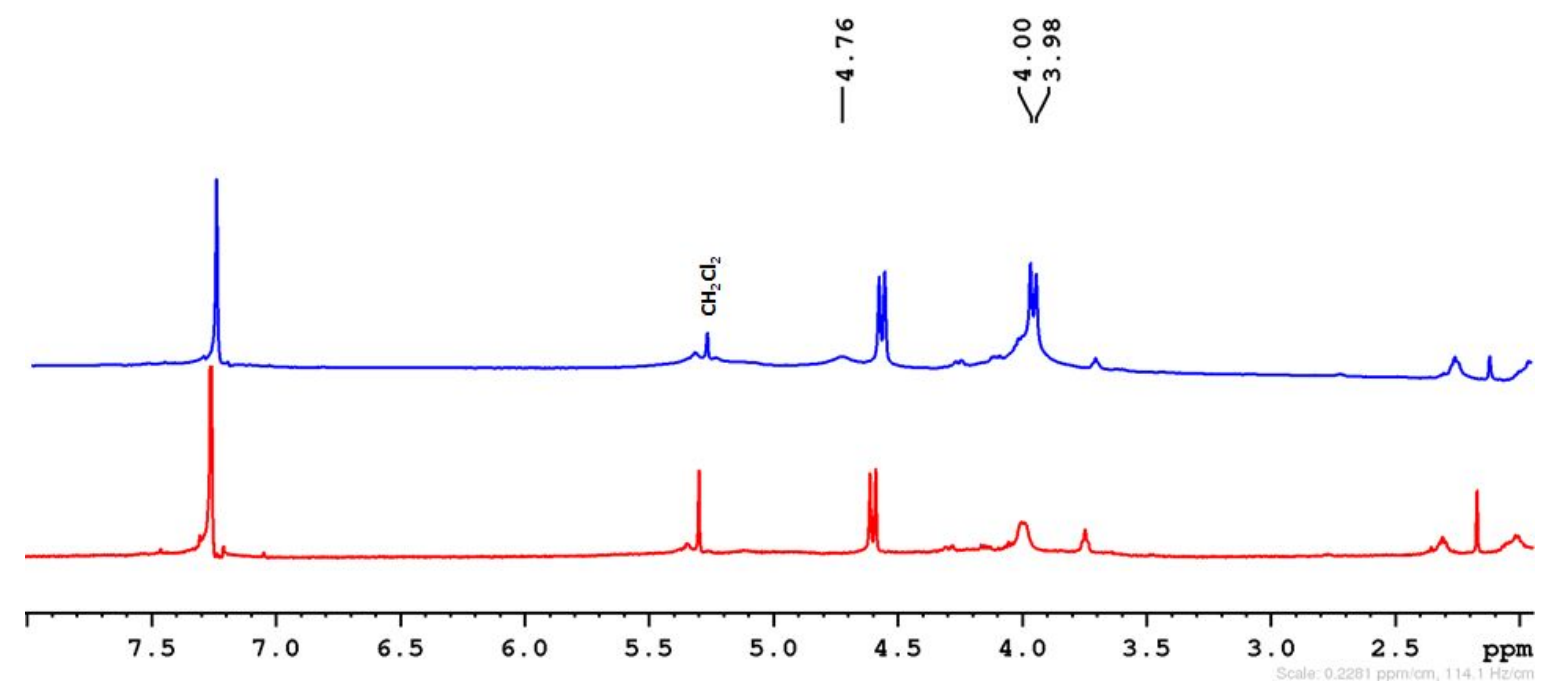

Figure S51. Stacked ${ }^{1} \mathrm{H}$ (bottom) and ${ }^{1} \mathrm{H}\left\{{ }^{11} \mathrm{~B}\right\}$ NMR (top) spectrum of nido-15 in $\mathrm{CDCl}_{3}$

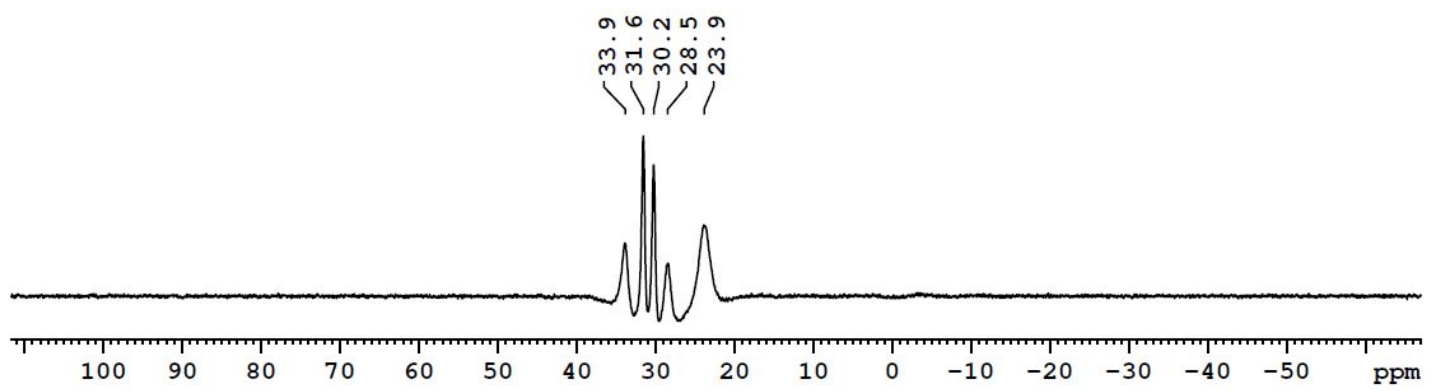

Figure S52. ${ }^{11} \mathrm{~B}\left\{{ }^{1} \mathrm{H}\right\} \mathrm{NMR}$ spectrum of nido-15 in $\mathrm{CDCl}_{3}{ }^{1}$ 


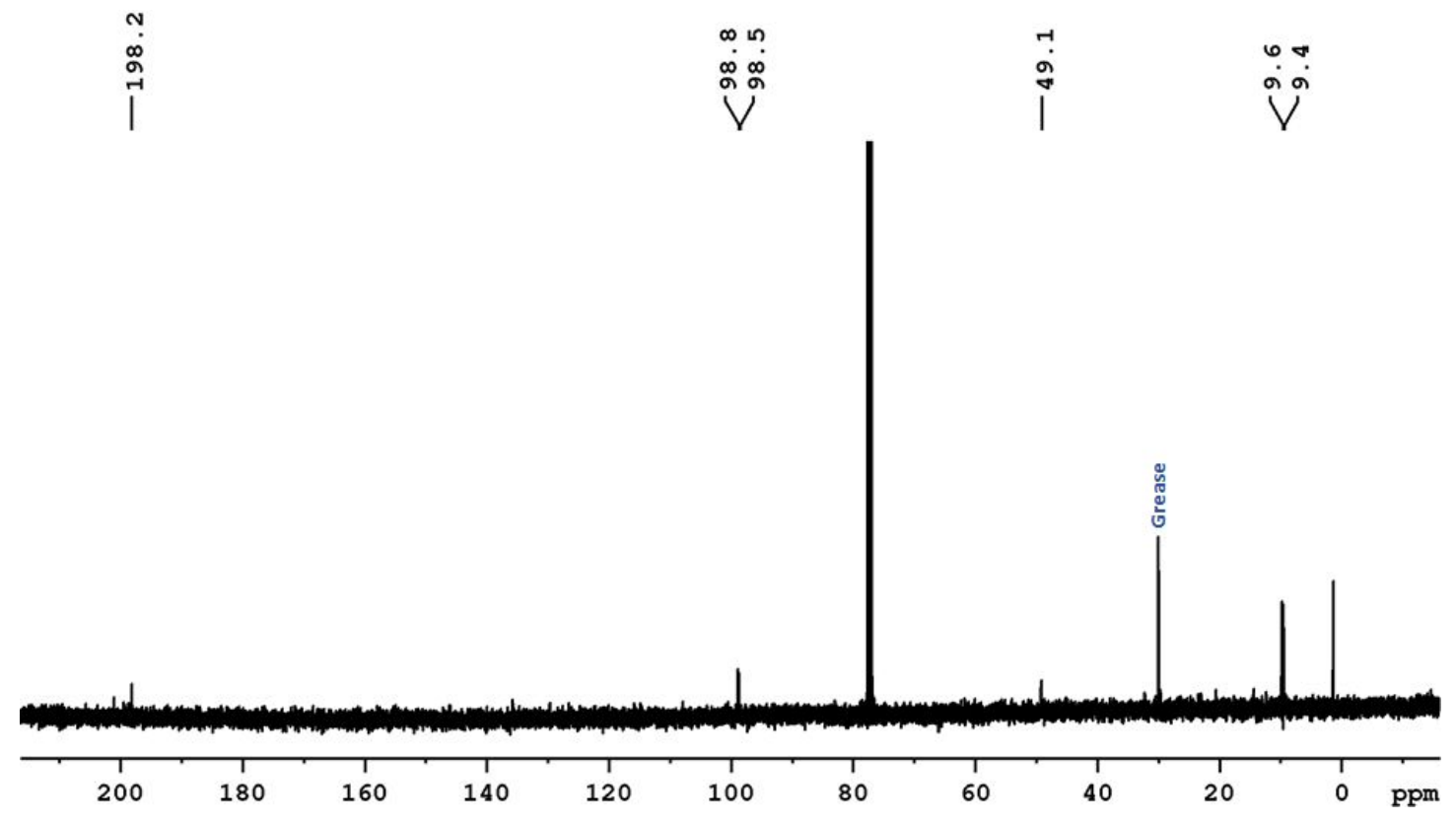

Fig. S53. ${ }^{13} \mathrm{C}\left\{{ }^{1} \mathrm{H}\right\}$ NMR spectrum of nido-15 in $\mathrm{CDCl}_{3}$

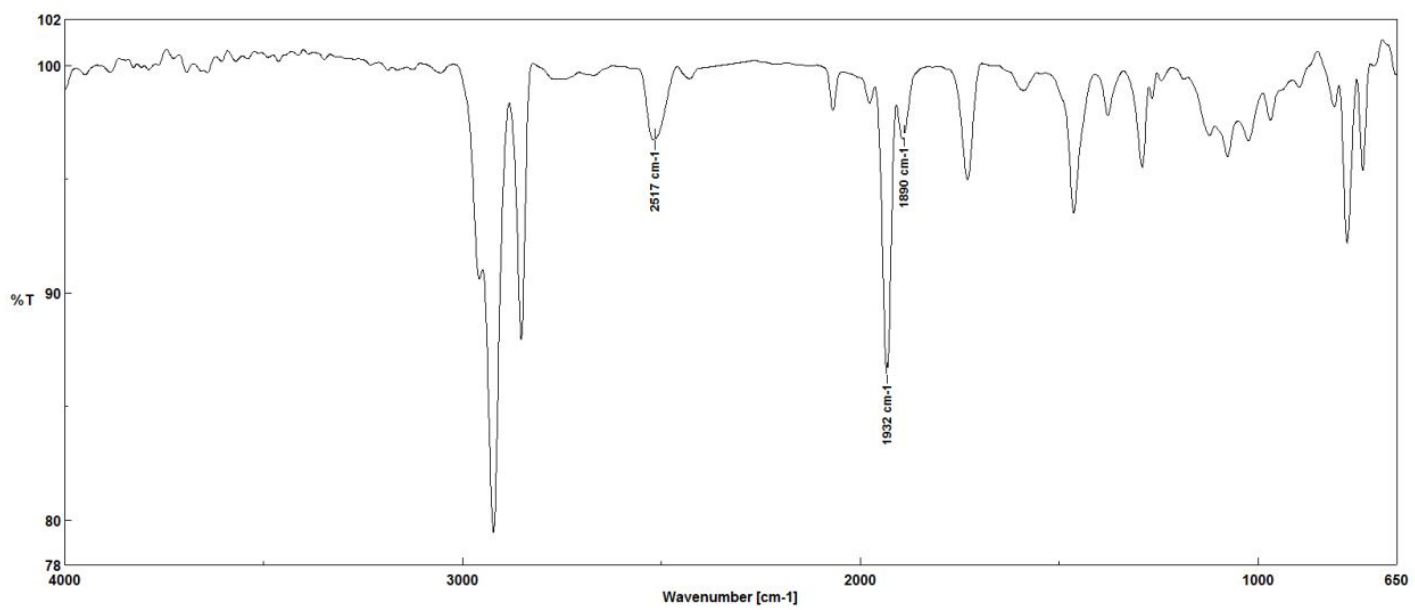

Figure S54. IR spectrum of nido-15 in $\mathrm{CH}_{2} \mathrm{Cl}_{2}$ 
Table S1. Selected Structural parameters and ${ }^{11} \mathrm{~B}$ NMR values for various ten vertex nido clusters. ${ }^{\mathrm{a}}$

\begin{tabular}{|c|c|c|c|c|c|c|c|}
\hline \multirow{3}{*}{ Clusters } & \multicolumn{4}{|c|}{ Structural parameters } & \multirow{2}{*}{\multicolumn{2}{|c|}{$\begin{array}{l}\text { Spectroscopic details } \\
{ }^{11} \mathrm{~B} \text { NMR (ppm) }\end{array}$}} & \multirow[b]{3}{*}{ Ref. } \\
\hline & \multicolumn{2}{|c|}{ Av. $d_{\mathrm{B}-\mathrm{E}}[\AA]^{\mathrm{b}}$} & \multicolumn{2}{|c|}{ Av. $d_{\mathrm{B}-\mathrm{B}}\left[\AA \AA^{\mathrm{c}}\right.$} & & & \\
\hline & Expt. & Calc. & Expt. & Calc. & Expt. & Calc. & \\
\hline 3 & 1.87 & 1.89 & 1.78 & 1.79 & $28.7,22.7,16.0,3.9$ & $24.8,22.6,15.0,2.6$ & This work \\
\hline 4 & 1.98 & 2.04 & 1.80 & 1.81 & $28.8,28.2,16.7,5.2$ & $28.4,24.7,15.3,3.6$ & This work \\
\hline 5 & 2.18 & 2.26 & 1.79 & 1.79 & $34.8,28.2,18.3,6.8$ & $37.8,24.5,16.4,4.2$ & This work \\
\hline 6 & 1.86 & 1.88 & 1.82 & 1.79 & $31.8,22.1$ & $29.0,26.7$ & 2 \\
\hline 7 & 1.98 & 2.02 & 1.80 & 1.78 & $30.8,29.8$ & $34.4,29.7$ & 2 \\
\hline 8 & 2.23 & 2.25 & 1.79 & 1.77 & $37.6,30.7$ & $45.8,30.5$ & 2 \\
\hline 9 & 2.03 & 2.04 & 1.81 & 1.83 & $21.8,21.3$ & $24.0,20.9$ & 2 \\
\hline 10 & 1.86 & 1.89 & 1.82 & 1.81 & $33.6,31.8,28.5,22.8$ & $33.6,31.4,25.5,23.6$ & This work \\
\hline 11 & 1.87 & 1.90 & 1.81 & 1.82 & $25.0,24.2,22.4,16.3$ & $26.4,23.3,19.6,17.7$ & This work \\
\hline 12 & 1.86 & 1.89 & 1.80 & 1.81 & $38.2,33.4,26.8,24.0$ & $33.4,31.1,29.9,23.7$ & This work \\
\hline 13 & 1.87 & 1.89 & 1.82 & 1.81 & $30.2,24.6,20.8,17.2$ & $26.9,23.9,23.3,17.5$ & This work \\
\hline$[\mathrm{A}]$ & - & - & 1.76 & - & $20.8,2.3$ & - & 3 \\
\hline [B] & - & - & 1.81 & - & $21.1,9.4,1.9$ & - & 4 \\
\hline
\end{tabular}


II Computational details: All the clusters were optimized using the Gaussian $16^{5}$ program. The gradient-corrected bp86 $6^{6}$ functional along with def2-svp basis set from EMSL ${ }^{7}$ Basis Set Exchange Library was used for optimization. The model compounds were fully optimized starting from X-ray coordinates in the gaseous state (no solvent effect). The calculations were executed with $\mathrm{Cp}$ analogues instead of $\mathrm{Cp}$ * for clusters 3-5 to reduce computational effort. Frequency calculations were carried out for the verification of the nature of the stationary state and to confirm the absence of any imaginary frequency which eventually confirmed the minima on the potential energy hypersurface for all structures. NMR chemical shifts were computed by employing the gauge-including atomic orbitals (GIAOs) method ${ }^{8}$ using the BP86/def2-SVP optimized geometries. Chemical shifts corresponding to ${ }^{11} \mathrm{~B}$ NMR were computed in relation to $\mathrm{B}_{2} \mathrm{H}_{6}$ (BP86 shielding constant for ${ }^{11} \mathrm{~B}$ NMR: $89.3 \mathrm{ppm}$ ) and were then transformed to the standard $\left[\mathrm{BF}_{3} . \mathrm{OEt}_{2}\right.$ ] scale by adding $16.6 \mathrm{ppm}$ (the experimental $\delta\left({ }^{11} \mathrm{~B}\right.$ ) value of $\mathrm{B}_{2} \mathrm{H}_{6}$ ) to the computed values. ${ }^{9}$ Wiberg bond indices $(\mathrm{WBI})^{10}$ was generated from natural bond orbital analysis $(\mathrm{NBO})^{11}$. All the optimized geometries and orbital pictures were drawn by Chemcraft ${ }^{12}$ visualization programs. Laplacian electronic distribution plots and Two-dimensional electron density and were generated using the Multiwfn package. ${ }^{13}$

Table S2. Topological parameters at selected bond critical points (BCPs) of nido-3'-5' and nido-10-13.

\begin{tabular}{cccccc}
\hline Clusters & BCP & $\rho(r)$ & $H(r)$ & $\nabla^{2} \rho(r)$ & $E L F$ \\
\hline $\mathbf{3}^{\prime}$ & Co2-S1 & 0.079 & -0.011 & 0.262 & 0.225 \\
$\mathbf{4}^{\prime}$ & Co1-Se1 & 0.111 & 0.054 & -0.094 & 0.848 \\
$\mathbf{5}^{\prime}$ & Co1-Te1 & 0.084 & 0.027 & 0.092 & 0.459 \\
$\mathbf{1 0}$ & B34-S4 & 0.135 & -0.127 & -0.194 & 0.625 \\
$\mathbf{1 1}$ & B1-S4 & 0.135 & -0.128 & -0.201 & 0.636 \\
$\mathbf{1 2}$ & C21-S5 & 0.217 & 0.245 & 0.295 & 0.334 \\
$\mathbf{1 3}$ & C21-S5 & 0.227 & 0.269 & 0.295 & 0.581 \\
\hline
\end{tabular}

Table S3. Selected geometrical parameters and wiberg indices (WBI) of nido-3'-5' and nido-10-13.

\begin{tabular}{llll|llll}
\hline & \multicolumn{3}{c|}{$3 \mathbf{3}^{\prime}$} & \multicolumn{5}{|c}{10} \\
\hline & Expt. & Cal. & WBI & & Expt. & Cal. & WBI \\
Co1-S1 & 2.205 & 2.221 & 0.604 & Co1-S1 & 2.208 & 2.233 & 0.568 \\
Co1-B5 & 2.051 & 2.109 & 0.450 & Co1-B35 & 2.106 & 2.111 & 0.411
\end{tabular}




\begin{tabular}{|c|c|c|c|c|c|c|c|}
\hline Co1-B1 & 2.096 & 2.092 & 0.437 & Co1-B31 & 2.095 & 2.097 & 0.451 \\
\hline B5-B6 & 1.928 & 1.910 & 0.488 & C21-S4 & 1.808 & 1.841 & 0.998 \\
\hline Co2-B1 & 2.100 & 1.973 & 0.563 & B34-B35 & 1.876 & 1.872 & 0.532 \\
\hline Co2-B6 & 2.067 & 2.053 & 0.495 & B34-S3 & 1.892 & 1.890 & 0.952 \\
\hline Co2-B8 & 1.937 & 2.074 & 0.443 & B34-S4 & 1.816 & 1.862 & 1.089 \\
\hline \multicolumn{4}{|c|}{$4 / 4^{\prime}$} & \multicolumn{4}{|c|}{11} \\
\hline & Expt. & Cal. & WBI & & Expt. & Cal. & WBI \\
\hline Co1-Se1 & 2.998 & 2.334 & 0.620 & Rh1-S1 & 2.316 & 2.362 & 0.467 \\
\hline Co1-B6 & 2.066 & 2.120 & 0.460 & Rh1-B3 & 2.162 & 2.219 & 0.304 \\
\hline Co1-B4 & 2.093 & 2.093 & 0.433 & Rh1-B5 & 2.184 & 2.214 & 0.333 \\
\hline B5-B6 & 1.919 & 1.916 & 0.488 & B1-B3 & 1.899 & 1.865 & 0.522 \\
\hline Co2-B8 & 1.953 & 1.974 & 0.562 & C21-S4 & 1.804 & 1.843 & 0.998 \\
\hline Co2-B5 & 2.061 & 2.056 & 0.496 & B3-S2 & 1.849 & 1.901 & 0.973 \\
\hline Co2-B4 & 2.091 & 2.072 & 0.442 & B3-S3 & 1.856 & 1.862 & 1.090 \\
\hline \multicolumn{4}{|c|}{$5 / 5^{\prime}$} & \multicolumn{4}{|c|}{12} \\
\hline & Expt. & Cal. & WBI & & Expt. & Cal. & WBI \\
\hline Co1-Te1 & 2.459 & 2.521 & 0.625 & Co1-S1 & 2.200 & 2.230 & 0.453 \\
\hline Co1-B1 & 2.083 & 2.127 & 0.483 & Co1-B6 & 2.082 & 2.103 & 0.449 \\
\hline Co1-B3 & 2.085 & 2.095 & 0.425 & Co1-B1 & 2.093 & 2.103 & 0.442 \\
\hline B1-B2 & 1.928 & 1.925 & 0.488 & B5-B6 & 1.822 & 1.828 & 0.751 \\
\hline Co1-B4 & 1.942 & 1.968 & 0.563 & B6-S5 & 1.865 & 1.867 & 0.924 \\
\hline Co1-B2 & 2.076 & 2.060 & 0.496 & C21- S5 & 1.747 & 1.784 & 0.879 \\
\hline Co1-B3 & 2.095 & 2.069 & 0.441 & C21-S4 & 1.635 & 1.649 & 1.198 \\
\hline \multicolumn{4}{|c|}{13} & & & & \\
\hline & Expt. & Cal. & WBI & & & & \\
\hline Rh1-S2 & 2.334 & 2.359 & 0.517 & & & & \\
\hline Rh1-B2 & 2.209 & 2.211 & 0.387 & & & & \\
\hline Rh1-B6 & 2.196 & 2.221 & 0.391 & & & & \\
\hline B1-B2 & 1.794 & 1.826 & 0.594 & & & & \\
\hline B2-S3 & 1.862 & 1.867 & 1.073 & & & & \\
\hline C21-S3 & 1.746 & 1.762 & 1.106 & & & & \\
\hline
\end{tabular}


C21-S5

Table S4. Calculated (DFT) energies of the HOMO and LUMO (eV) and HOMO-LUMO gaps ( $\triangle \mathrm{E}=\mathrm{E}_{\mathrm{LUMO}}{ }^{-}$ $\mathrm{E}_{\text {HOMO }}, \mathrm{eV}$ ) of nido-3'-5' and nido-10-13.

\begin{tabular}{|c|c|c|c|}
\hline Clusters & HOMO (eV) & LUMO (eV) & $\Delta \mathrm{E}_{\mathrm{H}-\mathrm{L}}(\mathrm{eV})$ \\
\hline $3^{\prime}$ & -5.225 & -3.049 & 2.176 \\
\hline $4^{\prime}$ & -5.213 & -3.091 & 2.122 \\
\hline $5^{\prime}$ & -5.205 & -3.180 & 2.025 \\
\hline 10 & -4.968 & -2.716 & 2.252 \\
\hline 11 & -4.717 & -2.387 & 2.330 \\
\hline 12 & -4.671 & -3.015 & 1.656 \\
\hline 13 & -4.652 & -2.738 & 1.914 \\
\hline
\end{tabular}
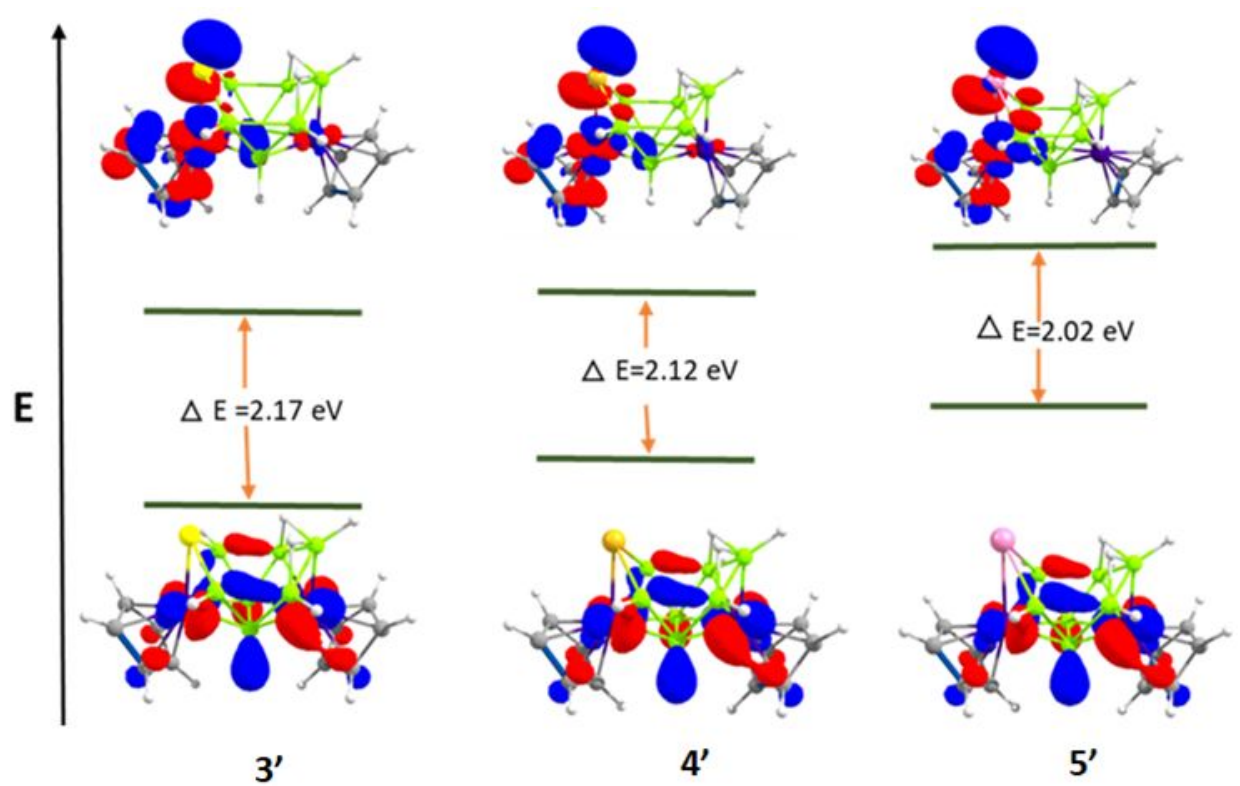
Figure S55. Frontier molecular orbital diagram of nido-3', 4' and 5'. Isosurfaces are plotted at an isovalue of $\pm 0.04\left(\mathrm{e} / \mathrm{bohr}^{3}\right)^{1 / 2}$.

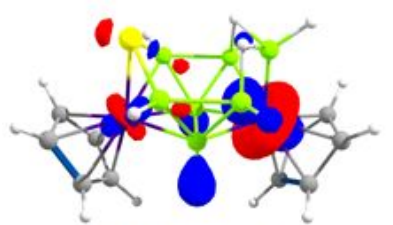

(a) HOMO-1

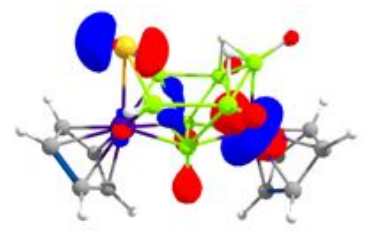

(b) HOMO-1

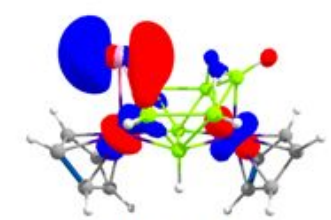

(c) HOMO-1

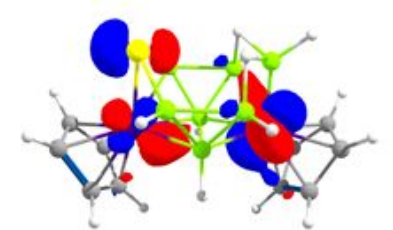

(d) HOMO-4

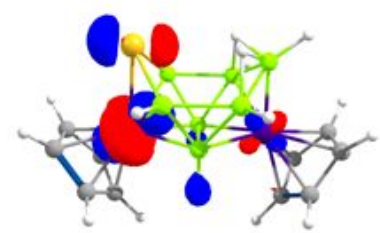

(e) HOMO-2

Figure. S56. Selected frontier molecular orbitals (a) and (d) for nido-3'; (b) and (e) for nido-4'; and (c) for $5^{\prime}$. Isosurfaces are plotted at an isovalue of $\pm 0.04\left(\mathrm{e} / \mathrm{bohr}^{3}\right)^{1 / 2}$.

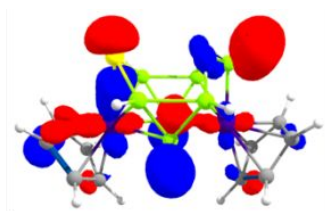

(a)

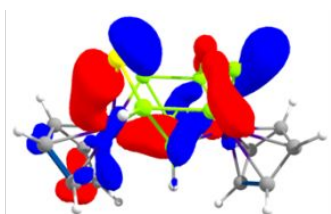

(b)

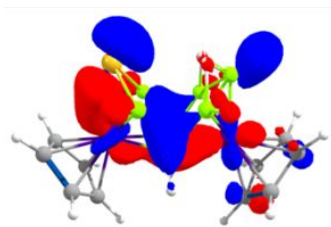

(c)

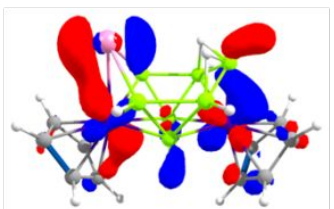

(f)

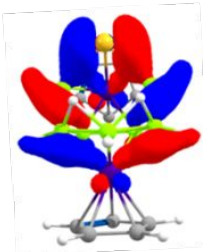

(d)

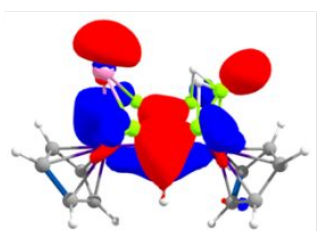

(g)

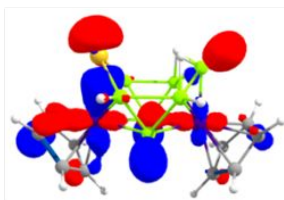

(e)

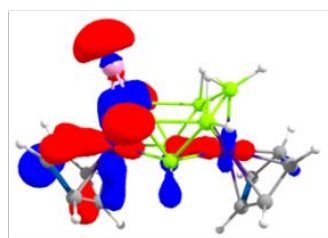

(h) 
Figure S57. Selected M-E bonding interaction obtained from molecular orbital analysis of nido-3', 4' and 5': (a) and (b) are HOMO-17 and HOMO-14 of nido-3' respectively; (c), (d) and (e) are HOMO-13, HOMO12 and HOMO-27 of nido-4' respectively; (f), (g) and (h) are HOMO-7, HOMO-13 and HOMO-17 of nido-5' respectively.

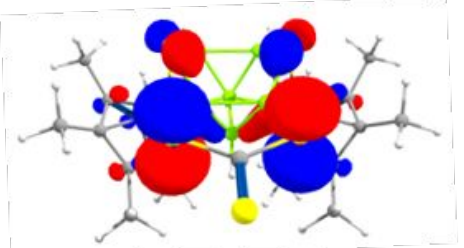

HOMO-2

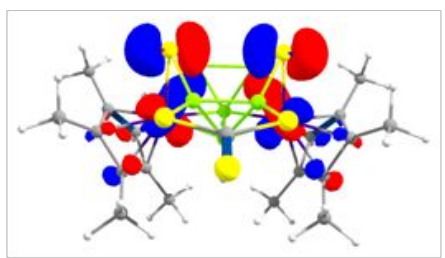

HOMO-4

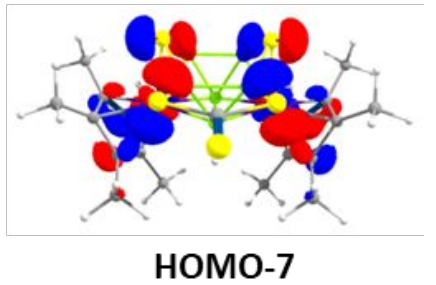

HOMO-7

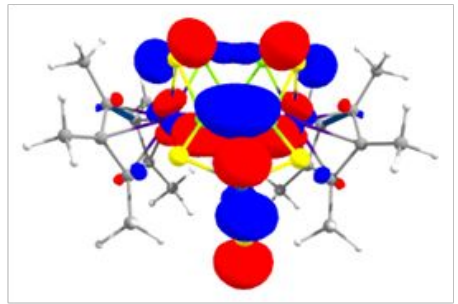

LUMO

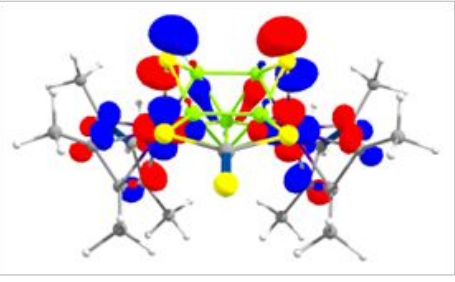

LUMO+2

Figure S58. Selected frontier molecular orbitals for nido-12. Isosurfaces are plotted at an isovalue of \pm 0.04 $\left(\mathrm{e} / \mathrm{bohr}^{3}\right)^{1 / 2}$.

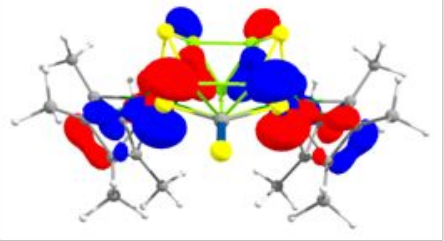

HOMO-7

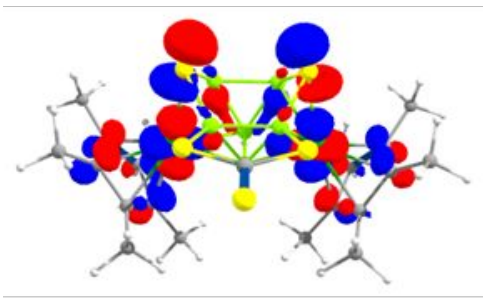

LUMO+1

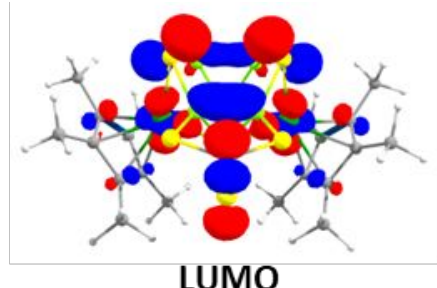

LUMO

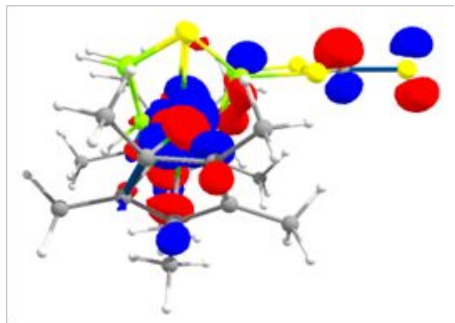

LUMO+2 
Figure S59. Selected frontier molecular orbitals for nido-13. Isosurfaces are plotted at an isovalue of \pm 0.04 $\left(\mathrm{e} / \mathrm{bohr}^{3}\right)^{1 / 2}$.

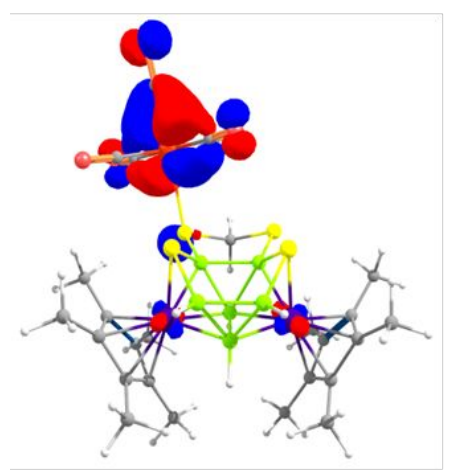

HOMO

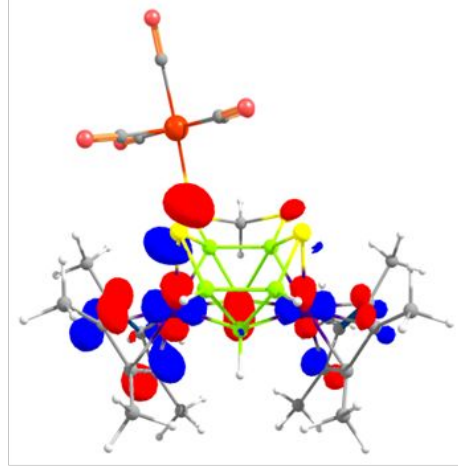

LUMO

Figure. S60. Selected frontier molecular orbitals of nido-15. Isosurfaces are plotted at an isovalue of \pm 0.04 $\left(\mathrm{e} / \mathrm{bohr}^{3}\right)^{1 / 2}$.

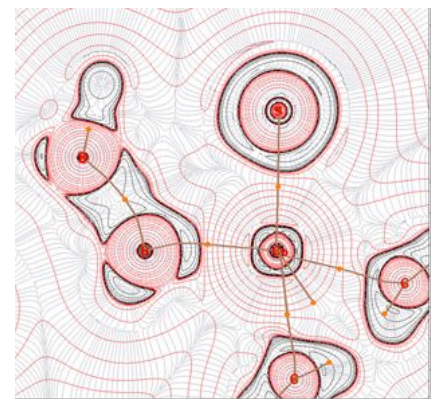

(a)

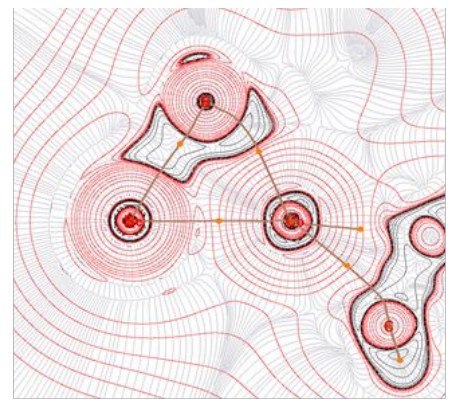

(b)

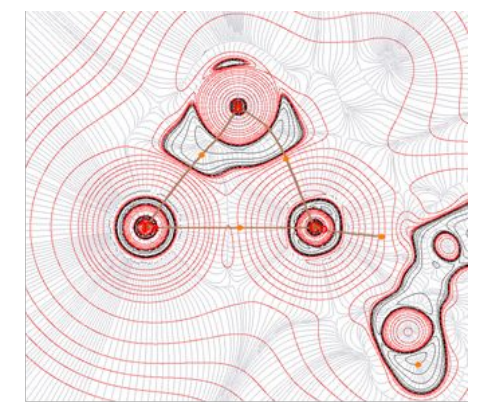

(c)

Figure S61. Contour-line diagram of the Laplacian of electron density in the Co-E bond of nido-3' (a), nido-4' (b) and nido-5' (c). The solid brown lines are bond paths, while orange spheres indicate the bond critical points. Area of charge concentration $\left[\nabla^{2} \rho(r)<0\right]$ are indicated by solid lines and area of charge depletion $\left[\nabla^{2} \rho(r)>0\right]$ are shown by dashed lines. 


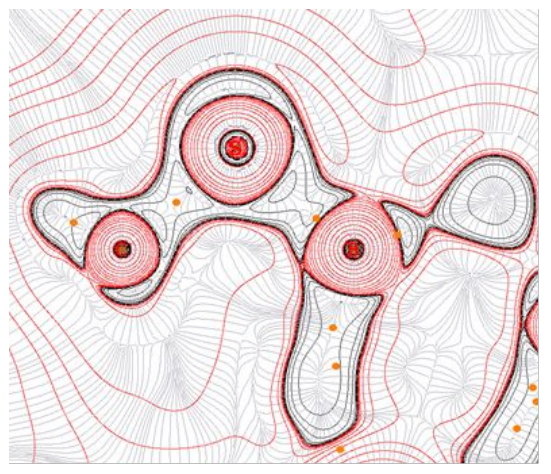

(a)

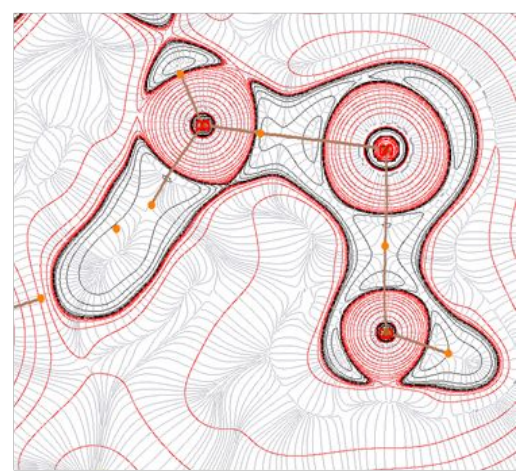

(b)

Figure S62. Contour-line diagram of the Laplacian of electron density in the B-S bonds of nido-10 (a) and nido-11 (b). The solid brown lines are bond paths, while green and orange spheres indicate the ring and bond critical points respectively. Area of charge concentration $\left[\nabla^{2} \rho(r)<0\right]$ are indicated by solid lines and area of charge depletion $\left[\nabla^{2} \rho(r)>0\right]$ are showed by dashed lines.

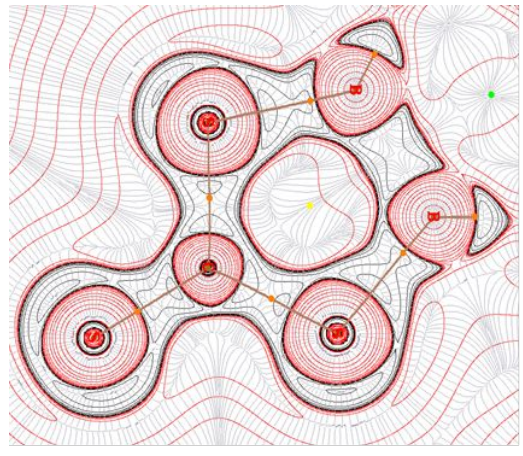

(a)

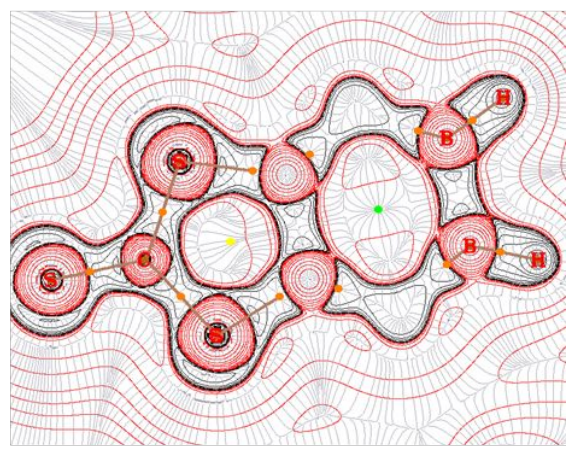

(b)

Figure S63. Contour-line diagram of the Laplacian of electron density in the nido-12 (a) and nido-13 (b). The solid brown lines are bond paths, while green and orange spheres indicate the bond and ring critical points respectively. Area of charge concentration $\left[\nabla^{2} \rho(r)<0\right]$ are indicated by solid lines and area of charge depletion $\left[\nabla^{2} \rho(r)>0\right]$ are showed by dashed lines. 


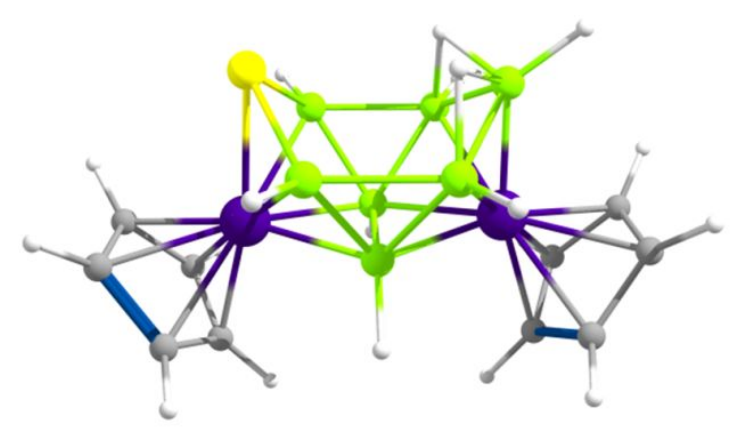

Figure S64. Optimized geometry of nido-3'

T. E. $=-3730.0240$ a. u.

Cartesian coordinates for the calculated structure of nido-3' (in $\AA$ ).

$\begin{array}{lrrr}\text { Co } & -1.803786000 & -0.092805000 & -0.000427000 \\ \text { Co } & 1.918082000 & 0.044482000 & -0.000099000 \\ \text { C } & 2.614449000 & -1.948405000 & -0.001167000 \\ \text { C } & 3.101183000 & -1.260424000 & -1.163001000 \\ \text { C } & 3.883766000 & -0.144340000 & -0.717998000 \\ \text { C } & 3.882833000 & -0.145416000 & 0.720063000 \\ \text { C } & 3.099638000 & -1.262125000 & 1.162349000 \\ \text { C } & -2.263533000 & -2.099518000 & 0.012868000 \\ \text { C } & -2.851630000 & -1.476536000 & 1.172183000 \\ \text { C } & -3.752789000 & -0.469561000 & 0.711919000 \\ \text { C } & -3.743316000 & -0.480787000 & -0.732080000 \\ \text { C } & -2.835791000 & -1.494473000 & -1.163980000 \\ \text { B } & 1.015060000 & 1.207893000 & -1.430989000 \\ \text { H } & 1.508985000 & 1.333243000 & -2.534178000 \\ \text { B } & -0.895567000 & 1.169846000 & -1.425028000 \\ \text { H } & -1.407264000 & 1.368455000 & -2.508156000 \\ \text { B } & 0.074642000 & -0.216005000 & -0.914008000 \\ \text { H } & 0.119485000 & -1.113176000 & -1.739358000 \\ \text { B } & 0.074524000 & -0.216464000 & 0.913553000 \\ \text { H } & 0.118836000 & -1.113556000 & 1.739032000 \\ \text { B } & 1.015005000 & 1.207242000 & 1.431166000 \\ \text { H } & 1.508688000 & 1.332047000 & 2.534530000 \\ \text { B } & -0.895551000 & 1.169115000 & 1.425130000 \\ \text { H } & -1.407309000 & 1.367315000 & 2.508307000 \\ \text { B } & 1.800129000 & 2.014222000 & 0.000328000 \\ \text { H } & 2.746290000 & 2.774191000 & 0.000284000 \\ \text { H } & 0.972828000 & 2.462634000 & 0.963242000 \\ \text { H } & 0.972698000 & 2.462956000 & -0.962337000 \\ \text { S } & -1.693882000 & 2.125926000 & 0.000264000 \\ \text { H } & -4.319720000 & 0.225132000 & 1.344916000 \\ \text { H } & -4.302224000 & 0.203350000 & -1.383415000 \\ \text { H } & -2.578317000 & -1.735189000 & -2.202564000 \\ \text { H } & -1.510446000 & -2.897074000 & 0.023992000 \\ \mathrm{H} & -2.608180000 & -1.700800000 & 2.217817000 \\ \text { H } & 2.874095000 & -1.519490000 & 2.204564000 \\ \mathrm{H} & 1.958688000 & -2.827821000 & -0.002264000\end{array}$




$\begin{array}{lrrr}\mathrm{H} & 2.877056000 & -1.516179000 & -2.205920000 \\ \mathrm{H} & 4.371844000 & 0.598064000 & -1.361606000 \\ \mathrm{H} & 4.370017000 & 0.596075000 & 1.365395000\end{array}$

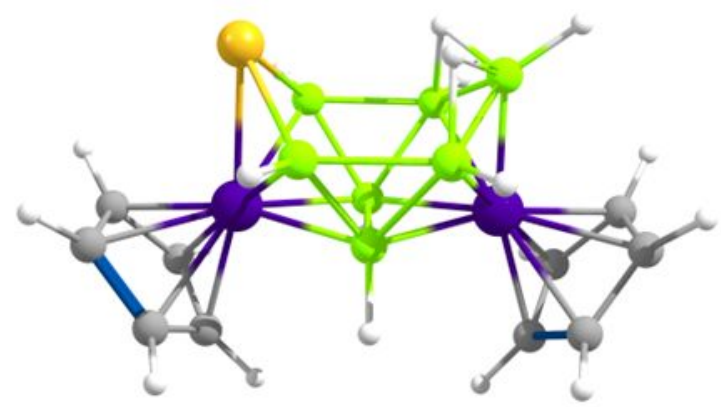

Figure S65. Optimized geometry of nido-4'

T. E. $=-5733.4447$ a. u. Cartesian coordinates for the calculated structure of nido-4' (in $\AA$ ).

$\begin{array}{lrrr}\text { Co } & 1.604954000 & 0.451767000 & -0.000012000 \\ \text { Co } & -2.089337000 & -0.039998000 & 0.000241000 \\ \text { C } & -2.973642000 & 1.876894000 & 0.000212000 \\ \text { C } & -3.391395000 & 1.146118000 & -1.162214000 \\ \text { C } & -4.063227000 & -0.040487000 & -0.718719000 \\ \text { C } & -4.062772000 & -0.040663000 & 0.719398000 \\ \text { C } & -3.390632000 & 1.145815000 & 1.162733000 \\ \text { C } & 1.851505000 & 2.500735000 & 0.000085000 \\ \text { C } & 2.493316000 & 1.951865000 & 1.167940000 \\ \text { C } & 3.496876000 & 1.040256000 & 0.722435000 \\ \text { C } & 3.496715000 & 1.040320000 & -0.722751000 \\ \text { C } & 2.493061000 & 1.951963000 & -1.167956000 \\ \text { B } & -1.078455000 & -1.111006000 & -1.434973000 \\ \text { H } & -1.567375000 & -1.288002000 & -2.533592000 \\ \text { B } & 0.821416000 & -0.861218000 & -1.469911000 \\ \text { H } & 1.332032000 & -0.964751000 & -2.566560000 \\ \text { B } & -0.278520000 & 0.392601000 & -0.911714000 \\ \text { H } & -0.413322000 & 1.292080000 & -1.725540000 \\ \text { B } & -0.278617000 & 0.392730000 & 0.911532000 \\ \text { H } & -0.413575000 & 1.292178000 & 1.725346000 \\ \text { B } & -1.078560000 & -1.111082000 & 1.434422000 \\ \text { H } & -1.567582000 & -1.288473000 & 2.532944000 \\ \text { B } & 0.821236000 & -0.860995000 & 1.469981000 \\ \text { H } & 1.331646000 & -0.964469000 & 2.566730000 \\ \text { Se } & 1.806387000 & -1.873909000 & 0.000159000 \\ \text { B } & -1.778456000 & -1.990225000 & -0.000291000 \\ \text { H } & -2.648637000 & -2.836292000 & -0.000464000 \\ \text { H } & -0.912372000 & -2.354141000 & 0.960581000 \\ \text { H } & -0.912517000 & -2.354125000 & -0.961334000 \\ \text { H } & 4.131408000 & 0.416132000 & 1.364536000\end{array}$




$\begin{array}{rrrr}\mathrm{H} & 4.131110000 & 0.416251000 & -1.365042000 \\ \mathrm{H} & 2.220862000 & 2.158215000 & -2.210147000 \\ \mathrm{H} & 1.018708000 & 3.214472000 & 0.000214000 \\ \mathrm{H} & 2.221314000 & 2.158001000 & 2.210207000 \\ \mathrm{H} & -2.404789000 & 2.814856000 & 0.000173000 \\ \mathrm{H} & -3.191934000 & 1.422622000 & 2.205396000 \\ \mathrm{H} & -3.193476000 & 1.423169000 & -2.204962000 \\ \mathrm{H} & -4.475135000 & -0.826569000 & -1.363627000 \\ \mathrm{H} & -4.474237000 & -0.826937000 & 1.364353000\end{array}$

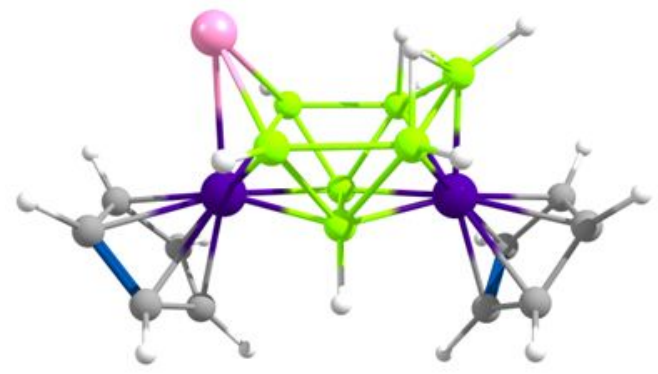

Figure S66. Optimized geometry of nido-5'

T. E. $=-3600.0410$ a. u.

Cartesian coordinates for the calculated structure of nido-5' (in $\AA$ ).

$\begin{array}{lrrr}\text { Co } & 2.269933000 & -0.113097000 & -0.000088000 \\ \text { C } & 3.710096000 & 0.907306000 & 1.162145000 \\ \text { C } & 4.229154000 & -0.354104000 & 0.719384000 \\ \text { C } & 4.229480000 & -0.354489000 & -0.718558000 \\ \text { C } & 3.710627000 & 0.906679000 & -1.162233000 \\ \text { C } & 3.389525000 & 1.684483000 & -0.000324000 \\ \text { B } & 1.142215000 & -1.057581000 & 1.442212000 \\ \text { H } & 1.616765000 & -1.296303000 & 2.535666000 \\ \text { B } & 1.142101000 & -1.057616000 & -1.442263000 \\ \text { H } & 1.616551000 & -1.296594000 & -2.535700000 \\ \text { B } & 0.524818000 & 0.524963000 & -0.910829000 \\ \text { H } & 0.769983000 & 1.410723000 & -1.714868000 \\ \text { B } & -0.713930000 & -0.549884000 & -1.521761000 \\ \text { H } & -1.200978000 & -0.536222000 & -2.633929000 \\ \text { B } & -0.713776000 & -0.549949000 & 1.521747000 \\ \text { H } & -1.200819000 & -0.536354000 & 2.633916000 \\ \text { B } & 0.524837000 & 0.524916000 & 0.910595000 \\ \text { H } & 0.770020000 & 1.410685000 & 1.714627000 \\ \text { Te } & -1.987028000 & -1.641455000 & 0.000019000 \\ \text { Co } & -1.343035000 & 0.796657000 & 0.000017000 \\ \text { C } & -2.017980000 & 2.407535000 & -1.168173000 \\ \text { C } & -3.137020000 & 1.642703000 & -0.722484000 \\ \text { C } & -3.136332000 & 1.643180000 & 0.723659000 \\ \text { C } & -2.016863000 & 2.408308000 & 1.167744000 \\ \text { C } & -1.306436000 & 2.862398000 & -0.000709000\end{array}$




$\begin{array}{lrrr}\text { B } & 1.737133000 & -2.007618000 & -0.000070000 \\ \mathrm{H} & 0.840534000 & -2.273368000 & -0.962089000 \\ \mathrm{H} & 0.841305000 & -2.273750000 & 0.962481000 \\ \mathrm{H} & -3.856593000 & 1.121151000 & 1.366359000 \\ \mathrm{H} & -3.857885000 & 1.120214000 & -1.364135000 \\ \mathrm{H} & -1.717186000 & 2.573332000 & 2.209720000 \\ \mathrm{H} & -0.384321000 & 3.456358000 & -0.001347000 \\ \mathrm{H} & -1.719340000 & 2.571892000 & -2.210550000 \\ \mathrm{H} & 2.943111000 & 2.686597000 & -0.000710000 \\ \mathrm{H} & 3.550318000 & 1.208643000 & 2.204712000 \\ \mathrm{H} & 4.542518000 & -1.184464000 & 1.364242000 \\ \mathrm{H} & 4.543174000 & -1.185182000 & -1.362827000 \\ \mathrm{H} & 3.551348000 & 1.207475000 & -2.205033000 \\ \mathrm{H} & 2.508206000 & -2.945440000 & -0.000451000\end{array}$

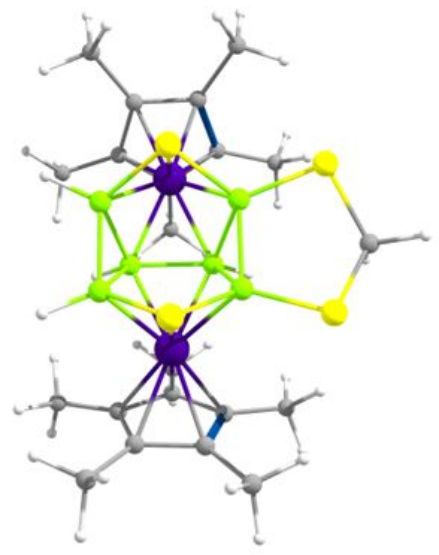

Figure S67. Optimized geometry of nido-10

T. E. $=-5328.8082$ a. u.

Cartesian coordinates for the calculated structure of nido-10 (in $\AA$ ).

$\begin{array}{llrr}\text { Co } & -1.900120000 & -0.330971000 & -0.20976900 \\ \text { C } & -2.577959000 & -1.435751000 & 1.423691000 \\ \text { C } & -3.133100000 & -0.097721000 & 1.503461000 \\ \text { C } & -3.900740000 & 0.120629000 & 0.309941000 \\ \text { C } & -3.848709000 & -1.092361000 & -0.497719000 \\ \text { C } & -3.047369000 & -2.059291000 & 0.197611000 \\ \text { C } & -1.822699000 & -2.135581000 & 2.511121000 \\ \text { H } & -1.192679000 & -1.434460000 & 3.091041000 \\ \text { H } & -1.168669000 & -2.930940000 & 2.106401000 \\ \text { H } & -2.532659000 & -2.615411000 & 3.221861000 \\ \text { C } & -2.980270000 & 0.870199000 & 2.637871000 \\ \text { H } & -3.922680000 & 0.947779000 & 3.223411000 \\ \text { H } & -2.728370000 & 1.885029000 & 2.259361000 \\ \mathrm{H} & -2.177730000 & 0.558869000 & 3.334201000 \\ \text { C } & -4.696780000 & 1.351539000 & -0.011659000 \\ \mathrm{H} & -5.731510000 & 1.258798000 & 0.387961000 \\ \mathrm{H} & -4.776790000 & 1.516739000 & -1.104289000 \\ \mathrm{H} & -4.241960000 & 2.257199000 & 0.436171000 \\ \mathrm{C} & -4.567309000 & -1.295471000 & -1.799309000\end{array}$




\begin{tabular}{|c|c|c|c|}
\hline $\mathrm{H}$ & -4.108099000 & -2.105321000 & -2.398629000 \\
\hline $\mathrm{H}$ & -4.555300000 & -0.375981000 & -2.418159000 \\
\hline $\mathrm{H}$ & -5.631859000 & -1.565842000 & -1.621999000 \\
\hline $\mathrm{C}$ & -2.786229000 & -3.478601000 & -0.209899000 \\
\hline $\mathrm{H}$ & -3.405999000 & -4.183681000 & 0.387061000 \\
\hline $\mathrm{H}$ & -1.722259000 & -3.751661000 & -0.056179000 \\
\hline $\mathrm{H}$ & -3.018369000 & -3.645381000 & -1.279399000 \\
\hline $\mathrm{Co}$ & 1.900140000 & -0.330850000 & -0.20976900 \\
\hline $\mathrm{C}$ & 2.578001000 & -1.435979000 & 1.423531000 \\
\hline C & 3.047631000 & -2.059169000 & 0.197371000 \\
\hline C & 3.848871000 & -1.091959000 & -0.497669000 \\
\hline $\mathrm{C}$ & 3.900610000 & 0.120871000 & 0.310251000 \\
\hline $\mathrm{C}$ & 3.132850000 & -0.097839000 & 1.503631000 \\
\hline C & 1.822931000 & -2.136570000 & 2.510591000 \\
\hline $\mathrm{H}$ & 2.533011000 & -2.619679000 & 3.218991000 \\
\hline $\mathrm{H}$ & 1.166471000 & -2.929530000 & 2.105131000 \\
\hline $\mathrm{H}$ & 1.195501000 & -1.435410000 & 3.093241000 \\
\hline C & 2.786691000 & -3.478449000 & -0.210349000 \\
\hline $\mathrm{H}$ & 3.020481000 & -3.645479000 & -1.279459000 \\
\hline $\mathrm{H}$ & 1.722381000 & -3.751130000 & -0.058239000 \\
\hline $\mathrm{H}$ & 3.405271000 & -4.183629000 & 0.387711000 \\
\hline C & 4.567721000 & -1.294639000 & -1.799189000 \\
\hline $\mathrm{H}$ & 5.632411000 & -1.564368000 & -1.621759000 \\
\hline $\mathrm{H}$ & 4.555230000 & -0.375139000 & -2.418019000 \\
\hline $\mathrm{H}$ & 4.109051000 & -2.104739000 & -2.398579000 \\
\hline $\mathrm{C}$ & 4.696510000 & 1.351951000 & -0.011049000 \\
\hline $\mathrm{H}$ & 4.241800000 & 2.257401000 & 0.437321000 \\
\hline $\mathrm{H}$ & 4.776150000 & 1.517651000 & -1.103629000 \\
\hline $\mathrm{H}$ & 5.731370000 & 1.259072000 & 0.388171000 \\
\hline $\mathrm{C}$ & 2.979670000 & 0.869881000 & 2.638161000 \\
\hline $\mathrm{H}$ & 3.921800000 & 0.947161000 & 3.224201000 \\
\hline $\mathrm{H}$ & 2.176700000 & 0.558591000 & 3.334011000 \\
\hline $\mathrm{H}$ & 2.728140000 & 1.884821000 & 2.259721000 \\
\hline $\mathrm{C}$ & -0.000061000 & 3.644830000 & 1.075141000 \\
\hline $\mathrm{H}$ & -0.000091000 & 4.745720000 & 1.202311000 \\
\hline $\mathrm{H}$ & -0.000061000 & 3.165520000 & 2.075201000 \\
\hline S & -1.707560000 & 0.885639000 & -2.073149000 \\
\hline S & -1.528751000 & 3.177409000 & 0.161071000 \\
\hline S & 1.707530000 & 0.885660000 & -2.073179000 \\
\hline S & 1.528579000 & 3.177490000 & 0.161011000 \\
\hline B & -0.934449000 & -0.838230000 & -2.001199000 \\
\hline $\mathrm{H}$ & -1.424359000 & -1.639050000 & -2.773909000 \\
\hline B & 0.000011000 & -1.184200000 & -0.526229000 \\
\hline $\mathrm{H}$ & 0.000111000 & -2.372890000 & -0.227269000 \\
\hline B & 0.934531000 & -0.838340000 & -2.001179000 \\
\hline $\mathrm{H}$ & 1.424511000 & -1.639090000 & -2.773889000 \\
\hline B & 0.936010000 & 1.529210000 & -0.472339000 \\
\hline B & -0.936060000 & 1.529240000 & -0.472249000 \\
\hline B & 0.000000000 & 0.319820000 & 0.467211000 \\
\hline $\mathrm{H}$ & -0.000050000 & 0.527800000 & 1.67218100 \\
\hline
\end{tabular}




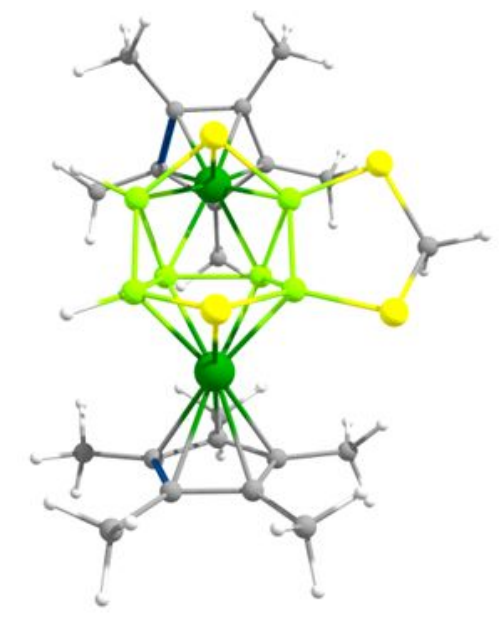

Figure S68. Optimized geometry of nido-11

T. E. $=-2784.4621$ a. u.

Cartesian coordinates for the calculated structure of nido-11 (in $\AA$ ).

$\begin{array}{lrrr}\mathrm{C} & -2.724807000 & -1.507238000 & 1.440053000 \\ \mathrm{C} & -3.334905000 & -0.195670000 & 1.592478000 \\ \mathrm{C} & -4.145322000 & 0.038347000 & 0.429201000 \\ \mathrm{C} & -4.088730000 & -1.150215000 & -0.422608000 \\ \mathrm{C} & -3.231335000 & -2.112535000 & 0.212274000 \\ \mathrm{C} & -1.901792000 & -2.218641000 & 2.473307000 \\ \mathrm{H} & -1.278129000 & -1.514355000 & 3.056911000 \\ \mathrm{H} & -1.228899000 & -2.965881000 & 2.010722000 \\ \mathrm{H} & -2.560501000 & -2.758623000 & 3.189801000 \\ \mathrm{C} & -3.163557000 & 0.750628000 & 2.744426000 \\ \mathrm{H} & -4.100962000 & 0.836522000 & 3.336222000 \\ \mathrm{H} & -2.891680000 & 1.768240000 & 2.385995000 \\ \mathrm{H} & -2.363974000 & 0.412601000 & 3.431816000 \\ \mathrm{C} & -4.979773000 & 1.262538000 & 0.180624000 \\ \mathrm{H} & -5.979221000 & 1.161013000 & 0.659961000 \\ \mathrm{H} & -5.147005000 & 1.434289000 & -0.900727000 \\ \mathrm{H} & -4.498253000 & 2.169725000 & 0.596860000 \\ \mathrm{C} & -4.862640000 & -1.343259000 & -1.695606000 \\ \mathrm{H} & -4.385651000 & -2.096304000 & -2.352805000 \\ \mathrm{H} & -4.939875000 & -0.400692000 & -2.273101000 \\ \mathrm{H} & -5.898833000 & -1.688661000 & -1.482738000 \\ \mathrm{C} & -2.940563000 & -3.510788000 & -0.249034000 \\ \mathrm{H} & -3.523230000 & -4.255415000 & 0.337491000 \\ \mathrm{H} & -1.865932000 & -3.760297000 & -0.133388000 \\ \mathrm{H} & -3.197324000 & -3.648351000 & -1.317297000 \\ \mathrm{C} & 2.725025000 & -1.507817000 & 1.439625000 \\ \mathrm{C} & 3.231848000 & -2.112286000 & 0.211580000 \\ \mathrm{C} & 4.088960000 & -1.149341000 & -0.422750000 \\ \mathrm{C} & 4.145099000 & 0.038795000 & 0.429670000 \\ \mathrm{C} & 3.334642000 & -0.196090000 & 1.592743000 \\ \mathrm{C} & 1.902278000 & -2.220138000 & 2.472454000 \\ \mathrm{H} & 2.561150000 & -2.761508000 & 3.187746000 \\ \mathrm{H} & 1.228610000 & -2.966341000 & 2.009304000\end{array}$




$\begin{array}{lrrr}\mathrm{H} & 1.279440000 & -1.516287000 & 3.057455000 \\ \mathrm{C} & 2.941710000 & -3.510403000 & -0.250541000 \\ \mathrm{H} & 3.197026000 & -3.646789000 & -1.319303000 \\ \mathrm{H} & 1.867507000 & -3.761052000 & -0.133504000 \\ \mathrm{H} & 3.525970000 & -4.254998000 & 0.334453000 \\ \mathrm{C} & 4.862970000 & -1.341687000 & -1.695786000 \\ \mathrm{H} & 5.898507000 & -1.689169000 & -1.483111000 \\ \mathrm{H} & 4.941962000 & -0.398356000 & -2.271780000 \\ \mathrm{H} & 4.384943000 & -2.092927000 & -2.354302000 \\ \mathrm{C} & 4.979106000 & 1.263444000 & 0.181859000 \\ \mathrm{H} & 4.496892000 & 2.170304000 & 0.598013000 \\ \mathrm{H} & 5.146888000 & 1.435527000 & -0.899352000 \\ \mathrm{H} & 5.978318000 & 1.162299000 & 0.661768000 \\ \mathrm{C} & 3.162860000 & 0.749709000 & 2.745041000 \\ \mathrm{H} & 4.100374000 & 0.836192000 & 3.336572000 \\ \mathrm{H} & 2.363757000 & 0.410853000 & 3.432582000 \\ \mathrm{H} & 2.890113000 & 1.767225000 & 2.386977000 \\ \mathrm{C} & -0.000150000 & 3.631550000 & 1.302163000 \\ \mathrm{H} & -0.000143000 & 4.717879000 & 1.521838000 \\ \mathrm{H} & -0.000216000 & 3.070416000 & 2.258603000 \\ \mathrm{~S} & -1.702647000 & 1.179789000 & -2.111189000 \\ \mathrm{~S} & -1.533747000 & 3.242616000 & 0.356489000 \\ \mathrm{~S} & 1.702610000 & 1.179840000 & -2.111095000 \\ \mathrm{~S} & 1.533553000 & 3.242563000 & 0.356670000 \\ \mathrm{~B} & -0.937092000 & -0.556866000 & -2.187076000 \\ \mathrm{H} & -1.419037000 & -1.278105000 & -3.037854000 \\ \mathrm{~B} & -0.000011000 & -1.074094000 & -0.743421000 \\ \mathrm{H} & -0.000035000 & -2.291078000 & -0.591946000 \\ \mathrm{~B} & 0.937141000 & -0.556879000 & -2.187034000 \\ \mathrm{H} & 1.419099000 & -1.278112000 & -3.037811000 \\ \mathrm{~B} & 0.932559000 & 1.671421000 & -0.443193000 \\ \mathrm{~B} & -0.932737000 & 1.671399000 & -0.443209000 \\ \mathrm{~B} & -0.000057000 & 0.373017000 & 0.414483000 \\ \mathrm{H} & -0.000068000 & 0.505285000 & 1.629704000 \\ \mathrm{Rh} & -2.001360000 & -0.266073000 & -0.266761000 \\ \mathrm{Rh} & 2.001306000 & -0.266047000 & -0.266695000\end{array}$




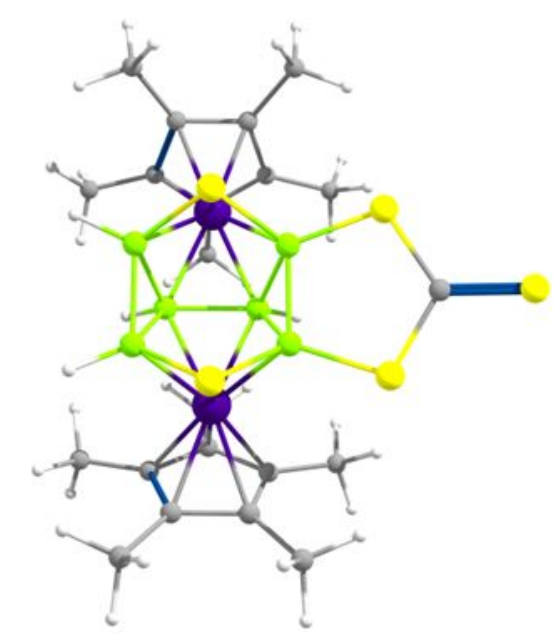

Figure S69. Optimized geometry of nido-12 T. E. $=-5725.7211$ a. u.

Cartesian coordinates for the calculated structure of nido-12 (in $\AA$ ).

$\begin{array}{lrrr}\mathrm{C} & -3.096237000 & -0.182740000 & 1.504006000 \\ \mathrm{C} & -3.880999000 & -0.056510000 & 0.306219000 \\ \mathrm{C} & -3.870483000 & -1.339812000 & -0.384976000 \\ \mathrm{C} & -3.077792000 & -2.257895000 & 0.383613000 \\ \mathrm{C} & -2.577967000 & -1.537789000 & 1.542274000 \\ \mathrm{C} & -1.821635000 & -2.155125000 & 2.677520000 \\ \mathrm{H} & -1.170957000 & -2.980898000 & 2.332357000 \\ \mathrm{H} & -1.189920000 & -1.413685000 & 3.202537000 \\ \mathrm{H} & -2.532286000 & -2.577540000 & 3.422968000 \\ \mathrm{C} & -2.904761000 & 0.870808000 & 2.553380000 \\ \mathrm{H} & -2.723204000 & 1.867594000 & 2.100858000 \\ \mathrm{H} & -3.804765000 & 0.947460000 & 3.202468000 \\ \mathrm{H} & -2.039821000 & 0.642815000 & 3.205615000 \\ \mathrm{C} & -4.664968000 & 1.150548000 & -0.118678000 \\ \mathrm{H} & -4.243674000 & 2.083847000 & 0.302692000 \\ \mathrm{H} & -4.691452000 & 1.258380000 & -1.221254000 \\ \mathrm{H} & -5.718032000 & 1.068232000 & 0.231746000 \\ \mathrm{C} & -4.617870000 & -1.647867000 & -1.648865000 \\ \mathrm{H} & -4.167331000 & -2.499415000 & -2.194701000 \\ \mathrm{H} & -5.674402000 & -1.912234000 & -1.421847000 \\ \mathrm{H} & -4.632167000 & -0.779254000 & -2.336635000 \\ \mathrm{C} & -2.856496000 & -3.714465000 & 0.104072000 \\ \mathrm{H} & -1.802766000 & -4.005130000 & 0.290359000 \\ \mathrm{H} & -3.500717000 & -4.344122000 & 0.756819000 \\ \mathrm{H} & -3.089342000 & -3.968797000 & -0.947787000 \\ \mathrm{C} & 2.577558000 & -1.537296000 & 1.542701000 \\ \mathrm{C} & 3.076990000 & -2.258350000 & 0.384431000 \\ \mathrm{C} & 3.870016000 & -1.341064000 & -0.384761000 \\ \mathrm{C} & 3.881156000 & -0.057351000 & 0.305679000 \\ \mathrm{C} & 3.096457000 & -0.182548000 & 1.503616000 \\ \mathrm{C} & 2.905646000 & 0.871598000 & 2.552518000 \\ \mathrm{H} & 2.041111000 & 0.643974000 & 3.205422000 \\ \mathrm{H} & 3.806065000 & 0.948536000 & 3.200990000\end{array}$




\begin{tabular}{|c|c|}
\hline $\mathrm{H}$ & 2.723884000 \\
\hline $\mathrm{C}$ & 1.820979000 \\
\hline $\mathrm{H}$ & 1.187064000 \\
\hline $\mathrm{H}$ & 1.172452000 \\
\hline $\mathrm{H}$ & 2.531511000 \\
\hline $\mathrm{C}$ & 2.855049000 \\
\hline $\mathrm{H}$ & 1.800995000 \\
\hline $\mathrm{H}$ & 3.088513000 \\
\hline $\mathrm{H}$ & 3.498409000 \\
\hline $\mathrm{C}$ & 4.617256000 \\
\hline $\mathrm{H}$ & 4.632155000 \\
\hline $\mathrm{H}$ & 5.673605000 \\
\hline $\mathrm{H}$ & 4.166178000 \\
\hline $\mathrm{C}$ & 4.665585000 \\
\hline $\mathrm{H}$ & 4.691735000 \\
\hline $\mathrm{H}$ & 4.244896000 \\
\hline $\mathrm{H}$ & 5.718735000 \\
\hline S & 1.704070000 \\
\hline S & -1.704120000 \\
\hline S & -1.519595000 \\
\hline S & 1.520159000 \\
\hline S & 0.000693000 \\
\hline $\mathrm{B}$ & 0.914301000 \\
\hline B & -0.914274000 \\
\hline B & 0.000062000 \\
\hline $\mathrm{H}$ & 0.000135000 \\
\hline B & -0.000126000 \\
\hline $\mathrm{H}$ & -0.000263000 \\
\hline B & 0.938341000 \\
\hline $\mathrm{H}$ & 1.424707000 \\
\hline B & -0.938641000 \\
\hline $\mathrm{H}$ & -1.42518200 \\
\hline $\mathrm{C}$ & 0.000452000 \\
\hline $\mathrm{Co}$ & 1.89938400 \\
\hline $\mathrm{Co}$ & -1.8994250 \\
\hline
\end{tabular}

1.868159000
-2.153353000
-1.411880000
-2.981314000
-2.572414000
-3.714987000
-4.004889000
-3.970188000
-4.344562000
-1.650170000
-0.781868000
-1.915137000
-2.501653000
1.149132000
1.256503000
2.082809000
1.066435000
0.361187000
0.361581000
2.890997000
2.890685000
5.301456000
1.189824000
1.190063000
0.090864000
0.440380000
-1.508191000
-2.652993000
-1.338558000
-2.230439000
-1.338257000
-2.230043000
3.755403000
-0.601663000
-0.601333000
-

2.099576000

2. 678491000

3.200797000

2.334562000

3. 425949000

0.105773000

0.291464000

$-0.945737000$

0.759433000

$-1.648487000$

$-2.336635000$

$-1.421311000$

$-2.193988000$

$-0.119988000$

$-1.222621000$

0.301141000

0.230094000

$-2.196300000$

$-2.196119000$

$-0.210043000$

$-0.210630000$

0.710416000

$-0.687483000$

$-0.687195000$

0.409060000

1.577340000

$-0.411449000$

0.023993000

$-1.913901000$

$-2.580989000$

$-1.913888000$

$-2.580982000$

0.135772000

$-0.194018000$

$-0.193888000$

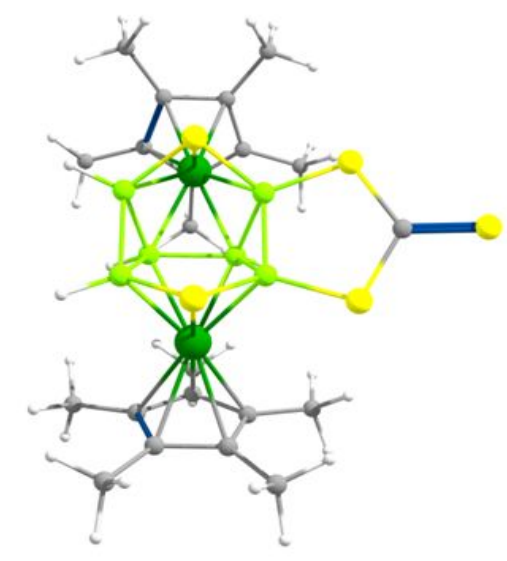

Figure S70. Optimized geometry of nido-13

T. E. $=-3181.3754$ a. u. 
Cartesian coordinates for the calculated structure of nido-13 (in $\AA$ ).

\begin{tabular}{|c|c|c|c|}
\hline $\mathrm{Rh}$ & -2.002505000 & -0.527489000 & -0.249173000 \\
\hline $\mathrm{Rh}$ & 2.004615000 & -0.524512000 & -0.249314000 \\
\hline $\mathrm{C}$ & -3.298585000 & -0.188931000 & 1.595833000 \\
\hline $\mathrm{C}$ & -4.126506000 & -0.086095000 & 0.423442000 \\
\hline $\mathrm{C}$ & -4.109852000 & -1.375852000 & -0.267087000 \\
\hline C & -3.264289000 & -2.270397000 & 0.475045000 \\
\hline & -2.727236000 & -1.526966000 & 1.609364000 \\
\hline & -1.905916000 & -2.117496000 & 2.717039000 \\
\hline $\mathrm{H}$ & -1.249287000 & -2.928897000 & 2.348821000 \\
\hline$H$ & -1.267813000 & -1.355274000 & 3.204299000 \\
\hline & -2.568209000 & -2.550510000 & 3.499668000 \\
\hline & -3.093370000 & 0.878113000 & 2.630719000 \\
\hline & -2.961671000 & 1.876961000 & 2.165890000 \\
\hline & -3.963073000 & 0.934351000 & 3.321785000 \\
\hline $\mathrm{H}$ & -2.192227000 & 0.681515000 & 3.243312000 \\
\hline & -4.949731000 & 1.107207000 & 0.030260000 \\
\hline & -4.481773000 & 2.053599000 & 0.365683000 \\
\hline & -5.087282000 & 1.169155000 & -1.067077000 \\
\hline $1+$ & -5.962016000 & 1.052369000 & 0.489393000 \\
\hline & -4.904931000 & -1.713155000 & -1.495897000 \\
\hline $\mathrm{H}$ & -4.438497000 & -2.536534000 & -2.071363000 \\
\hline & -5.935591000 & -2.032758000 & -1.224625000 \\
\hline & -4.996011000 & -0.842264000 & -2.174538000 \\
\hline C & -3.016539000 & -3.723354000 & 0.192558000 \\
\hline $\mathrm{H}$ & -1.954436000 & -3.994524000 & 0.360028000 \\
\hline $\mathrm{H}$ & -3.635480000 & -4.368722000 & 0.854614000 \\
\hline $\mathrm{H}$ & -3.262798000 & -3.982552000 & -0.855324000 \\
\hline $\mathrm{C}$ & 2.726278000 & -1.563091000 & 1.587485000 \\
\hline $\mathrm{C}$ & 3.292566000 & -2.264468000 & 0.441521000 \\
\hline $\mathrm{C}$ & 4.128799000 & -1.333262000 & -0.265159000 \\
\hline $\mathrm{C}$ & 4.112413000 & -0.062652000 & 0.459868000 \\
\hline $\mathrm{C}$ & 3.270683000 & -0.213155000 & 1.617076000 \\
\hline $\mathrm{C}$ & 3.030583000 & 0.822298000 & 2.676279000 \\
\hline $\mathrm{H}$ & 2.124757000 & 0.593031000 & 3.270338000 \\
\hline $\mathrm{H}$ & 3.889156000 & 0.876659000 & 3.381259000 \\
\hline $\mathrm{H}$ & 2.887238000 & 1.830189000 & 2.235056000 \\
\hline $\mathrm{C}$ & 1.901852000 & -2.201606000 & 2.665858000 \\
\hline $\mathrm{H}$ & 1.253428000 & -1.464170000 & 3.176671000 \\
\hline $\mathrm{H}$ & 1.254960000 & -3.003918000 & 2.261300000 \\
\hline $\mathrm{H}$ & 2.561931000 & -2.659136000 & 3.436311000 \\
\hline C & 3.075442000 & -3.713327000 & 0.115368000 \\
\hline $\mathrm{H}$ & 2.017560000 & -4.009456000 & 0.266226000 \\
\hline $\mathrm{H}$ & 3.334933000 & -3.937631000 & -0.937374000 \\
\hline $\mathrm{H}$ & 3.701518000 & -4.365624000 & 0.763831000 \\
\hline $\mathrm{C}$ & 4.945112000 & -1.621242000 & -1.492528000 \\
\hline $\mathrm{H}$ & 5.022980000 & -0.732042000 & -2.148711000 \\
\hline $\mathrm{H}$ & 5.979965000 & -1.922767000 & -1.216597000 \\
\hline $\mathrm{H}$ & 4.505459000 & -2.441423000 & -2.093032000 \\
\hline $\mathrm{C}$ & 4.919239000 & 1.155258000 & 0.110557000 \\
\hline & 07 & 0 & -0 \\
\hline
\end{tabular}




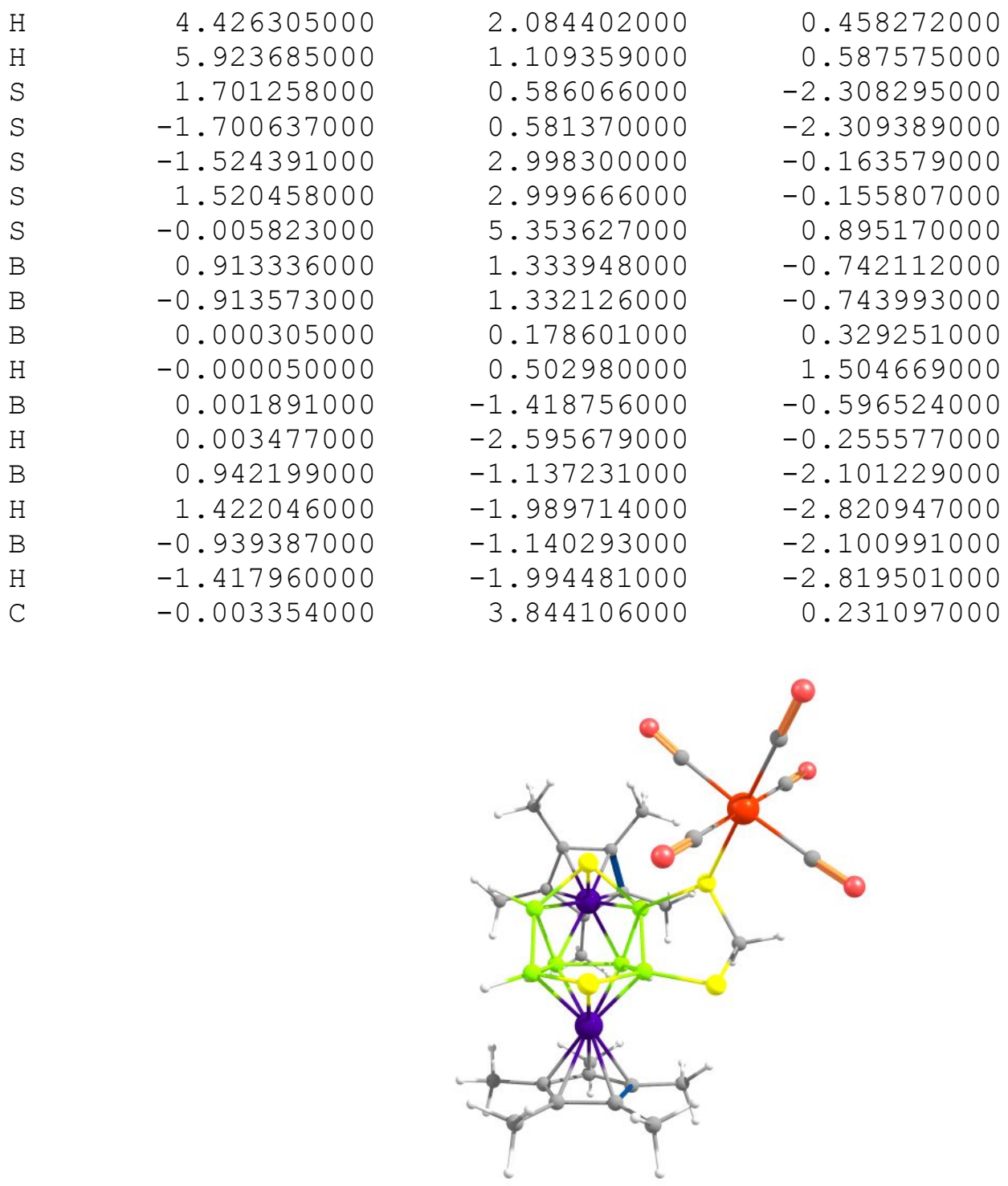

Figure S71. Optimized geometry of nido-15

T. E. $=-5962.4202$ a. u.

\section{Cartesian coordinates for the calculated structure of nido-15 (in $\AA$ ).}

$\begin{array}{lrrr}\text { C } & 0.815321000 & 3.233317000 & 1.608263000 \\ \text { C } & -0.119750000 & 3.651192000 & 0.601514000 \\ \text { C } & 0.635165000 & 4.106140000 & -0.559385000 \\ \text { C } & 2.036056000 & 3.982313000 & -0.263664000 \\ \mathrm{C} & 2.151235000 & 3.420417000 & 1.069879000 \\ \mathrm{C} & 3.432021000 & 3.257750000 & 1.827690000 \\ \mathrm{H} & 3.359863000 & 2.463760000 & 2.594724000 \\ \mathrm{H} & 4.276013000 & 3.013576000 & 1.154837000 \\ \mathrm{H} & 3.685701000 & 4.206903000 & 2.351097000 \\ \mathrm{C} & 3.183313000 & 4.419713000 & -1.124512000 \\ \mathrm{H} & 4.005429000 & 3.675840000 & -1.109834000 \\ \mathrm{H} & 2.875291000 & 4.554281000 & -2.179037000 \\ \mathrm{H} & 3.597587000 & 5.387664000 & -0.765532000 \\ \mathrm{C} & 0.037603000 & 4.670233000 & -1.814796000\end{array}$




\begin{tabular}{|c|c|c|c|}
\hline $\mathrm{H}$ & -0.927794000 & 4.186891000 & -2.062814000 \\
\hline $\mathrm{H}$ & -0.154070000 & 5.759674000 & -1.696819000 \\
\hline $\mathrm{H}$ & 0.711436000 & 4.539964000 & -2.683873000 \\
\hline $\mathrm{C}$ & -1.610369000 & 3.717206000 & 0.752053000 \\
\hline $\mathrm{H}$ & -2.133253000 & 3.614200000 & -0.218045000 \\
\hline $\mathrm{H}$ & -1.990335000 & 2.927404000 & 1.429614000 \\
\hline $\mathrm{H}$ & -1.906359000 & 4.698993000 & 1.184552000 \\
\hline $\mathrm{C}$ & 0.474338000 & 2.765138000 & 2.990929000 \\
\hline $\mathrm{H}$ & 1.285332000 & 2.147050000 & 3.423478000 \\
\hline $\mathrm{H}$ & 0.312244000 & 3.629844000 & 3.671897000 \\
\hline $\mathrm{H}$ & -0.452112000 & 2.155471000 & 2.990889000 \\
\hline $\mathrm{C}$ & 4.663261000 & -1.080018000 & 1.028514000 \\
\hline C & 5.130745000 & -1.292620000 & -0.331483000 \\
\hline $\mathrm{C}$ & 4.566902000 & -2.529725000 & -0.792274000 \\
\hline C & 3.771905000 & -3.098430000 & 0.290435000 \\
\hline $\mathrm{C}$ & 3.847452000 & -2.214049000 & 1.419128000 \\
\hline $\mathrm{C}$ & 3.237066000 & -2.455150000 & 2.766615000 \\
\hline $\mathrm{H}$ & 3.221897000 & -1.532694000 & 3.378922000 \\
\hline $\mathrm{H}$ & 2.191124000 & -2.817788000 & 2.669356000 \\
\hline $\mathrm{H}$ & 3.812082000 & -3.222436000 & 3.330086000 \\
\hline $\mathrm{C}$ & 5.119130000 & 0.021025000 & 1.935422000 \\
\hline $\mathrm{H}$ & 4.351289000 & 0.276893000 & 2.690709000 \\
\hline $\mathrm{H}$ & 6.035696000 & -0.292311000 & 2.483901000 \\
\hline $\mathrm{H}$ & 5.367047000 & 0.939203000 & 1.370714000 \\
\hline $\mathrm{C}$ & 6.088030000 & -0.405863000 & -1.069839000 \\
\hline $\mathrm{H}$ & 5.833589000 & 0.664694000 & -0.933315000 \\
\hline $\mathrm{H}$ & 7.127686000 & -0.554979000 & -0.703493000 \\
\hline $\mathrm{H}$ & 6.079493000 & -0.611312000 & -2.157546000 \\
\hline $\mathrm{C}$ & 4.797124000 & -3.176441000 & -2.126265000 \\
\hline $\mathrm{H}$ & 3.881654000 & -3.676266000 & -2.501121000 \\
\hline $\mathrm{H}$ & 5.112000000 & -2.440073000 & -2.890516000 \\
\hline $\mathrm{H}$ & 5.593158000 & -3.949971000 & -2.052259000 \\
\hline $\mathrm{C}$ & 3.072345000 & -4.425284000 & 0.255965000 \\
\hline $\mathrm{H}$ & 2.718373000 & -4.678604000 & -0.762722000 \\
\hline $\mathrm{H}$ & 3.764675000 & -5.234497000 & 0.578957000 \\
\hline $\mathrm{H}$ & 2.196509000 & -4.441773000 & 0.934259000 \\
\hline $\mathrm{C}$ & -3.748212000 & 1.174642000 & -1.132319000 \\
\hline $\mathrm{C}$ & -4.777744000 & 0.329422000 & 1.452200000 \\
\hline $\mathrm{C}$ & -5.460123000 & -1.070774000 & -0.964225000 \\
\hline $\mathrm{C}$ & -3.839514000 & -2.390411000 & 0.955759000 \\
\hline $\mathrm{C}$ & -2.684502000 & -1.544554000 & -1.590516000 \\
\hline $\mathrm{C}$ & -0.831989000 & -1.344452000 & 2.126474000 \\
\hline $\mathrm{H}$ & -0.113881000 & -0.947256000 & 2.871019000 \\
\hline $\mathrm{H}$ & -1.673699000 & -1.839353000 & 2.646373000 \\
\hline 0 & -3.823712000 & 2.167853000 & -1.738941000 \\
\hline 0 & -5.383039000 & 0.846852000 & 2.302282000 \\
\hline 0 & -6.469177000 & -1.349399000 & -1.485612000 \\
\hline 0 & -3.946591000 & -3.400890000 & 1.524442000 \\
\hline 0 & -2.134930000 & -2.088968000 & -2.458330000 \\
\hline $\mathrm{Co}$ & 3.019863000 & -1.197641000 & -0.25207600 \\
\hline $\mathrm{Co}$ & 1.106639000 & 2.089303000 & -0.146761000 \\
\hline W & -3.733342000 & -0.597073000 & -0.07148500 \\
\hline
\end{tabular}




$\begin{array}{lrrr}\text { B } & 2.525781000 & -0.313737000 & -2.088389000 \\ \mathrm{H} & 3.247376000 & -0.422413000 & -3.059714000 \\ \mathrm{~B} & 2.699297000 & 0.827780000 & -0.733994000 \\ \mathrm{H} & 3.754034000 & 1.448882000 & -0.765316000 \\ \mathrm{~B} & 1.579335000 & 1.296050000 & -2.036751000 \\ \mathrm{H} & 1.798813000 & 2.022583000 & -2.985460000 \\ \mathrm{~B} & 1.695726000 & 0.198732000 & 0.624452000 \\ \mathrm{H} & 1.815181000 & 0.225036000 & 1.841298000 \\ \mathrm{~B} & 0.007735000 & 0.315989000 & 0.050107000 \\ \mathrm{~B} & 0.928355000 & -1.305329000 & -0.000196000 \\ \mathrm{~S} & 1.468000000 & -1.835493000 & -1.727380000 \\ \mathrm{~S} & -0.256705000 & 1.116220000 & -1.620469000 \\ \mathrm{~S} & -1.502581000 & 0.109114000 & 1.194812000 \\ \mathrm{~S} & -0.011820000 & -2.551967000 & 1.021348000\end{array}$

\section{References}

(1) (a) Led, J. J.; Gesmar, H. Application of the Linear Prediction Method to NMR Spectroscopy. Chem. Rev. 1991, 91, 1413-1426. (b) Yang, L.; Simionescua, R.; Lough, A.; Yan, H. Some observations relating to the stability of the BODIPY uorophore under acidic and basic conditions. Dyes and Pigments 2011, 91, 264-267. (c) Weiss, R.; Grimes, R. N. Sources of Line Width in Boron-11 Nuclear Magnetic Resonance Spectra. Scalar Relaxation and Boron-Boron Coupling in $\mathrm{B}_{4} \mathrm{H}_{10}$ and $\mathrm{B}_{5} \mathrm{H}_{9}$. J. Am. Chem. Soc. 1978, 100, 1401-1405.

(2) Nandi, C.; Kar, S.; Zafar, M.; Kar, K.; Roisnel, T.; Dorcet, V.; Ghosh, S. Chemistry of Dimetallaoctaborane(12) with Chalcogen-Based Borate Ligands: Obedient versus Disobedient Clusters. Inorg. Chem. 2020, 59, 3537-3541.

(3) Venable, T. L.; Sinn, E.; Grimes, R. N. Cobaltaborane analogs of decaborane $\left(\mathrm{B}_{10} \mathrm{H}_{14}\right)$. Crystal and molecular structures of $\left.6-\left[\eta 5-\mathrm{C}_{5}\left(\mathrm{CH}_{3}\right)_{5}\right] \mathrm{CoB}_{9} \mathrm{H}_{13}, \quad 6,9-\left[\eta 5-\mathrm{C}_{5}\left(\mathrm{CH}_{3}\right)_{5}\right]_{2}\right]_{2} \mathrm{Co}_{2} \mathrm{~B}_{8} \mathrm{H}_{12}, \quad 5,7-\left[\eta^{5}-\right.$ $\left.\left.\mathrm{C}_{5}\left(\mathrm{CH}_{3}\right)_{5}\right]_{5}\right]_{2} \mathrm{Co}_{2} \mathrm{~B}_{8} \mathrm{H}_{12}$, and 6-Cl-5,7-[$\left.\eta^{5}-\mathrm{C}_{5}\left(\mathrm{CH}_{3}\right)_{5}\right]_{2} \mathrm{Co}_{2} \mathrm{~B}_{8} \mathrm{H}_{11}$. Inorg. Chem. 1982, 21, 895-904.

(4) Roy, D. K.; Bose, S. K.; Anju, R. S.; Ramkumar, V.; Ghosh, S. Synthesis and Structure of Dirhodium Analogue of Octaborane-12 and Decaborane-14. Inorg. Chem. 2012, 51, 10715-10722.

(5) Frisch, M. J.; Trucks, G. W.; Schlegel, H. B.; Scuseria, G. E.; Robb, M. A.; Cheeseman, J. R.; Scalmani, G.; Barone, V.; Mennucci, B.; Petersson, G. A.; Nakatsuji, H.; Caricato, M.; Li, X.; Hratchian, H. P.; Izmaylov, A. F.; Bloino, J.; Zheng, G.; Sonnenberg, J. L.; Hada, M.; Ehara, M.; Toyota, K.; Fukuda, R.; Hasegawa, J.; Ishida, M.; Nakajima, T.; Honda, Y.; Kitao, O.; Nakai, H.; Vreven, T.; Montgomery, J. A.; Peralta, Jr., J. E.; Ogliaro, F.; Bearpark, M.; Heyd, J. J.; Brothers, E.; Kudin, K. N.; Staroverov, V. N.; Keith, T.; Kobayashi, R.; Normand, J.; Raghavachari, K.; Rendell, A.; Burant, J. C.; Iyengar, S. S.; Tomasi, J.; Cossi, M.; Rega, N.; Millam, J. M.; Klene, M.; Knox, J. E.; Cross, J. B.; Bakken, V.; Adamo, C.; Jaramillo, J.; Gomperts, R.; Stratmann, R. E.; Yazyev, O.; Austin, A. J.; Cammi, R.; Pomelli, C.; Ochterski, J. W.; Martin, R. L.; Morokuma, K.; Zakrzewski, V. G.; Voth, G. A.; Salvador, P.; Dannenberg, J. J.; Dapprich, S.; Daniels, A. D.; Farkas, O.; Foresman, J. B.; Ortiz, J. V.; Cioslowski, J. ; Fox, D. J. Gaussian16, Rev. B.01; Gaussian, Inc., Wallingford CT, 2016. 
(6) Schmider, H. L.; Becke, A. D. Optimized density functionals from the extended G2 test set. J. Chem. Phys. 1998, 108, 9624-9631.

(7) EMSL Basis Set Exchange Library. https://bse.pnl.gov/bse/portal.

(8) (a) London, F. J. Théoriequantique des courants interatomiquesdans les combinaisonsaromatiques. J. Phys. Radium 1937, 8, 397-409. (b) Ditchfield, R. Self-consistent perturbation theory of diamagnetism. Mol. Phys. 1974, 27, 789-807. (c) Wolinski, K.; Hinton J. F.; Pulay, P. Efficient Implementation of the Gauge-Independent Atomic Orbital Method for NMR Chemical Shift Calculations. J. Am. Chem. Soc. 1990, 112, 8251-8260.

(9) Onak, T. P.; Landesman, H. L.; Williams, R. E.; Shapiro, I. The B ${ }^{11}$ Nuclear Magnetic Resonance Chemical Shifts and Spin Coupling Values for Various Compounds. J. Phys. Chem. 1959, 63, 1533-1535.

(10)Wiberg, K., Application of the pople-santry-segal CNDO method to the cyclopropylcarbinyl and cyclobutylcation and to bicyclobutane. Tetrahedron 1968, 24, 1083-1096.

(11)(a)Weinhold, F.; Landis, C. R. Valency and bonding: A natural bond orbital donor-acceptor perspective; Cambridge University Press: Cambridge, U.K., 2005. (b) Reed, A. E.; Curtiss, L. A.; Weinhold, F. intermolecular Interactions from a Natural Bond Orbital, Donor-Acceptor Viewpoint. Chem. Rev. 1988, 88, 899-926.

(12)Chemcraft - Graphical Software for Visualization of Quantum Chemistry Computations. https://www.chemcraftprog.com

(13)Lu, T.; Chen, F. Multiwfn: A multifunctional wavefunction analyzer. J. Comput. Chem. 2012, 33, 580-592. 